UNIVERSIDADE DE BRASÍLIA - CAMPUS CEILÂNDIA

PROGRAMA DE PÓS-GRADUAÇÃO EM CIÊNCIAS E TECNOLOGIAS DA SAÚDE

GABRIELLY CRAVEIRO RAMOS

Atividade simpática, parassimpática e metabólica influenciada pelo comportamento da distribuição do suporte de peso em pé adquirido na condição de hemiparesia crônica 
Atividade simpática, parassimpática e metabólica influenciada pelo comportamento da distribuição do suporte de peso em pé adquirido na condição de hemiparesia crônica

Tese de doutorado apresentada ao programa de pósgraduação em Ciências e Tecnologias da Saúde da Universidade de Brasília para obtenção do título de doutora em Ciências e Tecnologias da Saúde.

Área de concentração: Nanobiotecnologia aplicada à saúde

Orientadora: Dra. Claure Nain Lunardi Gomes Coorientador: Dr. Emerson Fachin Martins 
Ficha catalográfica elaborada automaticamente, com os dados fornecidos pelo(a) autor(a)

RAT872

a

Ramos, Gabrielly Craveiro

Atividade simpática, parassimpática e metabólica influenciada pelo comportamento da distribuição do suporte de peso em pé adquirido na condição de hemiparesia crônica / Gabrielly Craveiro Ramos; orientador Claure Nain Lunardi Gomes; co-orientador Emerson Fachin Martins. -- Brasilia, 2015. $83 \mathrm{p}$.

Tese (Doutorado - Doutorado em Ciências e Tecnologias em Saúde) -- Universidade de Brasilia, 2015.

1. Acidente vascular cerebral (AVC). 2 . Frequencia cardíaca (FC). 3. Óxido nítrico (NO). I. Gomes, Claure Nain Lunardi, orient. II. Martins, Emerson Fachin, co-orient. III. Título. 
Programa de Pós-Graduação em Ciências e Tecnologias da Saúde da Universidade de Brasília

\section{BANCA EXAMINADORA DA TESE DE DOUTORADO}

Aluna: Gabrielly Craveiro Ramos

Orientadora: Profa. Dra. Claure Nain Lunardi Gomes

Coorientador: Prof. Dr. Emerson Fachin Martins

Membros:

1. Profa. Dra. Claure Nain Lunardi Gomes (Presidente da Banca e Orientadora)

2. Profa. Dra. Priscila Valverde de Oliveira Vitorino (Convidada externa - PUC - GO)

3. Prof. Dr. João Paulo Chieregato Matheus (UnB)

4. Profa. Dra. Clarissa Cardoso dos Santos Couto Paz (UnB)

5. Prof. Dr. Felipe Augusto dos Santos Mendes (UnB)

6. Prof. Dr. Gerson Cipriano Júnior (Suplente - UnB)

Data: 25/09/2015 


\section{Dedico este trabalho...}

Aos meus pais, Aluízio (in memorian) e Vânia, que não mediram esforços, bem como apoiaram-me incondicionalmente durante toda a minha trajetória de estudos. A vocês eu devo tudo o que sou.

Ao meu querido esposo Antônio Carlos, pelo amor, compreensão, paciência e carinho. Sem você ao meu lado eu não conseguiria.

Ao meu irmão e companheiro Aluízio, por estar ao meu lado, incentivando e acreditando em meus projetos. Muito obrigada por ter substituído tantas vezes a figura do meu amado pai.

Aos meus filhos Rafael e Aluízio Neto, pelo amor incondicional dedicado a mim e pela paciência com que dividiram a mãe com as atividades que envolveram esta pesquisa. Vocês são maravilhosos!

Amo vocês! 


\section{AGRADECIMENTOS}

A Deus, maravilhoso, que na sua perfeição foi abrindo portas e desenrolando os problemas encontrados na confecção desta pesquisa.

Aos voluntários, seres pacientes e fantásticos, por estarem sempre disponíveis para a pesquisa. As Instituições e seus responsáveis, onde este trabalho foi realizado. Ao Fernando Veras, Divaina e Husys.

As Instituições de Ensino Superior e seus maravilhosos professores, aos quais agradeço a todos na figura da Profa. Érika, da Universidade Católica de Brasília - DF.

Aos professores envolvidos, orientadora Profa. Dra. Claure e coorientador, Prof. Dr. Emerson, muito obrigada.

Aos meus alunos, alguns únicos neste envolvimento, homenagem a Fabíola, Alexandra e Talita, em nome de todos.

Aos meus amigos, foram muitos os envolvidos, injusto esquecer alguém, assim, agradeço a todos em nome da Kelly.

Aos familiares, incansáveis na torcida e estímulo.

A minha funcionária, Bete, que aguentou firme e sempre esteve disponível para que eu pudesse viajar e chegar tarde.

Aos colegas e amigos da Pontifícia Universidade Católica de Goiás, que na figura do meu professor, amigo e diretor, Renato Sandoval, estendo um grande abraço e um obrigado pelos ouvidos sempre atentos aos meus prantos e reclamações.

Enfim... a vida, que na sua plenitude maior, consegue renovar sempre colocando, no nosso caminho pessoas que talvez não veremos mais, mas que por este pequeno instante, foram perfeitas: "Jesus, Paulo, Pedro, Lucas, João, Judas, Matheus, André, Thiago, Filipe, Bartolomeu, Tomé, Tadeu". 


\section{RESUMO}

\section{ABSTRACT}

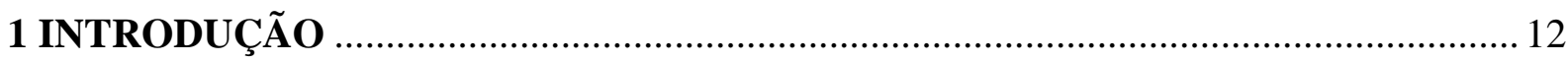

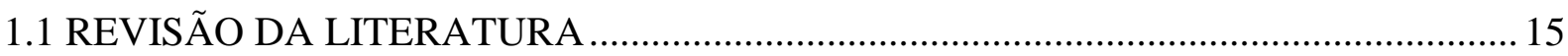

1.1.1 Distribuição do suporte de peso em pé no acidente vascular cerebral ........................... 15

1.1.2 Atividade simpática e parassimpática e variabilidade da frequência cardíaca................ 18

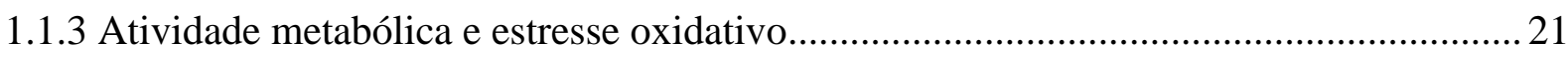

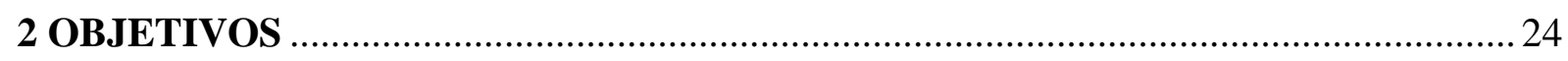

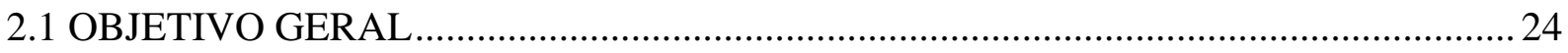

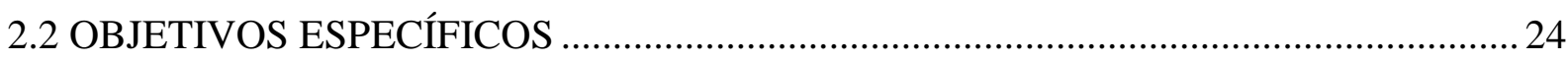

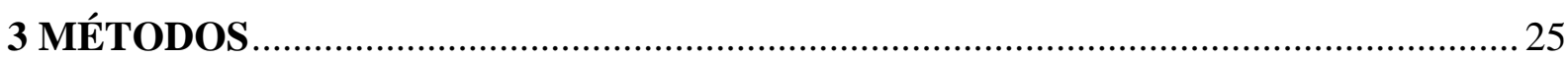

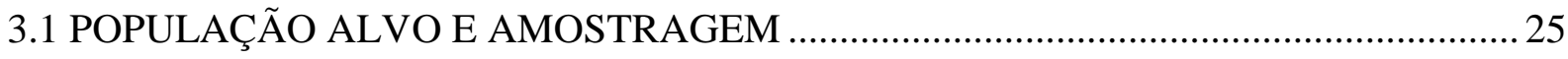

3.2 DELINEAMENTO DO ESTUDO E GRUPOS EXPERIMENTAIS ….............................26

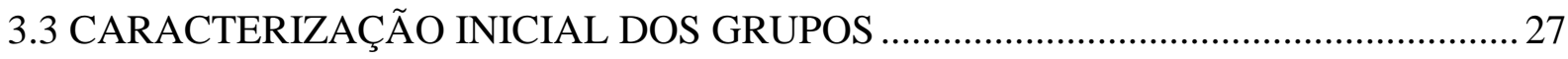

3.4 CARACTERIZAÇÃO DA ATIVIDADE NERVOSA SIMPÁTICA E

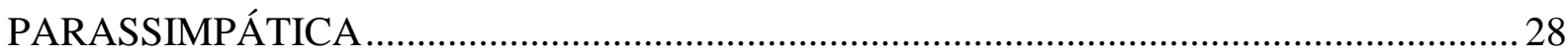

3.5 CARACTERIZAÇÃO DA ATIVIDADE METABÓLICA PELOS NÍVEIS NITRATO/

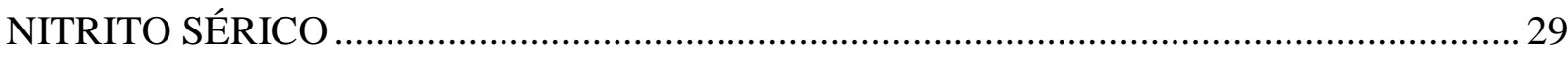

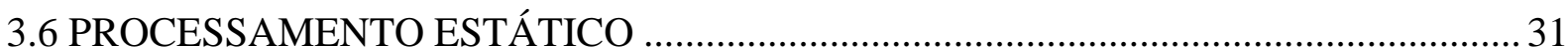

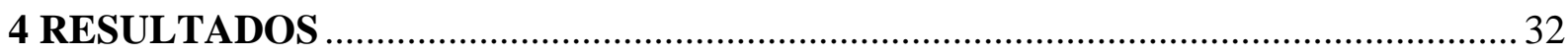

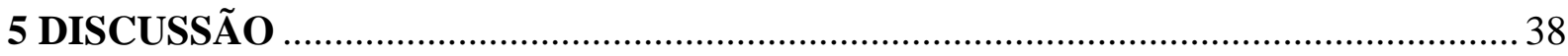

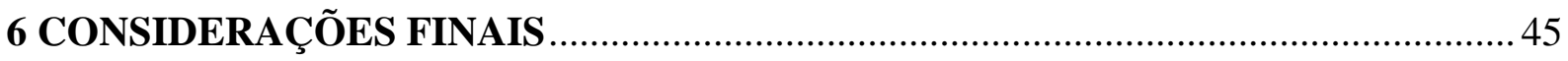

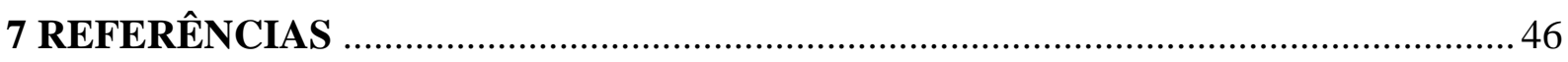

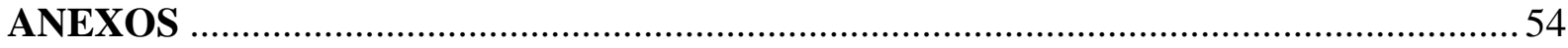

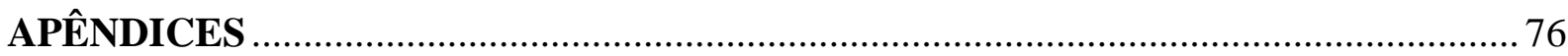




\section{LISTA DE ANEXOS E APÊNDICES}

Anexo A - Parecer do Comitê de Ética e Pesquisa da Universidade de Brasília.

Anexo B - Normas de Publicação do Artigo Ciêntífico.

Anexo C - Artigo Publicado.

Apêndice A - Termo de Consentimento Livre e Esclarecido (TCLE).

Apêndice B - Avaliação instrumental para coleta de dados da pesquisa. 
AF - Alta Frequência

ATP - Adenosina Tri Fosfato

AVC - Acidente Vascular Cerebral

AVD - Atividade de Vida Diária

BF - Baixa Frequência

CEP - Comitê de Ética e Pesquisa

$\mathrm{CM}$ - Centro de Massa

DF - Dominínio da Frequência

DT - Domínio do Tempo

ERO - Espécies Reativas do Oxigênio

ERN - Espécies Reativas do Nitrogênio

HPU - Hemicorpo Predominantemente Usado

HNPU - Hemicorpo Não Predominantemente Usado

IMC - Indíce de Massa Corpórea

MEEM - Mini Exame do Estado Mental

$\mathrm{NO}$ - Óxido Nítrico

NOS - Sintaxe do Óxido Nítrico

PUC GO - Pontifícia Universidade Católica de Goiás

RMSSD - Raiz Quadrada da Média do Quadrado das Diferenças entre os Intervalos RR

Normais Adjacentes

RS - Razão de Simetria

SDNN - Desvio Padrão de Todos os Intervalos RR Normais Gravados em um Intervaldo de Tempo.

SNA - Sistema Nervoso Autônomo

TCLE - Termo de Consentimento Livre e Esclarecido

UnB - Universidade de Brasília

VFC - Variabilidade da Frequência Cardíaca 


\title{
Atividade simpática, parassimpática e metabólica influenciadas pelo comportamento da distribuição do suporte de peso em pé adquirido na condição de hemiparesia crônica
}

\author{
RESUMO
}

Introdução: $\mathrm{O}$ acidente vascular cerebral (AVC) é a causa mais frequente de incapacidade neurológica crônica da população adulta. Esta afecção cerebrovascular pode gerar alterações tanto no controle postural, observada por assimetria na distribuição do suporte de peso em pé, quanto no controle autonômico, verificadas por meio das respostas simpática e parassimpática na variabilidade da frequência cardíaca (VFC). Assim, a modificação combinada dos controles promovida pelo dano encefálico poderia resultar em um aumento do gasto energético, fato que pode originar uma situação de estresse oxidativo, observável pela quantidade de nitrato sérico. Objetivo: Verificar se as atividades nervosas simpática e parassimpática, bem como a atividade metabólica observada pelos níveis de nitrato sérico são alteradas pelo tipo de suporte de peso em pé adotado cronicamente pelos sobreviventes de AVC. Métodos: Empregou-se delineamento de estudo transversal do tipo caso-controle em 51 sujeitos com hemiparesia crônica, cuja idade e índice de massa corpórea (IMC) foram utilizados para normalizar outros 57 sujeitos hígidos. Todos eram homens, com idade entre 40 e 70 anos. Os indivíduos hemiparéticos foram submetidos a mensurações por baropodometria computadorizada, para identificação do tipo de distribuição do suporte de peso em pé, definido pelo cálculo da razão de simetria (RS). Posteriormente, o grupo hemiparesia foi separado em três subgrupos definidos pela distribuição em: simétricos $(n=7)$, assimétricos com sobrecarga no hemicorpo não predominantemente usado (HNPU, n=7) e assimétricos com sobrecarga no hemicorpo predominantemente usado (HPU, $\mathrm{n}=5$ ). Os controles foram aleatoriamente separados para compor o subgrupo referência $(n=7)$. Para caracterizar a resposta da atividade simpática e parassimpática sobre a VFC foram realizados cálculos das funções derivadas da VFC no domínio do tempo e de frequência nas posturas supino, sentado e em pé, com duração de 5 minutos em cada postura e com intervalo de 2 minutos de repouso entre elas. Por fim, extraiu-se de amostras de sangue colhidas por sujeito o nível de nitrato sérico. Resultados: Os testes estatísticos não detectaram correlação significativa do RMSSD (parassimpático) com idade e valores de RS; embora o RMSSD do subgrupo simétrico tenha apresentado uma tendência ao aumento na postura em pé $(0,05<\mathrm{p}<0,10)$ da ordem de 3 vezes $(14,7$ para 47,6) quando comparado ao subgrupo referência. Na postura sentada, a variável baixa frequência $(\mathrm{BF})$ diminuiu de forma significativa para o subgrupo simétrico $(0,05 \pm 0,01)$ comparado ao subgrupo referência $(0,08 \pm 0,02)$. Já na postura em pé houve aumento significativo da alta frequência (AF) que foi detectado no subgrupo simétrico $(0,26 \pm 0,076)$ quando comparado ao subgrupo referência $(0,173 \pm 0,056)$. Em relação a concentração de nitrato sérico, nenhuma diferença significativa foi observada nos testes realizados. Conclusão: Os resultados obtidos sugerem uma possível associação da atividade parassimpática na distribuição do suporte de peso realizado por cada indivíduo ou grupo, principalmente, quando observados em posturas com maior esforço antigravitário nos sujeitos com hemiparesia que mantém uma distribuição mais simétrica deste suporte, sugerindo que os indivíduos do subgrupo hemiparesia, que adotaram distribuição mais simétrica de peso, poderiam estar fazendo maior esforço para manter a postura simétrica, esforço este que poderia ser o responsável pela adaptação cuja resposta foi observada no comportamento cardíaco. 
Palavras-chave: Acidente vascular cerebral (AVC), frequência cardíaca (FC), óxido nítrico (NO). 


\title{
Sympatetic, parasimpatetic and metabolic activities influenced by weight- bearing distribution behavior during upright position acquired in the chronic hemiparesis condition
}

\begin{abstract}
Introduction: The strokeis the most frequent cause of chronic neurological disability in adults. The cerebralvascular disorder can generate changes whether in the postural control, observed by asymmetry in the distribution of standing weight-bearing, or in the cardiac autonomic control through the sympathetic and parasympathetic response, changing the heart rate variability (HRV). Then the combined changes promoted by the encephalic injury could in increased energy expenditure, which may result in a condition of oxidative stress, observed by the amount of serum nitrate. Objective: To determine whether the sympathetic and parasympathetic nervous activities, and metabolic activity observed by serum nitrate levels are change by the type of weight-bearing standing chronically adopted by stroke survivors. Methods: The cross-sectional design was applied in the case-control type for 51 subjects with chronic hemiparesis whose age and body mass index (BMI) were used to normalize 57 others healthy subjects. All was men between 40 and 70 years. The hemiparetic subjects under went measurements computed baropodometry, to identify the type of standing weight-bearing defined by calculating the ratio of symmetry (RS). Subsequently, hemiparesis group was split in to three subgroups presented by distribution types: symmetric $(n=7)$, asymmetric overloading the nonpredominantly used hemibody (NPUH, n=7)) and asymmetric overloading the predominantly used in the hemibody $(\mathrm{PUH}, \mathrm{n}=5)$. Controls were randomly separated to compose the reference subgroup $(n=7)$. To characterize the sympathetic and parasympathetic response from HRV, we calculated derived functions from HRV in the time and frequency domain in supine, sitting and standing postures for 5 minutes each posture and a rest interval of two minutes between them. At last, we extracted from the blood samples the level of serum nitrate. Results: Statistical tests did not detect significant correlation between age and RMSSD (parassimpatic) values, although the RMSSD symmetric subgroup has shown a trend to increase during upright posture $(0.05<\mathrm{p}<0.10)$ to 3 times $(14.7$ to 47.6$)$ compared to the reference sub-group. In the sitting posture, thr variable low frequency (BF) decreased significantly in the symmetric subgroup $(0.05 \pm 0.01)$ compared to the reference subgroup $(0.08 \pm 0.02)$. While, in the standing posture, a significant increase in righ frequency (AF) was detected in the symmetric subgroup $(0.26 \pm 0.076)$ when compared to the reference sub-group $(0.173 \pm 0.056)$. None significant differences was observed from nitrate serum concentration. Conclusion: Our results suggest a possible association between parasympathetic activity and types of weight-bearing distribution, mainly observed in the postures demanding more antigravity-effort in the subjects with hemiparesis, which maintain a more symmetrical distribution of this support, suggesting that the individuals from the symmetric distribution coul be leading to adaptate the response observed in the cardiac performance.
\end{abstract}

Keywords: Stroke, Heart Rate (HR), (NO) 


\section{INTRODUÇÃO}

No envelhecimento populacional, alterações fisiológicas podem estar associadas a doenças crônicas e degenerativas, que promovem déficits funcionais e declínios da mobilidade ${ }^{(1)(2)(3)}$. Dentre elas, o acidente vascular cerebral (AVC) é a causa mais frequente de incapacidade neurológica crônica da população adulta e constitui a primeira causa de morte no Brasil ${ }^{(1)(4)(3)}$.

As manifestações clínicas presentes no AVC envolvem comumente alterações motora e sensitiva, prejudicando a funcionalidade, que podem limitar as habilidades para realizar atividades cotidianas como deambular, subir e descer escadas assim como autocuidar-se ${ }^{(1)(4)(3)}$.

O AVC pode desencadear alterações do controle motor, caracterizadas por uma alteração postural, que são observadas principalmente por assimetrias na distribuição do suporte de peso. Vários estudos foram realizados com o objetivo de avaliar o comportamento destas variáveis ${ }^{(5)(6)(7)}$.

Essas assimetrias podem ocasionar uma distribuição no suporte de peso em pé no lado não parético maior, para a maioria dos pacientes com hemiparesia, porém, o lado parético pode também ser sobrecarregado, assim como, distribuições simétricas no suporte de peso em pé poderão ser adotadas por este grupo ${ }^{(8)(7)(9)}$.

Ao que parece, esta distribuição do suporte de peso em pé pode ser influenciada pela lateralidade de controle encefálico presente no funcionamento do sistema nervoso. A lateralidade pode ser determinada por fatores filogenéticos e ontogenéticos. Pela filogênia, a preferência manual é derivada de uma assimetria interlateral, originária da maior capacidade de controle motor com a mão preferida em comparação com a mão não-preferida. Já o componente ontogenético, explica a lateralidade pelas experiências lateralizadas com os segmentos corporais ao longo da vida, constituindo o fator principal na formação da lateralidade humana. Uma das idéias centrais dessa proposição é de que o potencial de aprendizagem com os lados direito e esquerdo do corpo é equivalente. Assim, a vantagem de desempenho com um dado segmento corporal em relação ao segmento contralateral homólogo seria devida ao diferencial de prática entre ambos os segmentos ao invés de ser resultante de uma capacidade superior de um dos hemisférios cerebrais para controle e aprendizagem de ações motoras. A partir dessa perspectiva, tanto preferências manuais quanto assimetrias interlaterais de desempenho 
seriam moldadas por experiências sensoriais e motoras lateralizadas acumuladas durante o ciclo de vida ${ }^{(10)(11)(12)(13)(14)}$.

Mesmo em pessoas sem comprometimento neurológico, diferenças entre hemicorpos direito e esquerdo podem estar presentes e resultar da especialização de cada hemisfério e dos mecanismos distintos de controle postural ${ }^{(14)}$. Entretanto, a simples caracterização entre direito e esquerdo não revela a predominância de uso de um sujeito que, apesar de ser observada no lado direito para a maioria das populações estudadas em termos de preferência manual, pode também ser à esquerda para uma parcela da população. Notadamente em termos de distribuição do suporte de peso, a adoção de um tipo de distribuição no suporte de peso pode também revelar uma predominância de uso.

Vantagens específicas de controle motor favorecem aspectos do movimento quando partindo de suportes mais simétricos ou assimétricos durante a realização de tarefas, em sujeitos com lesões cerebrovasculares sediadas em um dos hemisférios cerebrais $^{(14)(7)(5)(15)(16)}$.

O raciocínio mais lógico para os indivíduos que convivem cronicamente com sequelas de AVC seria pensar que eles preferem adotar o lado não afetado como hemicorpo predominantemente usado (HPU) durante suas tarefas motoras, o que é chamado de uso por conveniência, ou seja, o hemicorpo predominantemente usado pode deixar de ser o preferido depois da lesão, por ser uma condição de mais fácil controle (7)(17)(15)(18).

Frente ao exposto, faz sentido constatar que as deficiências na estrutura e função relacionadas ao movimento tão prontamente observadas depois do AVC, podem estar associadas as disfunções cardiovasculares também apontadas na literatura para sujeitos que convivem cronicamente com condições de hemiparesia, promovendo além dos déficits motores, comprometimentos cardíacos e risco de morte súbita ${ }^{(18)(19)(20)}$.

Estas disfunções cardiovasculares e o risco de morte súbita estão presentes porque o insulto cerebrovascular pode atingir outras áreas cerebrais que são responsáveis pelo controle autonômico das funções viscerais, modificando o equilíbrio da atividade simpático vagal ou da função neurocárdica. A importância dos aspectos cardiovaculares descritos acima, soma-se as evidências de que a maioria dos óbitos ocorridos após os trinta dias subsequentes ao AVC são decorrentes de eventos cardíacos ${ }^{(18)(19)(20)(21)}$.

Muitas evidências demonstram que a disfunção cardíaca pode ser identificada pela atividade simpática e parassimpática mensuradas pela variabilidade da frequência 
cardíaca (VFC), e o padrão de médias cardíacas específicas e pode ser descrito como preditor de morte súbita ${ }^{(18)(19)(20)(21)}$.

A análise da VFC tem sido descrita como ferramenta para informar sobre os distúrbios na regulação do controle autonômico principalmente em diversas afecções cardíacas, contudo, observa-se também o uso desta ferramenta em afecções cerebrovasculares inclusive aquelas influenciadas pelo AVC ${ }^{(19)(20)(18)(21)}$.

Seguindo as possibilidades de uso em se manipular as informações obtidas pela VFC, podemos hipotetizar que o AVC pode comprometer tanto o controle postural, degenerando condições de assimetrias na distribuição do suporte de peso em pé, como também o controle cardíaco, por meio da atividade simpática e parassimpática, modificada e refletida na forma de VFC ${ }^{(19)(20)}$.

As posturas com distribuição do suporte de peso em pé assimetricamente distribuídas parecem gerar um maior gasto energético, entretanto, nenhum estudo apontou categoricamente as relações entre o controle postural alterado, que define as assimetrias, com modificações no controle autonômico da função cardíaca, para verificar se posturas com distribuição do suporte de peso em pé assimétricas poderiam estar associadas a melhor ou pior capacidade de modular a variabilidade da frequência cardíaca por meio de análises das respostas simpática e parassimpática ${ }^{(19)(20)}$.

Por outro lado, observa-se nesta população um aumento do gasto energético durante a execução de atividades rotineiras de vida diária e exercícios submáximos, fato que pode originar uma situação de estresse oxidativo produzido pelo organismo em distribuição de suporte de peso assimétrica ${ }^{(22)(23)}$.

Uma das formas de se confirmar o aumento no gasto energético é acompanhando o metabolismo do Óxido Nítrico (NO). Esta importante molécula tem um papel fundamental na manutenção cardiovascular. Trata-se de um radical livre que possui funções metabólicas altamente ativas, principalmente na regulação das atividades cardiovasculares. O NO é formado por células endoteliais, e promove vasodilatação, aumentando o fluxo sanguíneo local que inibe a agregação plaquetária, reduz a migração e adesão leucocitária e diminui a proliferação de células de músculos lisos (24)(25)

Ao longo dos anos, demonstrou-se que além da função do NO no sistema cardiovascular como sinalizador da vasodilatação, este composto influencia o sistema nervoso ao atuar como neurotransmissor, participando, por exemplo, em mecanismos de plasticidade sináptica ${ }^{(24)(25)}$. 
Por outro lado, a sua síntese exacerbada está relacionada a vários processos patológicos. Na presença de ânions superóxidos liberados por macrófagos, por exemplo, o NO é metabolizado à peroxinitrito, causando dano celular. Esta condição é conhecida como estresse oxidativo, que ocorre em diversas afecções, incluindo as afecções cerebrovasculares ${ }^{(26)(27)(28)(24)}$.

O estresse oxidativo é definido como o desequilíbrio entre a produção e a neutralização das espécies reativas do oxigênio (ERO), podendo ocorrer pelo excesso de produção de ERO e/ou pela deficiência nos mecanismos antioxidantes (26)(27)(28)(29)(24).

Um aspecto particularmente destrutivo do estresse oxidativo é a produção de espécies reativas de oxigênio, como radicais livres e peróxidos. Algumas dessas espécies com pouca reatividade podem ser convertidas em espécies mais reativas por meio de reações de oxidorredução envolvendo metais de transição ou outras espécies com capacidade de variar o seu estado de oxidação (como quinonas), espécies essas que podem causar danos celulares ${ }^{(26)(28)(30)}$.

A maioria das espécies que surgem por meio da redução do oxigênio molecular são produzidas em pequenas quantidades pelo organismo utilizando o metabolismo aeróbico e, quaisquer danos provocados, são reparados de forma constante. No entanto, em condições extremas de estresse oxidativo, os danos provocam esgotamento dos níveis de ATP, o que impede uma apoptose celular controlada e provoca a falha total do funcionamento da célula, causando necrose ${ }^{(23)(22)}$.

Diante do exposto a hipótese norteadora do trabalho seria tentar correlacionar os vários tipos de distribuição do suporte de peso em pé com a s alterações em sistema nervoso simpático cardíaco e sistema metabólico.

Porém, a literatura ainda carece de trabalhos que relacionem a distribuição do suporte de peso em pé com a atividade simpática, parassimpática e metabólica na população que sobreviveu ao AVC. Um estudo com este recorte pode ser realizado e, consequentemente, contribuir de forma satisfatória para o planejamento dos processos de reabilitação.

Assim, este trabalho objetiva verificar se a atividade nervosa simpática e parassimpática, bem como a atividade metabólica observada pelos níveis de nitrato sérico são influenciadas pelo tipo de suporte de peso em pé adotado cronicamente pelos sobreviventes de acidente vascular encefálico.

Os dados encontrados são de grande valor para a formulação de novos tratamentos destinados aos hemiparéticos, assim como podem influenciar a proliferação 
de pesquisas acadêmicas que associem estes parâmetros, enriquecendo o conhecimento sobre o assunto.

\subsection{REVISÃO DA LITERATURA}

\subsubsection{Distribuição do suporte de peso em pé no acidente vascular encefálico}

O AVC pode ser definido como uma síndrome, caracterizada pelo início súbito de um déficit neurológico, que persiste por mais de 24 horas. Ele reflete o envolvimento focal, por vezes global, do sistema nervoso central, atingindo, porém, distúrbio da circulação encefálica decorrete de um processo anatomopatológico nos vasos sanguíneos. Atualmente, o AVC é considerado uma das doenças que mais ocasiona mortes no Brasil assim como, em escala mundial, mas incapacita indivíduos ${ }^{(31)(32)}$.

Dentre os tipos de AVC destacam-se o isquêmico, que é a obstrução de alguma artéria do encéfalo causada por uma trombose ou por embolia cerebral, gerando a interrupção do fluxo sanguíneo local e representa cerca de $70 \%$ a $80 \%$ dos AVCs. Pode também ser hemorrágico caracterizado pela ruptura de um vaso intracraniano, gerando sangramento e formação de hematoma no parênquima cerebral. Apesar dos avanços terapêuticos estima-se que 50 milhões de sobreviventes ao AVC tenham que lidar diariamente com déficits físicos, cognitivos e emocionais ${ }^{(33)}$.

O AVC, isquêmico ou hemorrágico (figura 1), pode causar comprometimento de áreas cerebrais relacionadas ao controle postural, resultando em hemiparesia com suporte de peso assimetricamente distribuído ${ }^{(5)(6)(7)(34)}$. 


\section{AVC HEMORRÁGICO}

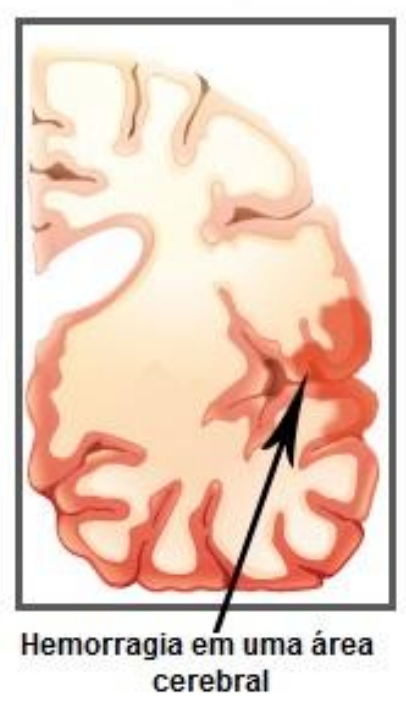

AVC ISQUÊMICO

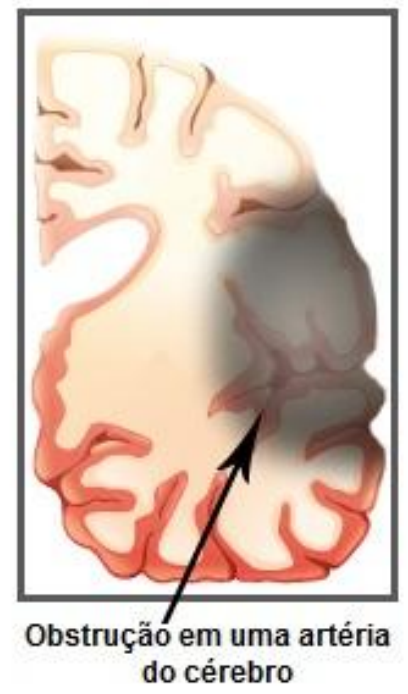

Figura 1- Desenho comparativo entre os tipos de AVE

(fonte: http://melhorcomsaude.com/conhecer-sintomas-AVC-salvar-vidas)

O controle postural depende diretamente da interação dos sistemas visual, vestibular, proprioceptivo e tegumentar, que juntos geram informações para o sistema nervoso central, onde as mesmas serão processadas e produzirão um comando motor que será responsável pelo movimento (figura 2) ${ }^{(35)(37)(36)}$.

O controle postural pode ser definido como a habilidade para manter o equilíbrio em relação à ação da gravidade por meio da manutenção ou retorno do centro de massa na base de suporte formada pelos apoios ${ }^{(35)(36)}$. Ajustes posturais automáticos (compensatórios e antecipatórios) são necessários para todas as tarefas motoras e precisam ser agregados aos movimentos voluntários, na tentativa de manter o centro de massa (CM) corporal alinhado e equilibrado sobre a base de sustentação ${ }^{(35)(37)(36)}$. 


\section{CONTROLE POSTURAL}

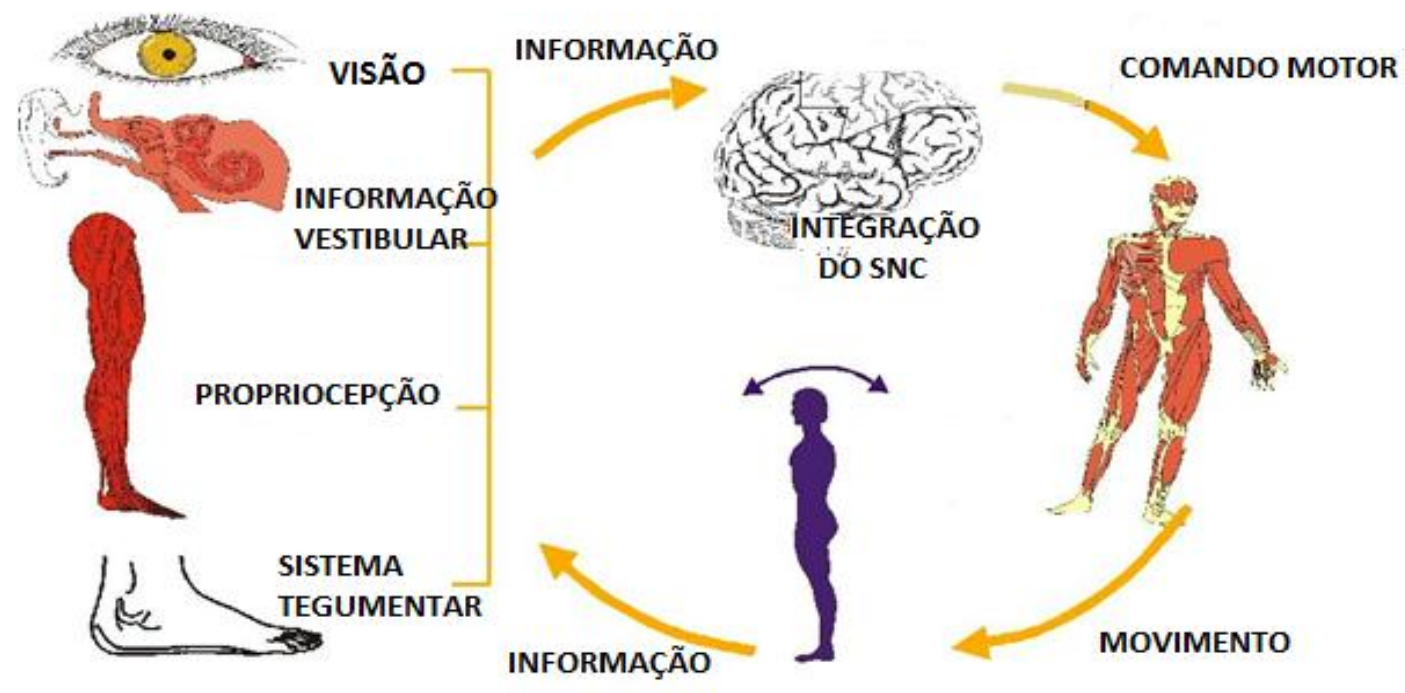

Figura 2- Ilustração demonstra a integração do sistema vestibular ao complexo controle da postura humana através de suas conexões.

(Adaptado da fonte www.zahstraces.bolgspot.com.br)

A independência para as atividades da vida diária (AVD) reflete uma boa estabilidade do controle postural e um equilíbrio adequado, e para isso, o indivíduo necessita ter o domínio desse controle postural, que é solicitado para a execução dessas atividades, por meio da capacidade de manter-se em diversas posições, responder automaticamente a movimentos voluntários do corpo e das suas extremidades e também reagir adequadamente a perturbações externas ${ }^{(38)(39)(40)(41)}$.

Os ajustes posturais também parecem ser influenciados pelo funcionamento lateralizado dos centros de controle encefálico. Os sistemas de controle postural em funcionamento unilateral ou bilateral podem gerar distribuição do suporte de peso em pé, de forma mais simétrica ou assimétrica, ao longo do plano sagital, que são diferenciadas ao depender da tarefa. Estudos que analisaram a influência da lateralidade na preferência de uso dos membros inferiores constataram que uma distribuição assimétrica no suporte de peso com sobrecarga para o lado não predominantemente usado pode representar uma estratégia para manter o hemicorpo predominantemente usado pronto para a execução de tarefas partindo da posição em pé ${ }^{(10)(11)(12)(13)(14)}$.

Por esta premissa, podemos estabelecer o raciocínio de que as assimetrias geradas por diferenças na distribuição do suporte de peso entre os hemicorpos direito e esquerdo resultantes de uma especialização de cada hemisfério cerebral e de 
mecanismos próprios de controle do movimento, afetaria a estabilidade postural que, segundo alguns autores, estaria diminuída com o aumento de assimetrias, contudo as evidências não são claras quanto a isso ${ }^{(10)(11)(12)(13)(14)}$.

Investigar a distribuição do suporte de peso na postura ortostática para indivíduos com hemiparesias, pode ser uma ferramenta interessante para a formulação de novos programas de reabilitação, uma vez que, teremos maior precisão na quantificação das simetrias e assimetrias posturais ${ }^{(42)}$.

Esta quantificação das simetrias e assimetrias posturais poderão ser realizadas por meio de mensurações da baropodometria computadorizada, para identificação do tipo de suporte de peso em pé, definido pelo cálculo da razão de simetria (RS) ${ }^{(31)}$.

O baropodometro permite a mensuração das pressões exercidas em vários pontos anatômicos da superfície plantar. Ele possibilita medidas precisas e linhas que mostram detalhadamente a trajetória do centro de pressão sobre as superfícies plantares durante a realização da marcha e em posição estática ${ }^{(31)}$.

Este aparelho é muito utilizado para detectar e gravar as pressões plantares sem interferir na marcha do paciente, e ainda pode ser útil para observar a ocorrência de anormalidades na marcha, controle de sustentação de peso, monitoração das desordens degenerativas dos pés e reeducação do paciente com hemiparesia ${ }^{(31)}$.

Pelo registro da quantidade de peso suportado pela superfície plantar de cada hemicorpo em contato com o solo é possível calcular uma razão de simetria entre o hemicorpo não predominantemente usado e o hemicorpo predominantemente usado, estabelecendo um indicador do tipo de distribuição de suporte de peso em pé adotado por um sujeito ${ }^{(17)}$.

A razão de simetria foi originalmente proposta como sendo calculada a partir do registro obtido em duas balanças antropométricas digitais dispostas paralelamente, estando o sujeito na posição ortostática com um pé em cada balança ${ }^{(7)}$.

Contudo, qualquer outro instrumento que faça registros do suporte de peso em pé em cada hemicorpo é capaz de fornecer valores que podem ser utilizados para o cálculo desta razão de simetria ${ }^{(17)}$.

O quociente obtido na razão de simetria considera a predominância de uso, estabelecendo uma relação entre a dominância de uso por um hemicorpo de sujeitos saudáveis com a conveniência de uso de um hemicorpo não parético para sobreviventes de $\operatorname{AVC}^{(7)(17)}$. 
Por esta razão de proporcionalidade, coeficientes com valor acima de 1 (um) indicariam comportamento assimétrico na distribuição do suporte de peso em pé que estaria sobrecarregando o hemicorpo não predominantemente usado, enquanto que valores inferiores a 1 (um) também indicariam comportamento assimétrico, porém com sobrecarga no hemicorpo predominantemente usado. Já os quocientes com valores iguais ou próximos de 1 (um), indicariam suporte de peso simétrico ${ }^{(7)}$.

\subsubsection{Atividade simpática e parassimpática e variabilidade da frequência cardíaca}

O coração, principal órgão responsável pelo transporte sanguíneo no organismo humano, recebe dupla inervação, correspondente ao sistema nervoso simpático e parassimpático (via nervo vago). A modulação simpática e parassimpática cardíaca é influenciada por informações dos barorreceptores, quimiorreceptores, sistema respiratório, sistema vasomotor, sistema termorregulador e sistema renina-angiotensinaaldosterona $^{(43)(44)}$.

$\mathrm{O}$ controle pelo sistema nervoso autônomo (SNA) fornece nervos aferentes e eferentes ao coração, na forma de terminações simpáticas por todo o miocárdio atrial e nódulo atrioventricular ${ }^{(45)}$. Este controle está intimamente ligado à frequência cardíaca (FC) e atividade barorreceptora ${ }^{(45)}$. O aumento da FC é consequência da maior ação da via simpática e da menor atividade parassimpática. A duração do ciclo cardíaco, medida pelo tempo transcorrido entre duas ondas $\mathrm{R}$ consecutivas do eletrocardiograma (intervalo R-R), não é constante, ocasionando uma variação entre os intervalos R-R sucessivos, denominada de variabilidade da frequência cardíaca (VFC) ${ }^{(46)(47)(48)(49)(50)}$. Atualmente uma maneira de se mensurar a frequência cardíaca de forma menos invasiva e mais eficaz é através da análise da variabilidade da frequência cardíaca.

A Variabilidade da Frequência Cardíaca (VFC) descreve as oscilações no intervalo entre batimentos cardíacos consecutivos (intervalo R-R), assim como oscilações entre frequências cardíacas instantâneas consecutivas. Mudanças nos padrões da VFC fornecem um indicador sensível e antecipado de comprometimentos na saúde. Uma alta variabilidade na frequência cardíaca é sinal de boa adaptação, caracterizando um indivíduo saudável, enquanto que, a baixa variabilidade é frequentemente associada a uma adaptação anormal e insuficiente do SNA ${ }^{(50)}$.

Atualmente, as funções derivadas da VFC têm sido utilizadas para compreensão de diversas condições como: doença arterial coronariana, miocardiopatia, hipertensão 
arterial, infarto do miocárdio, morte súbita, doença pulmonar obstrutiva crônica, insuficiência cardíaca e renal, diabetes, acidente vascular encefálico, doença de Alzheimer, leucemia, apneia obstrutiva do sono, epilepsia, enxaqueca, entre outros ${ }^{(50)}$.

Os fatores de risco cardiovasculares como, excesso de massa de gordura corporal, hiperglicemia, hiperinsulinemia, hipertensão arterial, dislipidemias e sedentarismo estão fortemente associados com a redução da VFC. Uma redução do tônus vagal cardíaco e, por conseguinte, da VFC, independentemente do protocolo de mensuração, está associada à disfunção autonômica cardíaca, doenças crônicodegenerativas, arritmias letais, eventos cardíacos isquêmicos em indivíduos saudáveis, e representa, dessa forma, um importante indicador do estado de saúde, fator prognóstico da morbi-mortalidade cardiovascular ${ }^{(46)}$.

Historicamente, seu interesse clínico surgiu em 1965, quando Hon e Lee demonstraram uma aplicação clínica bem definida para VFC na área de monitorização do sofrimento fetal. Em 1977, Wolf e colaboradores, mostraram associação entre VFC diminuída e maior risco de mortalidade após infarto agudo do miocárdio e confirmaram que a VFC era potente e independente preditor de mortalidade após infarto agudo do miocárdio. Este tipo de análise sofreu grande impulso após o estabelecimento da forte relação entre a VFC e mortalidade pós-infarto agudo do miocárdio, tendo a vantagem de possibilitar uma avalição não invasiva e seletiva da função autonômica, além de ser um recurso metodológico de grande simplicidade e fácil aplicação ${ }^{(46)(47)(48)(49)(50)(51)(52)}$.

Para caraterização das atividades nervosa simpática e parassimpática utilizamos a mensuração da VFC, que pode ser descrita por meio de métodos lineares por uma análise no domínio do tempo e no domínio da frequência (figura 3).

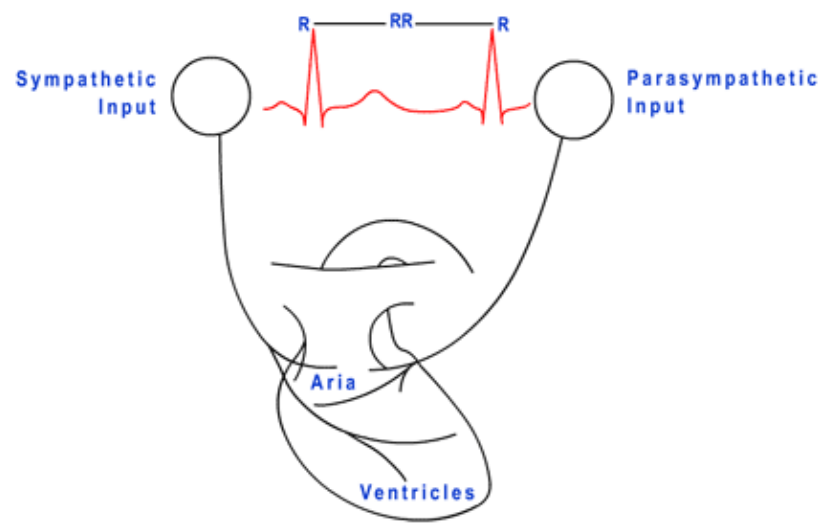

Figura 3 - Ilustração demonstra a relação da atividade simpática e parasimpática no controle da variação da frequEncia cadíaca.

(Adaptado da fonte: http://www.stresswatch.com/theory) 
Para a análise da VFC no domínio do tempo, assim denominada por expressar os resultados em unidade de tempo (milissegundos), mede-se a cada intervalo RR normal (batimentos sinusais) durante determinado intervalo de tempo e, a partir daí, com base em métodos estatísticos ou geométricos (média, desvio padrão e índices derivados do histograma ou do mapa de coordenadas cartesianas dos intervalos RR), calculam-se os índices tradutores de flutuações na duração dos ciclos cardíacos. A SDNN que representa os registros de longa duração e as atividades simpática e parassimpática, considerada individualmente, não permite que represente as alterações da VFC, pois são devidas ao aumento do tônus simpático ou à retirada do tônus vagal. Já a RMSSD representa a atividade parassimpática, sendo um bom parâmetro para análise da VFC, uma vez que, os resultados encontrados obtidos a partir da análise dos intervalos RR adjacentes ${ }^{(50)(53)(43)}$.

No domínio da frequência, a densidade de potência espectral é a mais utilizada atualmente, quando se trata de estudos com indivíduos em condições de repouso. Esta análise decompõe a VFC em componentes oscilatórios fundamentais, sendo que os principais representantes são a baixa frequência (BF), que é decorrente da ação conjunta dos componentes vagal e simpático sobre o coração, com predomínio simpático e a alta frequência $(\mathrm{AF})$ correspondente à modulação respiratória, que é um indicador da atuação do nervo vago sobre o coração ${ }^{(50)(43)(53)}$.

Estudos longitudinais e transversais sugerem que o exercício físico, quando praticado com intensidade, duração e frequência adequada, causam adaptações favoráveis ao sistema cardiovascular e à função neurocárdica, como aumento da VFC nos domínios do tempo (DT) (com aumento de SDNN e queda de RMSSD) e da frequência (DF) com aumento da BF e diminuição da AF em indivíduos jovens, de meia idade e também em idosos. Além disto, em atletas, é comprovado uma atividade parassimpática prevalente durante o repouso, o que estimula o SNA a auxiliar na modulação autonômica assim que o esforço é iniciado ${ }^{(43)(47)(54)}$.

Por outro lado, mudanças posturais também alteram a VFC, e têm sido utilizadas por vários estudos, indicando ser mensurações interessantes para alguns grupos em situações de repouso ${ }^{(97)(98)}$.

Mudanças nos padrões da VFC fornecem um indicador sensível e antecipado de comprometimentos da saúde. Alta VFC é sinal de boa adaptação, caracterizando um indivíduo saudável com mecanismos autonômicos eficientes. Inversamente, baixa VFC é frequentemente um indicador de adaptação anormal e insuficiente do SNA, o que pode 
indicar a presença de um mau funcionamento fisiológico no indivíduo, necessitando de investigações adicionais de modo a encontrar um diagnóstico específico ${ }^{(47)(43)(54)(55)(56)}$.

\subsubsection{Atividade metabólica e estresse oxidativo}

O NO (Óxido Nítrico), uma molécula gasosa atuante na sinalização de diferentes processos biológicos, é um radical livre que apresenta um elétron desemparelhado na última camada e uma meia-vida de 4 a 8 segundos em meio aquoso oxigenado. Descrito como um gás lábil - capaz de livre difusão nas membranas celulares, fator este que lhe confere uma alta atividade biológica - ele é produzido em diversa quantidade pelos neurônios, células endoteliais, plaquetas, neutrófilos em resposta aos estímulos homeostáticos. É também produzido por macrófagos, fibroblastos, hepatócitos em concentrações micromolares em respostas inflamatórias ou estímulos mitogênicos. Nestes casos, o papel biológico dele é defender contra os não-autopatôgenos que geram o estresse oxidativo ${ }^{(57)(58)(59)}$.

O NO, segundo a definição de Bredt e Snyder (1990), é um mensageiro molecular produzido a partir da arginina através da síntese de óxido nítrico (NOS) exercendo funções em diversos locais do organismo como sistema nervoso central e periférico, sistemas vascular e imunológico ${ }^{(60)(61)(62)(63)(64)(65)(66)}$.

O NO está envolvido no processo de morte celular durante eventos isquêmicos ${ }^{(66)}$. As concentrações de nitrato (metabólito do NO) encontram-se elevadas no líquido cefalorraquiano de pacientes vítimas de AVC do tipo isquêmico ${ }^{(67)}$.

A descoberta do NO como um mensageiro molecular difusível e reativo nos sistemas vascular e imunológico motivou a sua busca em outros locais do corpo. O NO foi encontrado em abundância no sistema nervoso central e periférico, sendo que nesses locais (principalmente no encéfalo), encontra-se a maior quantidade de NOS, a enzima responsável por sua formação. Estudos têm demonstrado que o NO estimula diversas funções fisiológicas neuronais. No sistema nervoso periférico o NO age de forma semelhante aos neurotransmissores clássicos na regulação da motilidade gastrointestinal, fluxo sanguíneo regional e função neuroendócrina ${ }^{(64)(65)}$.

No encéfalo, o NO age como um neuromodulador que controla a atividade comportamental, influenciando na formação da memória e intensificando respostas a estímulos dolorosos ${ }^{(68)}$. Existem evidências de que o NO poderia mediar à plasticidade neuronal ao participar de mecanismos de desenvolvimento e armazenamento de 
informações no encéfalo, com a potenciação de longo prazo no hipocampo e depressão de longo prazo no cerebelo ${ }^{(69)(70)(71)}$.

A biossíntese de NO em tecidos excitáveis não se restringe aos neurônios, tendo sido identificada produção de NO em músculo esquelético, onde regula a contratilidade e metabolismo musculares. A síntese de NO em tecidos excitáveis é regulada pelo aumento no cálcio intracelular, o qual, ativa a NOS através da dependência desta em relação à calmodulina ${ }^{(61)}$. Enquanto que quantidades reduzidas de NO atuam no funcionamento normal dos tecidos, o contrário, ou seja, uma produção excessiva pode mediar uma lesão tecidual, como na isquemia cerebral e em outras afecções como doença de Parkinson, esclerose lateral amiotrófica e doença de Huntington, bem como na distrofia muscular de Duchenne ${ }^{(72)(73)(61)}$. Na tabela abaixo, tem-se as ações fisiológicas do óxido nítrico, sendo importante para este trabalho principalmente os sistemas vascular e neurológico.

Tabela 1- Ações fisiológicas do óxido nítrico nos diversos sitemas orgânicos.

\begin{tabular}{|c|c|c|c|}
\hline \multicolumn{4}{|c|}{ NO (Oxido Nítrico) - Ações Fisiológicas } \\
\hline Orgão/ Sistema & Produção Reduzida & Produção Normal & Produção Aumentada \\
\hline Vascular & Hipertensão & Normotensão & Hipotensão \\
\hline Neurológico & Hipotonia & $\begin{array}{l}\text { Neurotransmissor } \\
\text { normal }\end{array}$ & $\begin{array}{l}\text { Inatividade de B12/ } \\
\text { Citocinas e oxidativas }\end{array}$ \\
\hline Imune & Infecção oportunista & Atividade macrófago & $\begin{array}{ll}\text { Excesso } & \text { de } \\
\text { Inflamação } & \end{array}$ \\
\hline Gastrointestinal & Candida H. pylori HIV & Imunidade normal & Inflamação \\
\hline Hepático & $\begin{array}{l}\text { Defesa Imune } \\
\text { Reduzida }\end{array}$ & $\begin{array}{l}\text { Atividade de cel. } \\
\text { Kupffer }\end{array}$ & Inatividade de $\mathrm{P} 450 \mathrm{~s}$ \\
\hline Muscular & Perfusão Reduzida & Contração normal & Fibromialgia \\
\hline
\end{tabular}

A produção de espécies reativas de oxigênio (ERO), de nitrogênio (ERN), entre outras espécies reativas, é parte integrante do metabolismo humano e é observada em diversas condições fisiológicas. ERO e ERN têm importante função biológica, como na fagocitose, fenômeno em que essas espécies são produzidas para eliminar o agente agressor. Por outro lado, quando sua produção é exacerbada, o organismo dispõe de um 
eficiente sistema antioxidante que consegue controlar e reestabelecer o equilíbrio. $\mathrm{O}$ estresse oxidativo resulta no desequilíbrio entre o sistema pró e antioxidante, com predomínio dos oxidantes, com dano subsequente. A célula, unidade de vida, é uma verdadeira usina de pró e antioxidantes ${ }^{(24)}$.

Em termos químicos, o estresse oxidativo consiste no aumento significativo do potencial de redução celular (tornando-se menos negativo), ou em uma diminuição significativa da capacidade redutora de pares redox celulares, como a glutationa ${ }^{(29)}$. Os efeitos do estresse oxidativo dependem da dimensão dessas variações. Uma célula é normalmente capaz de superar os efeitos nefastos do estresse oxidativo se as perturbações no equilíbrio redox forem pequenas, restabelecendo o equilíbrio normal intracelular, entretanto, quando observadas perturbações de maior escala, estas podem levar à morte celular, apoptose e até necrose ${ }^{(74)}$.

Uma forma de estimar a produção de NO é a quantificação de seu metabólito, o nitrato, o que pode ser realizado através de reações de quimioluminescência ${ }^{(74)}$. 


\section{OBJETIVOS}

\subsection{Objetivo Geral}

Verificar se a atividade nervosa simpática e parassimpática, bem como a atividade metabólica observada pelos níveis de nitrato sérico são associadas pelo tipo de suporte de peso em pé adotado cronicamente pelos sobreviventes de acidente vascular encefálico.

\subsection{Objetivos Específicos}

1. Identificar tipos de distribuição do suporte de peso em pé que possam estar sendo associados pela preferência de uso (lado dominante) no caso dos controles e pela conveniência de uso (lado não parético) no caso dos sujeitos que convivem com a condição de hemiparesia crônica e sujeitos hígidos.

2. Verificar se o comportamento da resposta nervosa simpática e parassimpática observado na frequência cardíaca estão alterados nos diferentes tipos de distribuição do suporte de peso (simétricos e assimétricos).

3. Correlacionar atividade parassimpática observada pela variável RMSSD com a idade e a razão de simetria na distribuição do peso em pé.

4. Avaliar as concentrações de nitrato sérico nos diferentes tipos de distribuição do suporte de peso. 


\section{MÉTODOS}

\subsection{População alvo e amostragem}

Cinquenta e um sujeitos adultos e com hemiparesia crônica participaram das avaliações iniciais deste estudo. Tratou-se de uma amostra de conveniência do Projeto de Extensão de Ação Contínua: Viver sem limites em um corpo pela metade (Brasília, Distrito Federal), no Centro de Reabilitação e Readaptação Dr. Henrique Santillo (CRER, Goiânia, Goiás) e na Associação dos Deficientes Físicos do Estado de Goiás (ADFEGO, Goiânia, Goiás).

Para serem incluídos no grupo hemiparesia os sujeitos precisavam: ser do sexo masculino e com idade entre 40 e 70 anos; possuir mais de seis meses pós-lesão encefálica do tipo isquêmica e em território de irrigação da artéria cerebral média, (confirmado por ressonância magnética, laudo médico ou características clínicas comuns a esta síndrome vascular) e ser capaz de manter-se em equilíbrio na posição ortostática, bipodal, por um período mínimo de 20 segundos para o registro da distribuição do suporte de peso em pé.

Foram excluídos, os indivíduos que tinham quaisquer outras afecções neurológicas além daquela que determinou o quadro de hemiparesia, bem como outros tipos de afecções nos sistemas cardiovascular ou pulmonar; e presença de doenças renal, hepática, neoplasias, distúrbios psiquiátricos. Foi critério de exclusão também características do hábito de vida como tabagismo e consumo de álcool (superior a 10 doses/semana). Além de casos de sujeitos que faziam uso de anti-inflamatórios, drogas no tratamento de dislipidemias, ansiolíticos, viagra, cialis e similares, drogas a base de nitrato ou medicamentos betabloqueadores.

Os indivíduos foram orientados a não praticar exercícios ao longo das 24 horas precedentes à coleta e todos deveriam concordar em assinar o Termo de Consentimento Livre e Esclarecido (TCLE) durante a entrevista.

Paralelamente às avaliações iniciais da população com hemiparesia, 57 sujeitos hígidos, com idade e Índice de Massa Corporal (IMC) similares aos sujeitos com hemiparesia foram também avaliados. Estes sujeitos foram recrutados por meio de convite direcionado aos usuários da Academia Melhor Idade (Academia de Ginástica 
Particular, Goiânia, Goiás) para formar o grupo controle. Somente este grupo praticava atividade física leve, por no mínimo 30 minutos, duas vezes por semana.

O estudo foi aprovado pelo Comitê de Ética e Pesquisa (CEP) da Faculdade de Ciências da Saúde (FS) da Universidade de Brasília (Anexo A) conforme resolução ${ }^{\circ}$ 466/12 do Conselho Nacional de Saúde. Todos os participantes assinaram o TCLE e todas as Instituições onde os voluntários foram selecionados assinaram a carta de anuência, concordando com o estudo. Os dados foram coletados nos meses de maio e junho de 2013.

\subsection{Delineamento do estudo e grupos experimentais}

Trata-se de um delineamento de estudo observacional (não intervencional), analítico, do tipo transversal em caso-controle. O caso foi definido pelos sujeitos com hemiparesia (grupo hemiparesia) e seu controle formado pelos sujeitos hígidos normalizados ao grupo hemiparesia durante o recrutamento por idade e IMC (grupo controle).

Para verificar o tipo de distribuição do suporte de peso em pé, utilizou-se a baropodometria computadorizada que fornece a porcentagem de suporte de peso em cada pé e, posteriormente, estes valores em porcentagem foram utilizados para o cálculo da razão de simetria $(\mathrm{RS})^{(17)}$.

A RS é calculada pelo quociente dos valores do HNPU (numerador) sobre o HPU (denominador) descritos na equação: $\mathrm{RS}=\frac{H N P U}{\mathrm{HPU}}($ Equação 1$)$. Posto a forma de cálculo, é possível verificar que a RS se refere a um valor adimensional.

O quociente obtido nesta razão considera a predominância de uso, estabelecendo uma relação entre a dominância de uso por um hemicorpo para o grupo controle e relação de conveniência de uso do hemicorpo não parético para o grupo hemiparesia.

Conforme Martins e colaboradores $(2011)^{(7)}$, a principal vantagem em se utilizar a RS é a possibilidade de fazer uma comparação direta entre os hemicorpos cujo valor já define o tipo de distribuição do suporte de peso em pé com base nos limites de simetria $(0,888<$ RS < 1,072) obtidos em população de referência já disponível na literatura.

Desta forma valores dentro dos limites de referência caracterizaram as distribuições de suporte de peso simétricas, enquanto valores acima e abaixo destes 
limites caracterizaram distribuições assimétricas, respectivamente, para o HNPU e para o HPU.

O registro da distribuição no suporte de peso em pé foi realizado com o indivíduo na posição ortostática, olhando para um ponto fixado a três metros de distância sobre a plataforma baropodométrica, durante 20 segundos. A porcentagem apresentada ao final dos 20 segundos era a média dos valores obtidos durante o período.

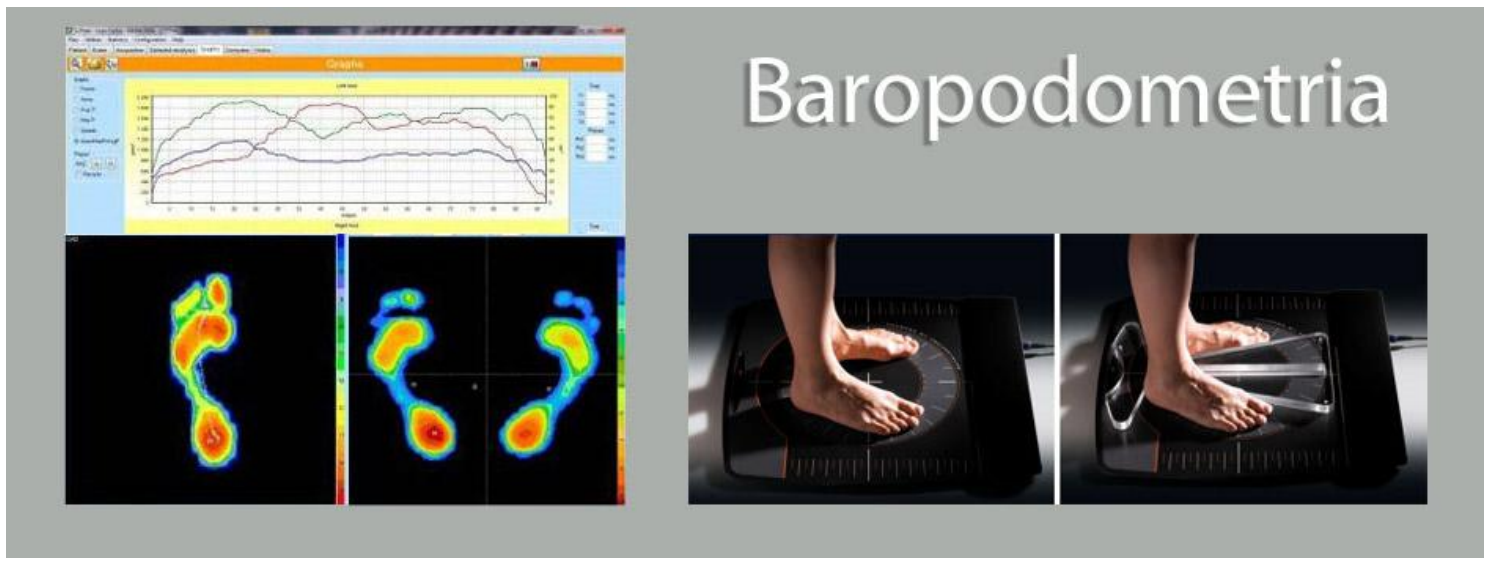

Figura 4- Desenho ilustrativo da baropodometria computadorizada.

(fonte: http://retejo.blogspot.com.br/2013/02/palmilha-postural-para-melhor-qualidade.html)

Uma vez identificada a RS dos integrantes no grupo hemiparesia e controle, subgrupos foram separados para as análises da variabilidade da frequência cardíaca e da concentração de nitrato sérico por tipo de distribuição do suporte de peso. Um subgrupo de referência $(n=7)$ foi formado pelos integrantes do grupo controle com RS dentro dos limites de referência, ou seja, eram todos hígidos com distribuição simétrica do suporte de peso em pé.

Além deste subgrupo de referência formado a partir do grupo controle, do grupo hemiparesia, foram separados 19 indivíduos categorizados em subgrupos definidos pelo tipo de distribuição de suporte de peso em pé. Desta forma, foram também analisados os subgrupos do grupo hemiparesia com distribuição de peso: simétrica $(n=7)$, assimétrica HNPU (n=7) e assimétrica HPU (n=5). 


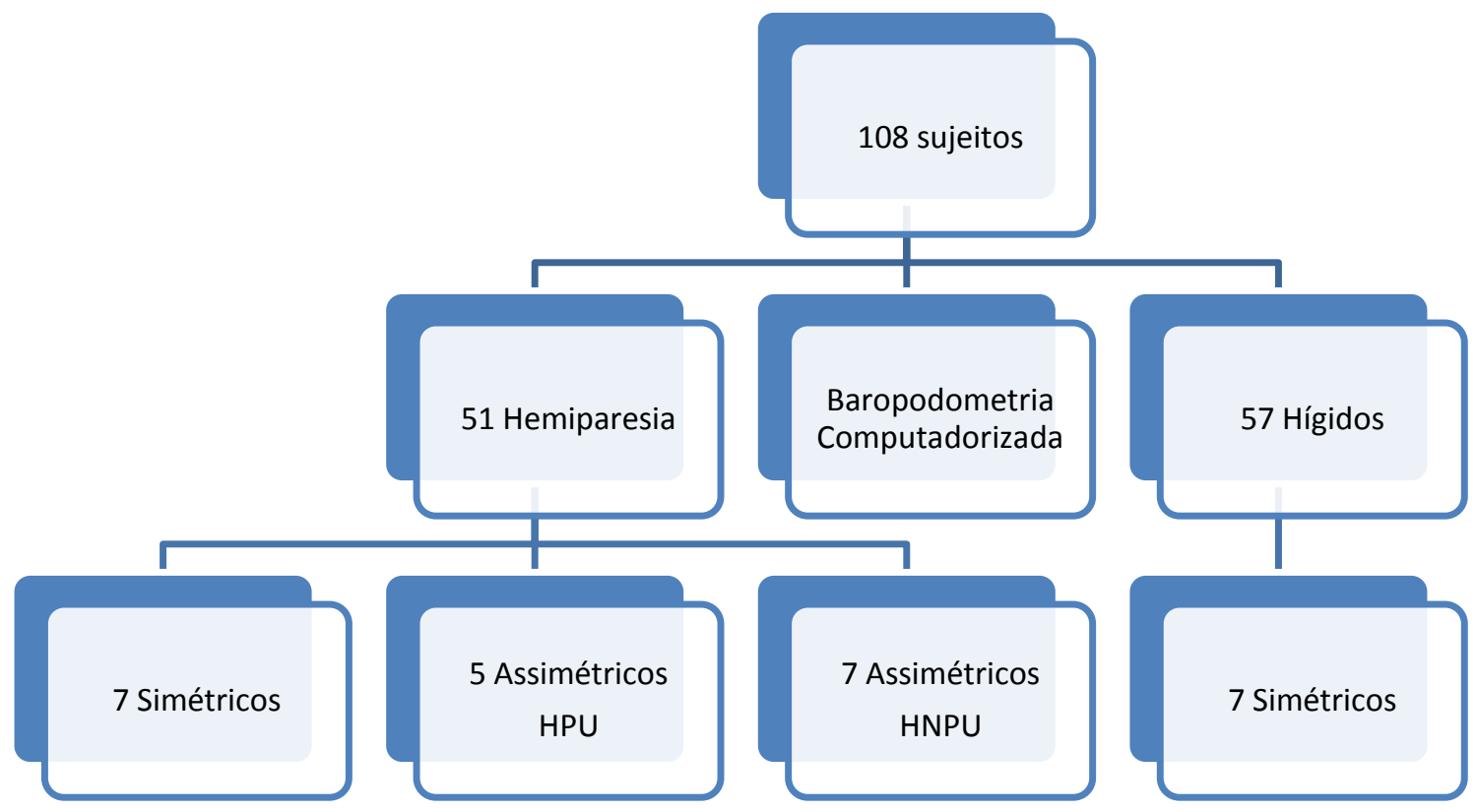

Figura 5- Fluxograma do delineamento amostral.

\subsection{Caracterização inicial dos grupos}

Para caracterizar inicialmente os grupos hemiparesia e controle realizamos uma entrevista para coletar dados sociodemográficos, idade e IMC dos indivíduos. Além destes dados sociodemográficos, somente no grupo hemiparesia foram registradas características do Acidente Vascular Cerebral (AVC) e da sequela hemiparética, incluindo cronicidade e magnitude da mesma, além do relato do membro mais utilizado antes da instalação da hemiparesia decorrente do AVC, observado através da aplicação do teste de dominância de membro inferior, Inventário de Waterloo.

Questionários específicos como Mini-Exame do Estado Mental (MEEM) ${ }^{(75)}$, que avalia a orientação espacial, cognição e memória do indivíduo, com score entre 030 e ponto de corte acima de 27 , e Escala de Ashworth modificada ${ }^{(76)}$, que avalia o grau de espasticidade com score de 0 a 7 e ponto de corte abaixo de 2 para membros inferiores, foram aplicados.

\subsection{Caracterização da atividade nervosa simpática e parassimpática}

Para mensuração da variabilidade da frequência cardíaca (VFC) os indivíduos foram orientados a permanecerem em repouso por um período de 10 minutos, evitando conversar com os experimentadores. Em seguida dava-se inicio à coleta da FC, durante 
5 minutos e sequencialmente nas posturas em supino (deitado de barriga para cima), sentado e em pé. O indivíduo mantinha a respiração controlada e com intervalo de repouso de dois minutos entre as mudanças posturais.

Para a obtenção da frequência cardíaca (FC) e dos intervalos R-R (iR-R), utilizou-se um Frequencímetro Polar modelo S810i® (Polar ElectroCo.Ltda. Kempele, Finland). Este sistema tem incorporado um microprocessador para detectar, instantaneamente, a despolarização ventricular, correspondendo a onda R do ECG, com uma frequência de amostragem de $500 \mathrm{~Hz}$ e resolução temporal de 2 milissegundos (ms), deste modo, calculando a FC instantaneamente e armazenando os iR-R ${ }^{(77)}$.

Os iR-R foram captados a partir de uma cinta com transmissor codificado (figura 5A), posicionada na região do tórax, na altura do $5^{\circ}$ espaço intercostal, transmitidos para uma interface ligada a um computador compatível, responsável pelo armazenamento e processamento dos sinais (figura 6).

As variações em tempo real eram acompanhadas no visor do relógio de pulso (figura 6B).
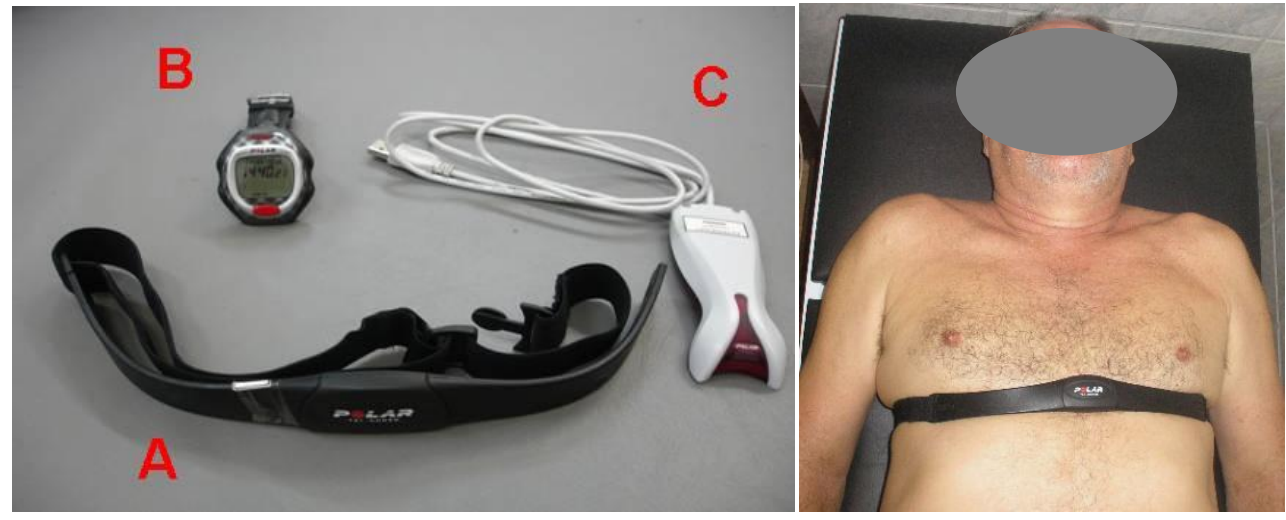

Figura 6 - A: cinta com transmissor codificado; B: frequencímetro polar; C: interface. Ao lado, fotografia indicando a colocação da cinta no quinto espaço intercostal para captação da FC.

Após o processamento dos sinais, foi realizada uma inspeção visual da distribuição dos iR-R (ms) obtidos nas condições de repouso supino, sentado e em pé para eliminar os trechos que continham picos, de modo a selecionar um intervalo que apresentasse maior estabilidade do traçado dos iR-R do ECG ${ }^{(78)}$. Para determinação exata do trecho de análise, foi considerado o número de pontos dos dados coletados. 


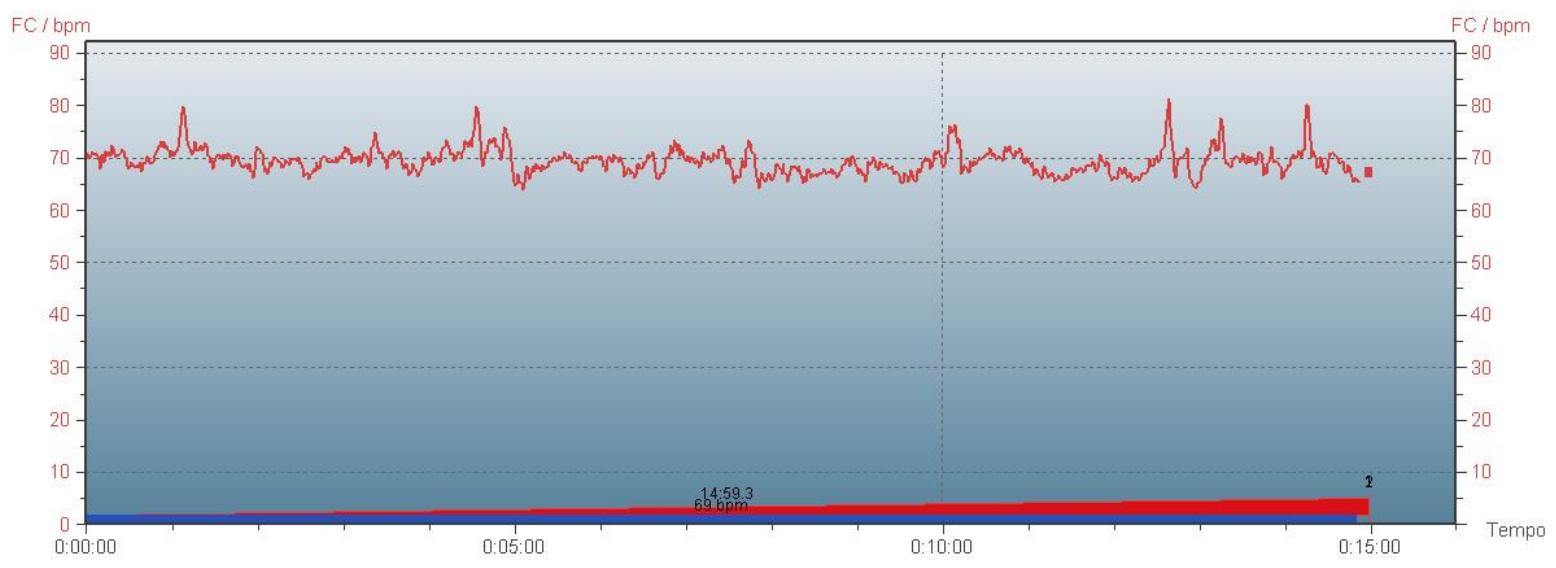

Figura 7- Representação de um tacograma dos valores absolutos da FC (bpm) no software Polar Precision Performace, captado durante 15 minutos.

As variáveis derivadas da VFC utilizadas na análise das posturas supino, sentada e em pé foram: FC (frequência cardíaca), iR-R (intervalos R-R), RMSSD (raiz quadrada da média do quadrado das diferenças entre os intervalos RR normais adjacentes, em um intervalo de tempo, expresso em m/s), SDNN (desvio padrão de todos os intervalos RR normais gravados em um intervalo de tempo, expresso em $\mathrm{m} / \mathrm{s}$ ), BF (componente de baixa frequência, com variação de 0,04 a $0,15 \mathrm{~Hz}$ ) e AF (componente de alta frequência, com variação de 0,15 a $0,4 \mathrm{~Hz}$ ). Os resultados de RMSSD e SDNN representam a análise da VFC no domínio do tempo e BF e AF no domínio da frequência, que são métodos lineares de análises.

\subsection{Caracterização da atividade metabólica pelos níveis de nitrato/nitrito sérico}

Para a mensuração do nitrato/nitrito sérico os indivíduos dos subgrupos hemiparéticos simétricos $(\mathrm{n}=7)$, assimétricos com distribuição do suporte de peso em pé no hemicorpo não predominanatemente usado (HNPU; $n=7$ ), assimétricos com distribuição do suporte de peso no hemicorpo predominantemente usado (HPU; n=5) e o grupo referência $(n=7)$, foram designados para os procedimentos de coleta sanguínea.

As amostras de sangue foram coletadas, após o consentimento dos participantes, por venopunção, por um técnico em enfermagem habilitado para o procedimento, dos 26 sujeitos, em tubos contendo ácido etilenodiaminotetracético (EDTA) com o anticoagulante. As amostras foram mantidas em banho de gelo até o momento da centrifugação, a qual foi realizada em centrífuga refrigerada $\left(4^{\circ} \mathrm{C}\right)$ a $1500 \mathrm{~g}$ por $10 \mathrm{~min}$, logo após a coleta. 
O plasma ultrafiltrado de peso molecular (10 ou 30Kda) foi obtido usando uma centrifuga comercial de ultrafiltração. Este procedimento removeu a hemoglobina, que poderia causar uma redução drástica na intensidade de fluorescência. $O$ ensaio de nitrito-nitrato utilizou no máximo $10 u l$ do filtrado. A conversão de nitrato em nitrito requer de 1 a 2 horas para 95\% de conversão.

Após o processo de centrifugação, realizado por técnico laboratorial habilitado para o procedimento, foi pipetado $10 u l$ de plasma, codificado com as siglas representativas de cada subgrupo da coleta e armazenado em nitrogênio líquido, até o momento de análise laboratorial.

O kit de ensaio fluorométrico utilizado, o Cayman`s Nitrato/Nitrito é um método preciso e conveniente para a mensuração da concentração total de nitrito-nitrato em processo simples de duas etapas ${ }^{(79)(80)}$.

Uma vez que o óxido nítrico (NO) sofre uma série de reações no meio biológico, tendo como produto final in vivo a combinação de íons nitrito e nitrato, para mensurar o produto final de óxido nítrico (nitrito + nitrato), pode-se utilizar ambas as curvas padrões tanto de nitrito ou nitrato para a determinação destes íons no plasma sanguíneo.

Foi realizada a construção da curva padrão de nitrato contendo oito poços da placa de análise para a construção da curva padrão. A curva padrão de nitrito também foi construída contendo 8 poços, sendo importante que a mesma seja feita em triplicata para a obtenção de melhores dados.

A primeira etapa foi converter o nitrato em nitrito utilizando o nitrito redutase. A segunda etapa foi a adição de DAN (2,3 diaminonaftaleno), fornecida por uma solução ácida, e seguido da adição de $\mathrm{NaOH}$ (hidróxido de sódio), aumentando assim a detecção da fluorecência do produto, NAT 1(H)-naphthotriazole. A mensuração da fluorescência do composto NAT determina a concentração de nitrito no plasma sanguíneo (figura 8).

A leitura da placa foi realizada em um espectofluorimétrico (Hitachi F-700) usando uma excitação em comprimento de onda de $360 \mathrm{~nm}$ e uma emissão de fluorescência em $430 \mathrm{~nm}$.

As curvas padrões foram dispostas em gráficos e os valores obtidos para as amostras de plasma de cada grupo foram relacionados a estas curvas. Os valores de nitrito não foram conclusivos, entretanto os valores de nitrato, expressos em picomol foram determinados e estão apresentados na Tabela 2. 


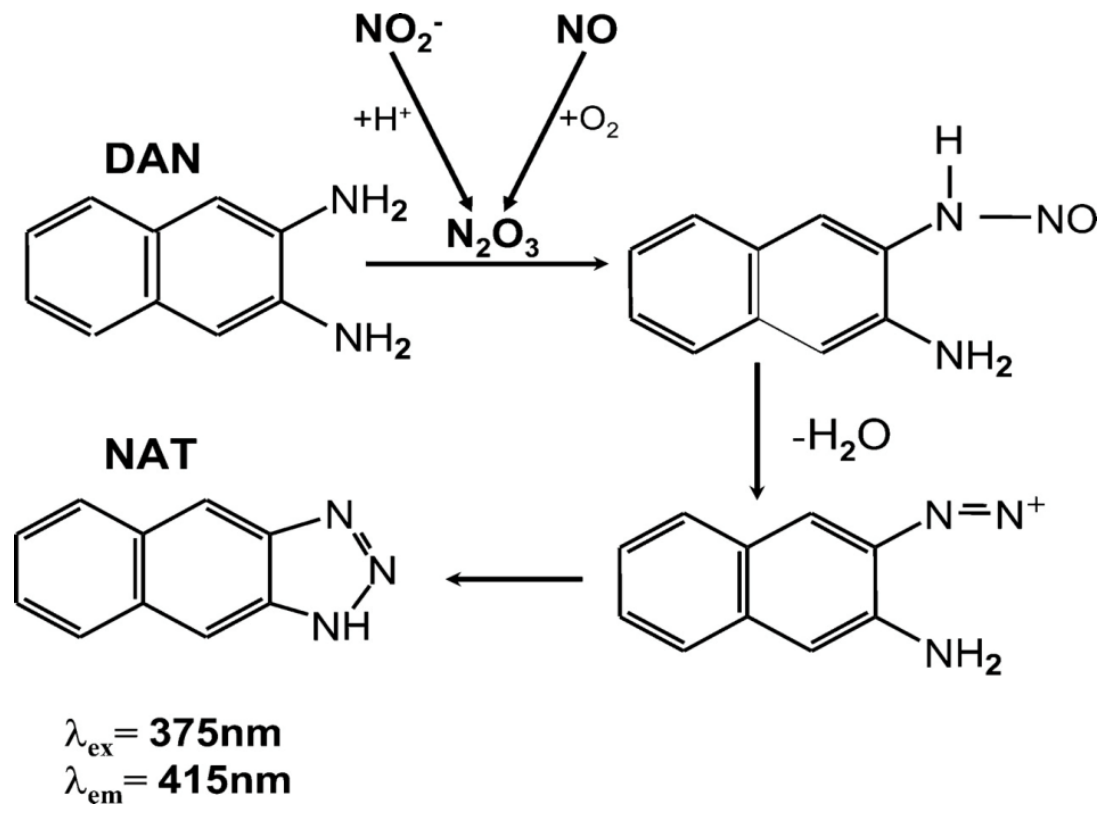

Figura 8- Equações químicas do método de detecção de nitrito-nitrato através de medidas espectrofluorimétricas : DAN (2,3- diaminonaftaleno) em emio ácido na presença de oxigênio reage com íons nitrito e óxido nítrico; formando trióxido de nitrogênio que se liga a amina do DAN tendo como produto final o NAT (1 (H)-naftotriazol) cuja emissão de fluorescência é detectada em $415 \mathrm{~nm}$.

\subsection{Processamento estatístico}

Para caracterização da amostra, primeiramente foi aplicado o teste de normalidade Kolmogorov-Smirnov para verificar a aproximação entre a distribuição das variáveis e a distribuição normal dos dados (Gaussiana). As variáveis analisadas não apresentaram distribuição Gausiana, assim testes não paramétricos foram aplicados. Os dados clínicos, idade, IMC, cronicidade da lesão e score de MEEM foram apresentados de forma descritiva em média e desvio padrão.

Foram utilizadas as porcentagens da distribuição no suporte de peso do lado esquerdo e direito e entre os hemicorpos preferidos para uso (HNPU e HPU), que foram também usadas para o cálculo da razão de simetria (RS), como o que já foi detalhado no item delineamento do estudo e grupos experimentais. Para análise das variáveis relacionadas à distribuição do suporte de peso em pé utilizou-se o teste Mann-Whitney a fim de promover comparações entre os grupos controle e hemiparéticos e o teste Wilcoxon pareado para comparações entre os hemicorpos.

$\mathrm{Na}$ análise da VFC, tivemos dois momentos, o primeiro foi a correlação das variáveis RMSSD com a idade e a RS, detectados por meio do teste de Correlação de Sperman. Em um segundo momento, médias e desvio padrão foram calculados para 
todas as variáveis (FC, i-RR, SDDN, RMSSD, BF, AF, ES e concentração de nitrato sérico) e a seguir, foram aplicados os testes de Kruskal-Wallis e pós-teste de Dunn para comparações múltiplas, resultando na apresentação das diferenças significativas.

Para todos os testes estatísticos aplicados foi considerado um nível de significância de $\mathrm{p}<0,05(5 \%)$. 
Os participantes inicialmente amostrados por conveniência e recrutados para formar os grupos controle e hemiparesia (adultos do sexo masculino e idosos com idade variando entre 40 e 70 anos) não apresentaram diferenças etárias significativas entre os grupos (Tabela 2).

A tabela 2 apresenta a caracterização inicial das variáveis e também permite observar que os grupos possuíam medidas antropométricas similares (sem diferenças significativas), embora o grupo controle tenha apresentado média do Índice de Massa Corporal (IMC) compatível com sobrepeso (25 < IMC < 30).

Os sujeitos do grupo hemiparesia estavam convivendo com sua deficiência há pelo menos 6 meses, com cronicidade variando entre 6 e 264 meses ( 1 a 22 anos). Em termos de cognição, o Mini Exame do Estado Mental (MEEM) revelou estado cognitivo preservado para o grupo hemiparesia (acima de 27 pontos).

A baropodometria computadorizada registrou suporte de peso variando de $50,9 \%$ a $65,3 \%$ no hemicorpo esquerdo e de $34,7 \%$ a $49,1 \%$ no hemicorpo direito para os participantes do grupo controle, enquanto que essa variação foi de 35,2\% a 69,3\% e de $30,7 \%$ a $64,8 \%$, respectivamente, para os hemicorpos esquerdo e direito do grupo hemiparesia. Essa variação não proporcionou diferenças significativas entre os grupos que sobrecarregavam significativamente em $7 \%$ a $8 \%$ o hemicorpo direito.

Ao organizar o suporte de peso definido pelo hemicorpo predominantemente usado observamos que a diferença significativa entre os hemicorpos permaneceram para os dois grupos, porém com a inversão do lado sobrecarregado no grupo hemiparesia (Tabela 2). Isso quer dizer que a porcentagem da distribuição no suporte de peso continuou a ser maior no hemicorpo não predominantemente usado (HNPU) para o grupo controle (considerando que o hemicorpo predominantemente usado neste grupo é definido pela dominância, o lado direito para a maioria) e passou a ser maior no hemicorpo predominantemente usado (HPU) para o grupo hemiparesia (considerando que o hemicorpo predominantemente usado neste grupo é o não parético).

Esse comportamento resultou em uma razão de simetria (RS) maior que 1 para o grupo controle (sobrecarga do HNPU) e menor que 1 para o grupo hemiparesia (sobrecarga do HPU) conforme também descrito na tabela 2. 
Dos 51 participantes inicialmente amostrados no grupo hemiparesia, após a baropodometria computadorizada e os critérios de exclusão, restaram 19, que foram subdivididos entre os subgrupos de hemiparesia: simétricos $(n=7)$, assimétricos sobrecarregando o HNPU (n=7) e assimétricos sobrecarregando o HPU (n=5). Além disso, alguns participantes do grupo controle $(n=7)$ também foram selecionados por similaridade de idade e IMC para formar um subgrupo de referência que foi usado nas comparações (Tabela 3).

Tabela 2.Caracterização inicial das variáveis obtidas nos grupos controle e hemiparesia.

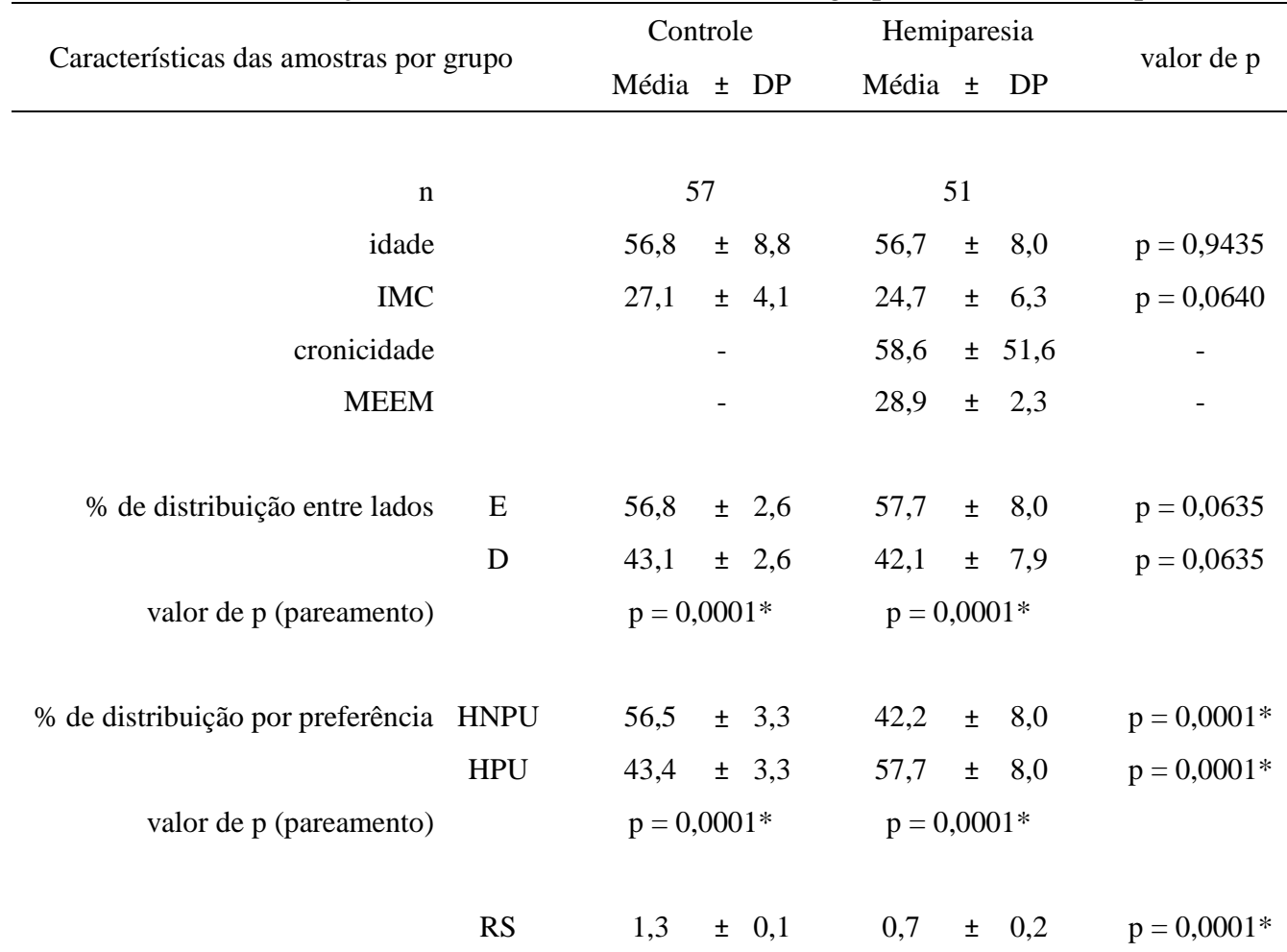

Os valores por variável (idade em anos, IMC - Índice de Massa Corporal, cronicidade em meses e score do MEEM - Mini Exame do Estado Mental) são apresentados em tamanho (n) e Média \pm Desvio Padrão (DP) para os grupos controle e hemiparesia. A porcentagem (\%) de distribuição do suporte de peso foi observada entre os lados (E - esquerdo e D - direito) e entre os hemicorpos preferidos para uso (HNPU Hemicorpo Não Predominantemente Usado e HPU - Hemicorpo Predominantemente Usado). Ao final foi apresentada a Razão de Simetria (RS) pelo quociente entre o HNPU e o HPU. Diferenças significativas $(\mathrm{p}<0,05)$ foram detectadas pelo teste Mann-Whitney para comparações entre os grupos controle e hemiparesia e pelo teste Wilcoxon pareado para comparações entre os hemicorpos.

Nenhuma diferença etária e de IMC significativa foi observada comparando os grupos referência, os simétricos, os assimétricos para o HNPU e os assimétricos para o HPU entre eles. Além disso, dentre os subgrupos formados a partir do grupo hemiparesia, uma homogeneidade em termos de cronicidade e cognição avaliada pelo MEEM foi também observada (Tabela 3). 
Conforme observado na figura 9, os valores de RMSSD de todos os participantes do grupo hemiparesia foram testados em função da sua correlação com a idade e a razão de simetria, indicando um índice de correlação de Spearman $\left(\mathrm{r}^{2}\right)$ muito próximo de zero para idade e menor que 0,5 para RS. Desta maneira, pode-se observar que não há correlação entre idade e RMSSD e RS e RMSSD. Analisando os dados, o que é possível identificar, é que existe um acúmulo de indivíduos na região entre os valores de RMSSD (0 a 50), e que somente por dois indivíduos que estão nos valores de referência 75 e 125 respectivamente, provalvemente foi o que não gerou a significância, isto pode ter sido decorrente do quantitativo amostral.
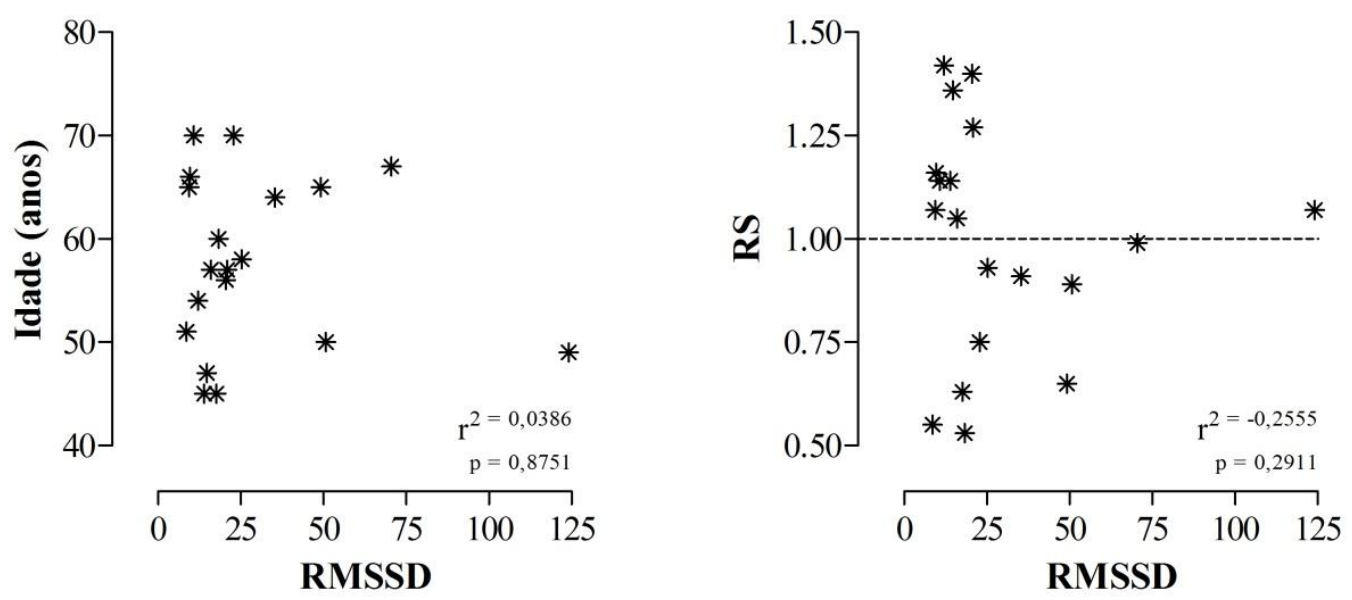

Figura 9. Gráficos de dispersão das variáveis obtidas no grupo hemiparesia que foram associadas pelo teste de correlação de Spearman. Os níveis de correlação entre as variáveis Root Mean Square SuccessiveDifference - RMSSD e Idade (esquerda) e as variáveis RMSSD e Razão de Simetria - RS (direita) estão indicados pelos coeficientes de correlação de Spearman $\left(r^{2}\right)$ e pelos valores de $p$. No gráfico da direita uma linha descontínua foi colocada para melhor visualizar os sujeitos com valores de RS que indicam uma distribuição simétria ( $\mathrm{RS}=1$ ), assimétrica com sobrecarga do hemicorpo não predominantemente usado - HNPU (RS > 1) e assimétrica com sobrecarga do hemicorpo predominantemente usado - HPU $(\mathrm{RS}<1)$.

Na tabela 3 estão organizadas pelos subgrupos as variáveis de caracterização inicial, bem como as variáveis utilizadas para identificar o comportamento da distribuição do suporte de peso em pé, as variáveis para verificar o comportamento da variabilidade da frequência cardíaca em três posturas (supino, sentado e em pé) e, ainda, os valores da concentração de nitrato sérico para avaliar o estresse oxidativo.

Conforme já descrito, em termos de faixa etária e características de composição corporal, todos os subgrupos apresentaram-se similares, sem diferenças significativas de idade (média entre subgrupos de 57 anos) e IMC (média entre subgrupos de 25). 
Na posição em supino, nenhuma diferença significativa entre os subgrupos foi constatada na comparação entre as variáveis obtidas da variabilidade da frequência cardíaca (tabela 3). Entretanto, na posição sentada, menor valor significativo da variável BF (destacada na tabela 3) foi detectada somente quando comparamos o subgrupo hemiparesia simétrico e o subgrupo referência.

Na postura em pé, menor valor da variável BF não foi observada, porém um maior valor significativo da variável AF foi encontrado na comparação destes valores do subgrupo hemiparesia simétrico com os valores de referência. Ainda, na posição em pé, uma tendência $(0,05<\mathrm{p}<0,10)$ de aumento da ordem de mais de três vezes (de 14,7 para 47,36) para a variável RMSSD foi detectada na comparação do subgrupo hemiparesia simétrico com o subgrupo de referência.

Em resumo, somente os hemiparéticos com distribuição de suporte de peso simétrico diferiram do grupo referência em termos das variáveis de controle autonômico.

Em relação ao estudo do controle metabólico os valores de óxido nítrico e nitrito foram descartados devido a valores inconclusivos na coleta. Entretanto, após a análise dos dados obtidos da dosagem de nitrato sérico nos subgrupos e referência, não foi encontrada nenhuma diferença estatística para os valores de concentração sérica do nitrato. 
Tabela 3. Comparação das variáveis de estudo por subgrupos.

\begin{tabular}{|c|c|c|c|c|c|c|c|c|c|c|c|c|c|c|}
\hline \multirow{3}{*}{$\begin{array}{l}\text { Grupos de variáveis } \\
\text { Caracterização inicial }\end{array}$} & \multirow{2}{*}{\multicolumn{2}{|c|}{ Variáveis }} & \multirow{2}{*}{\multicolumn{3}{|c|}{$\begin{array}{c}\text { Referência } \\
(\mathrm{n}=7)\end{array}$}} & \multirow{2}{*}{\multicolumn{3}{|c|}{$\begin{array}{c}\text { Simétrico } \\
(\mathrm{n}=7)\end{array}$}} & \multicolumn{3}{|c|}{ Hemiparesia } & \multirow{2}{*}{\multicolumn{3}{|c|}{$\begin{array}{c}\text { Assimétrico HPU } \\
(\mathrm{n}=5)\end{array}$}} \\
\hline & & & & & & & & & Assimét & $\begin{array}{l}\text { ico } \\
=7)\end{array}$ & HNPU & & & \\
\hline & & idade & 56,71 & \pm & 9,96 & 58,57 & \pm & 7,19 & 56,43 & \pm & 9,14 & 58,20 & \pm & 10,18 \\
\hline & & $\mathrm{IMC}$ & 23,99 & \pm & 3,14 & 24,44 & \pm & 3,57 & 26,70 & \pm & 6,32 & 24,22 & \pm & 2,75 \\
\hline & & cronicidade & & - & & 54,57 & \pm & 48,95 & 68,71 & \pm & 54,79 & 58,60 & \pm & 63,46 \\
\hline & & MEEM & & - & & 29,43 & \pm & 0,79 & 27,71 & \pm & 3,40 & 29,40 & \pm & 0,89 \\
\hline \multirow[t]{18}{*}{ Variabilidade da frequência cardíaca } & supino & FC & 73,53 & \pm & 15,03 & 75,89 & \pm & 13,12 & 68,98 & \pm & 7,48 & 66,31 & \pm & 11,09 \\
\hline & & iRR & 791,60 & \pm & 160,90 & 860,10 & \pm & 134,70 & 881,50 & \pm & 94,44 & 898,20 & \pm & 106,20 \\
\hline & & RMSSD & 39,31 & \pm & 22,76 & 42,73 & \pm & 61,61 & 27,59 & \pm & 14,91 & 24,16 & \pm & 18,45 \\
\hline & & SDNN & 51,89 & \pm & 22,80 & 53,04 & \pm & 51,61 & 46,66 & \pm & 9,93 & 53,52 & \pm & 27,93 \\
\hline & & $\mathrm{BF}$ & 0,07 & \pm & 0,02 & 0,06 & \pm & 0,01 & 0,06 & \pm & 0,03 & 0,05 & \pm & 0,01 \\
\hline & & $\mathrm{AF}$ & 0,22 & \pm & 0,06 & 0,27 & \pm & 0,08 & 0,22 & \pm & 0,07 & 0,20 & \pm & 0,10 \\
\hline & sentado & FC & 78,74 & \pm & 16,11 & 78,14 & \pm & 15,31 & 70,76 & \pm & 6,23 & 69,95 & \pm & 10,67 \\
\hline & & iRR & 854,00 & \pm & 185,70 & 797,10 & \pm & 153,10 & 855,50 & \pm & 71,04 & 876,30 & \pm & 133,70 \\
\hline & & RMSSD & 28,04 & \pm & 31,17 & 47,36 & \pm & 72,61 & 24,86 & \pm & 6,83 & 24,18 & \pm & 7,37 \\
\hline & & SDNN & 44,43 & \pm & 26,89 & 50,01 & \pm & 44,70 & 43,07 & \pm & 7,41 & 43,32 & \pm & 12,21 \\
\hline & & $\mathrm{BF}$ & 0,08 & \pm & 0,02 & $\mathbf{0 , 0 5 *}$ & \pm & 0,01 & 0,07 & \pm & 0,03 & 0,08 & \pm & 0,03 \\
\hline & & $\mathrm{AF}$ & 0,22 & \pm & 0,08 & 0,28 & \pm & 0,07 & 0,24 & \pm & 0,07 & 0,20 & \pm & 0,05 \\
\hline & em pé & FC & 83,94 & \pm & 13,74 & 71,45 & \pm & 31,68 & 76,09 & \pm & 6,75 & 74,80 & \pm & 11,67 \\
\hline & & iRR & 732,9 & \pm & 113 & 765,6 & \pm & 135,3 & 795,4 & \pm & 67,19 & 820,6 & \pm & 132 \\
\hline & & RMSSD & 14,7 & \pm & 7,395 & $47,36^{\mathrm{t}}$ & \pm & 39,78 & 14,66 & \pm & 4,466 & 23,34 & \pm & 15,36 \\
\hline & & SDNN & 41,09 & \pm & 20,26 & 50,69 & \pm & 36,89 & 34,14 & \pm & 12,98 & 39 & \pm & 9,305 \\
\hline & & $\mathrm{BF}$ & 0,069 & \pm & 0,022 & 0,056 & \pm & 0,018 & 0,06 & \pm & 0,022 & 0,046 & \pm & 0,005 \\
\hline & & $\mathrm{AF}$ & 0,173 & \pm & 0,056 & $0,26^{*}$ & \pm & 0,076 & 0,226 & \pm & 0,082 & 0,162 & \pm & 0,011 \\
\hline Estresse oxidativo & & Nitrato & 1,096 & \pm & 0,166 & 1,18 & \pm & 0,215 & 0,989 & \pm & 0,109 & 1,206 & \pm & 0,358 \\
\hline
\end{tabular}

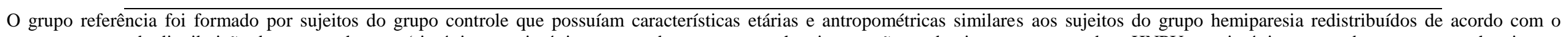

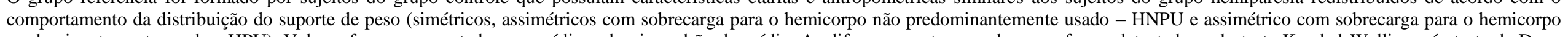

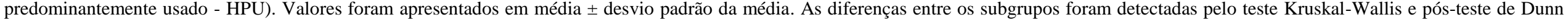

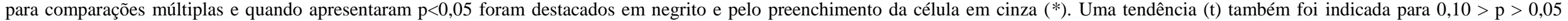




\section{DISCUSSÃO}

O presente estudo, cujo objetivo geral foi investigar se a atividade nervosa simpática e parassimpática, bem como atividade metabólica observada pelos níveis de nitrato sérico, são alteradas pelo tipo de suporte de peso em pé adotado cronicamente pelos sobreviventes de acidente vascular cerebral (AVC).

Todos os resultados significativos encontrados estão relacionados ao subgrupo hemiparesia simétrico quando comparado ao subgrupo referência. Como trata-se de pacientes crônicos e adaptados pode-se dizer que seja o início de uma possível justificativa referente as significâncias encontradas.

Por outro lado, já se encontra muito bem descrito ${ }^{(89)(90)(91)}$ que mudanças posturais influenciam a VFC em repouso, seja esta postura mais ativa ou passiva, em que ocorrem variações no tônus vago-simpático. A mudança postural desencadeia importantes modificações nas variáveis cardiovasculares por meio de desvios hidrostáticos e pelas respostas reflexas adaptativas causadas por deslocamento de sangue das extremidades superiores em direção às inferiores, diminuição do débito cardíaco e da pressão arterial sistêmica, ativação dos mecanorreceptores arteriais e cardiopulmonares e integração de informações periféricas e centrais ${ }^{(88)(89)(90)}$. Se estas mudanças modificam a VFC em sujeitos normais, que dirá de sujeitos com hemiparesia fazendo esforço para manter uma postura simétrica.

Nas mudanças posturais, as atividades parassimpáticas e simpáticas devem trabalhar de forma antagônica para uma condição ideal de funcionamento do SNA, ou seja, na postura supino, temos um aumento do parassimpático e uma diminuição do simpático, passando para a postura sentada, o parassimpático diminui e o simpático aumenta e ao atingir a postura em pé, o parassimpático diminui um pouco mais e o simpático aumenta um pouco mais ${ }^{(89)(90)(91)}$.

Com isto, os resultados da alta frequência $(\mathrm{AF})$ reforça essa proposição sugerida, pois representa também a resposta parassimpática do SNA observada na função cardíaca. O aumento nos valores de AF adquiridas na postura em pé dos indivíduos com hemiparesia do subgrupo simétrico, quando comparados ao subgrupo referência, sugere que estes indivíduos desenvolverem habilidades de compensação deste esforço corporal para a manutenção da simetria, com posterior melhora da atividade parassimpática.

Outra função derivada da VFC e que foi significativamente alterada nos hemiparéticos simétricos em comparações aos demais grupos, trata-se da baixa frequência (BF) na postura 
sentada, que foi significativamente menor para o subgrupo simétrico quando comparado ao subgrupo referência. Como BF é um componente de baixa frequência que mostra uma ação conjunta do vagal e do simpático, mas com predomínio simpático, a explicação também aconteceria com relação às mudanças posturais, já que com o aumento da postura teremos um aumento do simpático e diminuição do parassimpático ${ }^{(89)(90)(91)}$ para indivíduos com comportamentos posturais dentro da normalidade, porém, como o nosso resultado para o subgrupo simétrico foi contrário, demonstrando um aumento parassimpático, a atividade simpática para este caso só poderia diminuir, já que os dois sistemas trabalham sempre de forma antagônica.

É curioso notar que esta atividade melhorada foi somente observada na postura em pé, provavelmente em consequência de um maior esforço para mantê-la (tabela 3). Paralelo a este raciocínio, podemos utilizar o comportamento destas funções derivadas da VFC observado em indivíduo atleta de longa data, que, em repouso, apresenta valores altos para o comportamento da atividade cardíaca parassimpática, refletindo uma boa adaptação do SNA adquirida com o treinamento crônico ${ }^{(87)}$.

Esse comportamento, de acordo com a literatura ${ }^{(87)}$, é provocado pelo treinamento físico constante, que gera uma baixa frequência cardíaca de repouso, valores de intervalos R$\mathrm{R}$ maiores, ou seja, maior intervalo entre cada batimento cardíaco, o que é excelente para impulsionar o início de uma atividade física ${ }^{(87)}$. Provavelmente essa mesma adaptação do SNA pode ter ocorrido no nosso subgrupo de hemiparesia simétrica, que, no intuito de manter a simetria postural, desenvolveu ajuste parassimpático para tal esforço.

A significância foi encontrada somente para a postura sentada, e observando a tabela 3, os valores se mantiveram na postura em pé, com pouquíssima alteração, esta observação reforça ainda mais a comparação deste subgrupo simétrico com o comportamento cardíaco do atleta em repouso, que possui a resposta cardíaca simpática com mínima alteração em seus valores basais, reforçando que mesmo diante da simetria, na postura em pé, o subgrupo simétrico faz um esforço maior para a manutenção postural que aumenta muito seus valores do controle cardíaco parassimpático, com alterações mínimas na resposta simpática, reagindo no comportamento cardíaco semelhante ao atleta.

Se for verdadeira a hipótese de que sujeitos com hemiparesia crônica e distribuição simétrica do suporte de peso, assim como indivíduos atletas em treinamento crônico, desenvolveram adaptações no comportamento da resposta parassimpática que melhor os preparam na condição de repouso para o início de uma atividade; teríamos que a indução da simetria reflete um esforço do controle postural em manter uma distribuição de suporte 
igualmente distribuída em um corpo com respostas desbalanceadas pela lesão e um único hemisfério que é benéfica no sentido de aprimorar as respostas parassimpáticas (93). Entretanto, a confirmação desta hipótese não poderia ser feita por meio de um estudo transversal como este, limitação deste estudo.

Estudos propõem que em situações de danos cerebrais (agudos e crônicos), como no AVC, observa-se um aumento das substâncias indicativas de estresse oxidativo ${ }^{(27)(94)}$ e outros propõem uma relação do estresse oxidativo presente em alterações de atividades simpáticas e parassimpáticas ${ }^{(95)(96)}$. Os nossos resultados obtidos da análise em todos os subgrupos e referência para a dosagem sérica de nitrato, não apresentaram diferença estatísticas entre os grupos. Este resultado corrobora com estudos que mostram que apesar de ser uma situação crônica, ocorre uma adaptação nas atividades simpáticas e parassimpáticas regulando a concentração destes ions estabilizando o estresse oxidative (NOx). Ciancarelli et al., (2013) ${ }^{(99)}$ em estudo de pacientes que sofreram AVC e submetidos ou não a intervenção de neuroreabilitação, os valores de NOx foram reduzidos nos pacientes reabilitados aproximando-se aos valores do controle, sugerindo que o NO está envolvido como um provável rápido mensageiro ativando no cérebro processos neuronais promovidas pela reabilitação neurológica e que pode influenciar a recuperação após acidente vascular cerebral ${ }^{(99)}$.

Os grupos apresentaram, conforme o esperado, uma homogeneidade relacionada às medidas das características relacionadas a idade e IMC entre hemiparéticos e controles. Esse comportamento esperado reflete o cuidado metodológico tomado no recrutamento dos participantes que formaram o grupo controle, normalizados pela mesma faixa etária, gênero e IMC. Desta forma, tais variáveis não influenciaram as análises.

Marigold e Eng (2006) ${ }^{(36)}$, Asseldonk et al., (2006) ${ }^{(6)}$; Bièreet al.,(2010) ${ }^{(38)}$ e Martins et al.,(2011) ${ }^{(7)}$ encontraram as mesmas características etárias e antropométricas observadas em nosso estudo. Embora nem todas as pesquisas citadas tenham usado métodos de normalização por variáveis etárias e antropométricas, neste estudo tomamos este cuidado metodológico que permitiu eliminar influências determinadas pelo gênero, alterações estruturais e funcionais decorrentes das mudanças na composição corporal que ocorrem em função da idade e hábitos de vida.

A amostra que compôs o grupo hemiparesia deste estudo, formada exclusivamente por homens, variou de 40 a 70 anos de idade com uma média de composição corporal entre normopesos e sobrepesos, conforme revelada pelo IMC (tabelas 2 e 3). Como a média de idade permaneceu entre 55 e 58 anos de idade e o IMC variou entre 24 e 26 nos subgrupos formados, poderíamos pensar que as variações determinariam algum tipo de influência no 
comportamento de variáveis de interesse no estudo, visto que evidências apontam que o peso corporal aumenta até os 75 anos de idade e as medidas do corpo refletem a saúde geral de indivíduos e populações ${ }^{(81)}$. Entretanto, ao normalizar os grupos e subgrupos pelas variáveis idade e IMC encontradas no grupo principal de medidas (grupo hemiparesia), garantimos a mesma proporção de diversidade etária e antropométrica em todos os grupos e subgrupos.

Neste estudo foi adotado um limite mínimo de cronicidade de 6 meses após a lesão, limite este comumente assumido nas pesquisas com populações de pessoas com hemiparesia (7)(36). Embora alguns autores discutam um período mínimo diferente para cronicidade em hemiparesia.

Teixeira-Salmela e colaboradores (2005), por exemplo, consideraram o mínimo de 9 meses de lesão cerebrovascular para composição da amostra, relatando a média de cronicidade em meses, do grupo estudado. Já Marigold e Eng (2006) adotaram no mínimo 1 ano de lesão, com média de cronicidade da lesão em 4,1 anos. Costa, Bezerra e Oliveira (2006) consideraram somente a cronicidade da lesão com média de 4 anos, sem relatar o tempo mínimo pós-lesão na composição de sua amostra. Embora a definição mínima para inclusão de sujeitos com hemiparesia crônica tenha variado, a média de cronicidade em todos os estudos tem permanecido similares em torno de 4 anos. Essa cronicidade também foi observada em nosso estudo que registrou 58,5 meses que corresponde a 4,8 anos para grupo hemiparesia.

Valores menores de cronicidade foram encontrados por Azevedo e colaboradores (2008), que, como nós, consideraram mínimo de 6 meses de lesão, porém com média da cronicidade de 2,4 anos. Trindade e colaboradores (2008) consideraram o mínimo de 1 ano pós-lesão e média de cronicidade de 3 anos e 6 meses, enquanto que Martins e colaboradores (2011) consideraram 6 meses de convívio com a lesão, encontrando cronicidade média de 2 anos e 4 meses. Estes pesquisadores constataram valores de cronicidade de quase metade do tempo observado por nós.

Talvez a média de cronicidade da lesão de quase 5 anos, demonstrado em nossa amostra, reflita a característica do participante advinda dos locais onde eles foram recrutados, uma vez que, estes voluntários foram selecionados em instituições de atendimentos especializadas na reabilitação de pessoas com hemiparesia, estão tendo atendimentos bemsucedidos que garantem sobrevida depois do acidente cerebrovascular. Além disto, o fato de estarem convivendo com a hemiparesia por muito tempo pode determinar adaptações estruturais e funcionas nos mecanismos de controle. 
Como era esperado com base em trabalhos já publicados ${ }^{(82)(83)(84)(13)(17)(85)}$, nossa amostra de indivíduos com hemiparesia também apresentou sujeitos com três tipos de distribuição de suporte de peso em pé: (1) simétrico, (2) assimétrico com sobrecarga no HNPU e (3) assimétrico com sobrecarga no HPU (Tabela 2). Estudos de lateralidade revelam que a distribuição do suporte de peso em pé é resultado de um controle antecipatório de ajuste postural prévio do movimento voluntário, o que pode gerar assimetrias na distribuição do suporte em indivíduos com e sem hemiparesia ${ }^{(10)(11)(12)}$, evidenciados também nos nossos resultados.

Interessante foi notar que mesmo antes da separação em subgrupos por tipos de distribuição do suporte de peso em pé, a análise da lateralidade somente considerando os lados direito e esquerdo, revelou uma assimetria de sobrecarga no hemicorpo esquerdo tanto no grupo controle como no grupo hemiparesia. Esta evidência poderia sugerir que não existe diferença na forma de distribuição do suporte de peso em pé entre hemicorpos determinados pela lesão de um dos hemisférios cerebrais.

Entretanto, quando esta análise é feita considerando-se a predominância de uso, em uma perspectiva de que o hemicorpo mais usado pelos controles seria o dominante e o mais usado pelos hemiparéticos seria o hemicorpo não afetado, o comportamento de distribuição de suporte de peso em pé aparentemente similar ao do controle quando analisado considerando os lados direito/esquerdo se inverte no grupo hemiparesia na análise HNPU/HPU. Por esta última análise, ambos os grupos teriam uma tendência a sobrecarregar o HNPU.

Esta evidência nos leva a refletir sobre duas questões primordiais que emergem dos aspectos relacionados à lateralidade do controle da função motora: (1) por qual motivo, em sujeitos sem comprometimento neurológico, a sobrecarga se instalaria no HNPU? E, (2) por que essa sobrecarga passa a ser feita no HPU em sujeitos que estão cronicamente convivendo com a hemiparesia?

Referente à primeira problematização, podemos recorrer às evidências de Wang e Newell (2013) que estudaram a distribuição no suporte de peso de pessoas sem comprometimento neurológico e encontraram relações assimétricas na distribuição de suporte de peso. Em sua discussão, os autores desenvolvem a ideia de que, durante a execução de atividades motoras diversas, seria mais conveniente que o membro dominante permanecesse livre para realizar as ações, enquanto que o não dominante se responsabilizaria de fornecer o apoio durante a realização das mesmas. Nesta mesma linha de sugestão encontramos Grouios e colaboradores (2009), Bell e Gabbard (2000), Haddad e colaboradores (2011) e Klaycioglu 
e colaboradores (2008) em tom uníssono ao sugerir que, nos controles, a sobrecarga se instalaria no HNPU para mantero HPU livre para uma possível tarefa motora.

A proposição de resposta para a segunda questão inicia-se no consenso de que a paresia instalada no hemicorpo afetado forçaria os sujeitos com hemiparesia a adotarem posturas assimétricas. Impulsionados por este consenso, muitos pesquisadores propõem estratégias terapêuticas baseadas na busca da simetria corporal, partindo da premissa da recuperação da simetria perdida e fundamental para o controle motor ${ }^{(36)(34)(6)}$.

Embora pareça racional pensar nos benefícios da simetria, a literatura científica apresenta outras evidências e discussão, mantendo o debate ainda em aberto ${ }^{(14)(35)(9)}$.

Ao que parece, principalmente com base em nossos resultados, existe uma pequena assimetria postural que é acentuada e invertida pela instalação da hemiparesia (tabela 2). Contudo, nossos resultados ainda não contribuíram para fechar as discussões nesta temática, visto que nossos objetivos se limitaram a utilizar os diferentes tipos de distribuição de suporte de peso para explorar possibilidades de associação entre este suporte, mais simétrico ou assimétrico, com alterações no controle autonômico e metabólico. 
Foi possível observar a distribuição do suporte de peso em pé e classificar os indivíduos de acordo com simetrias e assimetrias, principalmente levando em consideração a preferência de uso;

Foi possível observar o comportamento das respostas simpática e parassimpática para o subgrupo simetria quando comparado ao subgrupo referência, mostrando um comportamento de adaptação parassimpática para as posturas sentado e em pé;

Não foi possível encontrar uma correlação entre RMSSD com idade e RS, porém, o desenho gráfico formado pode sugerir que haja esta possível correlação, que talvez não foi significativa pelo quantitativo amostral;

Em relação ao estresse oxidativo, análise dos dados obtidos da dosagem de nitrato sérico nos subgrupos e referência, não foi encontrada nenhuma diferença estatística para os valores de concentração sérica do nitrato. Entretanto, não foi observado um aumento deste marcador nos subgrupos de AVC, o que pode indicar uma adaptação parassimpática.

Foi possível identificar a adaptação parassimpática nas posturas com maior esforço antigravitário nos sujeitos com hemiparesia simétricos, possivelmente devido a uma manutenção crônica de distribuição simétrica de suporte de peso. 


\section{REFERÊNCIAS}

1. Fernandes MB, Cabral DL, Souza RJP, Sekitani HY, Teixeira-Salmela L, Laurentino GEC. Independência funcional de indivíduos hemiparéticos crônicos e sua relação com a fisioterapia. Fisioter. Mov. 2012; 25(2): 333-41.

2. Cordova C, Silva VC, Moraes CF, Simões HG, Nobrega OT. Acute exercise performed close to the anaerobic threshold improves cognitive performance in elderly females. Braz Med Biol Res, 2009; 42(5): 458-464.

3. Teixera-Salmela LF, Oliveira ESG, Resende GP. Fortalecimento muscular e condicionamento físico em hemiplégicos. Acta Fisiát. 2000; 7(3); 108-118.

4. Giriko CH, Azevedo RAN, Kuriki HU, Carvalho AC. Capacidade functional de hemiparéticos crônicos submetidos a um programa de fisioterapia em grupo. Fisioter. Pesq. 2010; 17(3): 214-9.

5. Anker LC, Weerdesteyn V, Van Nes IJW, Nienhuis B, Straatman H, Geurts ACH. The relation between postural stability and weight distribution in healthy subjects. Gait and Post. 2008; 27: 471-477.

6. Aruin AS. The effect of asymmetry of posture on anticipatory postural adjustments.Neurosc. Let. 2006; 401: 150-153.

7. Martins EM, Barbosa PHFA, Menezes LT, Sousa PHC, Costa AS. Comparação entre medidas de descarga de peso, simetria e transferência de peso em indivíduos com e sem hemiparesia. Fisioter. e Pesq. 2011;.(3): 228-34.

8. Genthon N, Rougier P, Gissot AS, Froger J, Pélissier J, Pérennou D. Contribution of Each Lower Limb to Upright Standing in Stroke Patients. Stroke. 2008; 39; 1793-1799.

9. Roerdink M, Geurts ACH, De Haart M, BeekPJ. On the Relative Contribution of the Paretic Leg to the Control of Posture After Stroke. Neurorehabil Neural. 2008.

10. Hadadd JM, Rietdyk S, Ryu JH, Seaman JM, Silver TA, Kalish JA, et al. Postural asymmetries in response to holding evently and unevently distributed loads during selfselected stance. J Mot Behav. 2011; 43(4): 345-55.

11. Barut C, Ozer CM, Sevinc O, Gunnus M, Yunten Z. Relationship between hand and foot preferences. J Neurosc. 2007; 117(2): 177-85.

12. Kalaycioglu C, Kara C, Atbasoglu C, Nalcaci E. Aspects of foot preference: differential relationships of skilled and unskilled foot movements with motor asymmetry. Lateral. 2008; 13(2): 124-42. 
13. Grouios G, Hatzitaki V, Kollias N, Koidou I. Investigating the stabilising and mobilising features of footedness. Lateral. 2009; 14(4): 362-80.

14. Mutha PK, Haaland KY, SainburgRL.The effects of brain lateralization on motor control adaptation. J Mot Behav. 2012; 44(6): 455-69.

15. Pereira LC, Botelho AC, Martins EF. Relationships between body symmetry during weight bearing and functional reach among chronic hemiparetic patients. Rev Bras Fisioter. 2010; 14(3): 229-66.

16. Babyar SR, Peterson MG, Bohannon R, Perennou D, Reding M. Clinical examination tools for lateropulsion or pusher syndrome following stroke: a systematic review of literature. Clin Rehabil. 2009; 23(7): 639-50.

17. de Menezes LT, Barbosa PHFA, Costa AS, Mundim AC, Ramos, GC, Paz CCSC, et al. Baropodometric technology used to analyse types of weight bearing during hemiparetic upright position.Fisioter Mov. 2012; 25(3): 583-94.

18. Colvicchi F, Bassi S, Santini M, Caltagirone C. Prognostic implications of rigth-sede insular damage, cardiac autonomic derangement, and arrhythmias after acute ischemic stroke. Stroke. 2005; 36: 1710-1715.

19. Dutsh M, Burger M, Dorfler C, Schawab S, Hilz MJ. Cardiovascular autonomic function in post stroke patients. Neurology. 2007; 2249-2255.

20. McLaren A, Keer S, Allan L, Steen N, Ballard C, Allen J, Murray A, Kenny R. R. Autonomic function impaired in elderly stroke survivors. Stroke. 2005; 36: 1026-1030.

21. Robinson TG, Dawson SL, Eames PJ, Panerai RB, Potter JF. Cardiac Baroreceptor Sensitivity Predicts Long-Term Outcome After Acute Isquemic Stroke. Stroke. 2003; 34: 705712.

22. Lee Y, Shacter E. Oxidative stress inhibits apoptosis in human lymphoma cells. J Biol Chem. 1999; 274 (28): 92-8.

23. Lelli J, Becks L Dabrowska M, Hinshaw D. ATP converts necrosis to apoptosis in oxidant-injured endothelial cells. Free Radic Biol Med. 1998; 25 (6): 694-702.

24. Vasconcelos SML, Goulart, MOF, Moura JBF, Manfredine V, Kubota LT. Espécies reativas de oxigênio e de nitrogênio, antioxidantes e marcadores de dano oxidativo em sangue humano: principais métodos analíticos para a sua determinação. Quim. Nova, 2007; (5), 13231338 .

25. Tatsch E, Bochi GV, Pereira RS, Kober H, Oliveira JR, Moresco RN. Influência dos anticoagulantes e da temperatura de armazenamento sobre os níveis sanguíneos de nitrito. J Bras Patol Med Lab. 2011; (2): 147-150. 
26. Dusse LMS, Vieira LM, Carvalho MG. Revisão sobre óxido nítrico. J Bras Patol e Med Lab. 2003; (4): 343-50.

27. Guix FX, et al. The physiology and pathophysiology of nitric oxide in the brain.Prog.Neurobiol. 2005; (2): 126-152.

28. Heinrich TA, Silva RS, Miranda KM, Switzer CH, Wink DA, Fukuto JM. Biological nitric oxide signalling: chemistry and terminology. Brit J of Pharmacol. 2013; 169; 14171419.

29. Schafer F, Buettner G. Redox environment of the cell as viewed through the redox state of the glutathione disulfide/ glutathione couple. Free Radic Biol Med. 2011; 30 (11): 1191-212.

30. Valko M, Morris H, Cronin M. Metals, toxicity and oxidative stress. Curr Med Chem. 2005; 12 (10): 1161-1208.

31. Schuster R, Zadra K, Luciano M, Polese J, Mazzola D, Sander I, Pimentel G. Análise da pressão plantar em pacientes com acidente vascular encefálico. Rev Neurocienc. 2008; (3): 179-183.

32. Faria C, Reis D, Salmela L. Nadeau S. Desempenho de hemiplégicos no giro de $180^{\circ}$ realizado em direção ao lado parético e não parético antes e após um programa de treinamento. Rev. Bras. Fisioter. 2009; (5): 451-459.

33. Brol AM, Bortoloto F, Magagnin NMS. Tratamento de restrição e indução do movimento na reabilitação funcional de pacientes pós Acidente Vascular Encefálico: uma revisão bibliográfica. Fisioter em Mov. 2009; (4): 497-509.

34. Pérennou D. Weight bearing asymmetry is standing hemiparetic patients. J Neurol Neurosurg Psyachiatry. 2005:76: 621.

35. Horak FB. Mechanistic and physiological aspects. Postural orientation and equilibrium: what do we need to know about neural control of balance to prevent falls? Age Ageing. 2006; 35 (2): 7-11.

36. Marigold DS, Eng JJ. The relationship of asymetricweigth-bearing with postural sway and visual reliance in stroke. Gait \& Post. 2006; 23: 249-255.

37. Weerdt WD, Spaepen A. "Equilibrium”, In: Functional Human Movement: Measurement and Analysis, Eds.: Durward, B. R., Baer, G. D., Rowe, P. J. Edinburg, ButterworthHeinemann. 2001; 13: 203-218.

38. Briére A, Lauziére S, Gravel D, Nadeau S. Perception of weigth-bearing distribution during sit-to-stand tasks in hemiparetic and healthy individuals. Stroke. 2010; 1704-1708.

39. Figueiredo KMOB, Lima KC, Guerra RO. Instrumentos de avaliação do equilíbrio em idosos: artigo de revisão. Rev. Bras. Cineantropom. Desem Hum. 2007; 9 (4): 408 - 413. 
40. Puckree T, Naidoo P. Balance and stability -focused exercise program improves stability and balance in pacients after acute stroke in a resource-poor setting. American Acad of Phys Med and Rehabil. 2004; 1081-1087.

41. Saj A, Honoré J, Davroux J, Coello Y, Rousseaux M. Effect of posture on the perception of verticality in neglect patients. Stroke. 2005; 2203-2205.

42. Trípoli F, Moreira S, Oberg T, Lima N. Tarefas orientadas e biofeedback: efeitos na transferência de peso em hemiparéticos. Acta Fisiatr. 2008; (4): 220-224.

43. Marães VRFS. Frequência cardíaca e sua variabilidade: análises e aplicações. Rev Andal Med Deporte 2010; 3(1): 33-42.

44. Paschoal MA, Volanti VM, Pires CS, Fernandes FC. Variabilidade da frequência cardíaca em diferentes faixas etárias. Rev Bras Fisioter. 2006; (4): 413-419.

45. Rajendra AU, Paul JK, Kannathal N, Lim CM, Suri JS. Heart rate variability: a review. Med Bio Eng Comput. 2006; 44(12): 1031-51.

46. Cambri LT, Fronchetti L, De-Oliveira FR, Gevaerd MS. Variabilidade da freqüência cardíaca e controle metabólico. Arq Sanny Pesq Saúde. 2008; 1(1): 72-82.

47. Lopes FL, pereira FM, Reboredo MM, Castro TM, Vianna JM, Novo Jr JM, Silva LP. Redução da variabilidade da frequência cardíaca em indivíduos de meia-idade eo efeito do treinamento de força. Rev Bras Fisioter, São Carlos. 2007; (2); 113-119.

48. Perseguini NM, Takahashi ACM, Rebelatto ES, Borghi-Silva a, Porta A, Montano N, Catai. Spectral and symbolic analysis of the effect of gender and postural change on cardiac autonomic modulation in health elderly subjects. Braz J Med Biol Res. 2011; 44 (1): 29-37.

49. Zuttin RS, Moreno MA, César MC, Martins LEB, Catai AM, Silva E. Avaliação da modulação autonômica da frequência cardíaca nas posturas supina e sentada de homens jovens sedentários. Rev Bras Fisioter, São Carlos. 2008; (1): 7-12.

50. Vanderlei LCM, Pastre CM, Hoshi RA, Carvalho TD, Godoy MF. Noções básicas de variabilidade da frequência cardíaca e sua aplicabilidade clínica. Rev Bras Cir Cardiovasc. 2009; 24(2): 205-217.

51. Hon EH, Lee ST. Eletronic evaluations of the fetal heart rate patterns preceding fetal death. Am J Obstet Gynecol. 1965; 87: 817-26.

52. Wolf MM, Varigos GA, Hunt d, Sloman JG. Sinus arrhythmia in acute myocardial infarction. Med J Aust. 1978; 2(2): 52-3.

53. Ferreira LL, Douza NM, Bernardo AFB, Vitor ALC, Valenti VE, Vanderlei LCM. Variabilidade da frequiência cardíaca como recurso em fisioterapia: análise de periódicos nacionais. Fisioter Mov. 2013; 26 (1): 25-36. 
54. Almeida MB, Araújo CG. Efeitos do treinamento aeróbico sobre a frequiência cardíaca. Rev Bras Med Esporte. 2003; 9(2):104-12.

55. Marães VRFS, Santos MDB, Catai AM, Moraes FR, Oliveira L, Gallo JrL et al. Modulação do sistema nervoso atonômico na resposta da freqüência cardíaca em repouso e à manobra de vasalva com incremento da idade. 2004; 8(2): 97-103.

56. Alonso DO, Forjaz CLM, Rezende LO, Braga AMFW, Barreto ACP, Negrão CE et al. Comportamento da freqüência cardíaca e da sua variabilidade durante as diferentes fases do exercício físico progressivo. Arq Bras Cardiol. 1998; 71: 787-92.

57. Dias RG, Negrão CE, Krieger MH. Óxido nítrico e sistema cardiovascular: ativação celular, reatividade vascular e variante genética. Arq Bras Cardiol. 2011; 96 (1): 68-75.

58. Moncada S. The L-arginine: nitric oxide parhway. Acta Phisiol.Scand. 1992; (145): 201227.

59. Nathan C. Nitric oxide as a secretory product of mammalian cells. Faseb Journal. 1992; (6): 3051-3064.

60. Bredt DS, Snyder SH. Isolation of nitric oxide synthetase, a calmodulin requiring enzyme. Proc Natl Acad Sci USA. 1990; 87: 682-685.

61. Christopherson KS, Bredt DS. Nitric oxide in excitable tissues: physiological roles and disease. J Clin Invest. 1997; 100: 2424-2429.

62. Steiner AA, Carnio EC, Antunes-Rodrigues J, Branco LG. Role of nitric oxidein systemic vasopressin-induced hypothermia. Am J Physiol 1998; 275: 937-941.

63. Perotti CA, Nogueira MS, Antunes-Rodrigues J, Carnio EC. Effects of a neuronal nitric oxide synthase inhibitor on lipopoly saccharide-induced fever. Braz J Med Biol Res 1999; 32: 1381-1387.

64. Steiner AA, Antunes-Rodrigues J, McCann SM, Branco LG. Antipyretic roleof the NOcGMP pathway in the anteroventral preoptic region of the rat brain.Am J Physiol Regul Integr Comp Physiol 2002; 282: 584-593.

65. Ventura RR, Gomes DA, Reis WL, Elias LL, Castro M, Valença MM, Carnio EC, Rettori V, McCann SM, Antunes-Rodrigues J. Nitrergic modulation of vasopressin, oxytocin and atrial natriuretic pepti desecretion in response tosodiumin take and hypertonic blood volume expansion. Braz J Med Biol Res. 2002; 35: 1101-1109.

66. Ashwal S, Tone B, Tian HR, Cole DJ, Pearce WJ. Core and penumbral nitricoxide synthase activity during cerebral ischemia and reperfusion. Stroke. 1998; 29: 1037-1047.

67. Castillo J, Rama R, Dávalos A. Nitric oxide - related brain damage in acuteischemic stroke. Stroke 2000; 31: 852-857. 
68. Zhang J, Snyder SH. Nitric oxide in the nervous system. Annu Rev Pharmacol Toxicol 1995; 35: 213-233.

69. Schuman EM, Madison DV. Nitric oxide and synaptic function. Annu Rev Neurosci 1994; 17: 153-183.

70. Shibuki K, Okada D. Endogenous nitric oxide release required for long-termsynaptic depression in the cerebellum. Nature. 1991; 349: 326-328.

71. Son H, Hawkins RD, Martin K, Kiebler M, Huang PL, Fishman MC, KandelER. Longterm potentiation is reduced in mice that are doubly mutant inendothelial and neuronal nitric oxide synthase. Cell. 1996; 87: 1015-1023.

72. Samdani AF, Dawson TM, Dawson, VL.Nitric oxide synthase in models offocalischemia.Stroke. 1997; 28: 1283-1288.

73. Brenman JE, Chao D, Xia SH, Aldape K, Bredt D. Nitric oxide synthase complexed with dystrophin and absent from skeletal muscle sarcolemma in Duchenne muscular dystrophy. Cell. 1995; 82: 743-752.

74. Feelisch M, Stamler JS, editors. Methods in nitric oxide research. Chichester. John Wiley and sons; 1996.

75. Folstein MF, Folstein SE, Mc Hugh PR. "Mini-mental state". A practical method for grading the cognitive state of patients for tha clinician. J Psychiatry Res.1975; 12: 189-198.

76. Bohannon RW, Smith MB. Interrater reliability of a Modified Ashworth Sacale of muscle spasticity. Phys Ther 1987; 67 : 206-7.

77. Ruha A, Sallinen S, Nissilã S. A real time microprocessor .QRS detector system with a $1 \mathrm{~ms}$ timing accuracy for the measurement of ambulatory HRV.Trans Biomed Eng. 1997; 44: 159-67.

78. Malik M. Task Force of the European Society of Cardiology and the North American Society of Pacing and Electrophysiology. Heart rate variability: standards of measurement, physiological interpretation and clinical use. Circulation. 1996; 93(5): 1043-1065.

79. Miles AM, Cher Y, Owens MW, et al. Fluorometric determination of nitric oxide. Methods.1995; 7: 40-47.

80. Misko TP, Schilling RJ, Salvemini D. et al. A fluorometric assay for the measurement for nitrite in biological samples. Anal.Biocherm. 1993; 214: 11-16.

81. Pantoni CBF, Reis MS, Martins LEB, Catai AM, Costa D, Borghi-Silva A. Estudo da modulação autonômica da freqüência cardíaca em repouso de pacientes idosos com doença pulmonar obstrutiva crônica. Rev Bras Fisioter. 2007; 11(1): 35-41. 
82. Gabbard C, Hart S. A question of foot dominance. The J Gener Psychol. 1996; 123(4): 289-296.

83. Elias LJ, Bryden MP, Bulman-Fleming MB. Footedness is a better predictor than is handedness of emotional lateralization. Neuropsy. 1998; 36(1): 37-43.

84. Bell J, Gabbard C. Foot preference changes through adulthood. Laterality. 2000; 5(1): 6368.

85. Wang Z, Newell KM. Footedness exploited as a function of postural task asymmetry. Laterality. 2013; 18(3): 303-318.

86. KopelainenJt, Huikuri HV, Sotaniemi KA, Myllyla VV. Abnormal heart rate variability reflecting autonomic dysfunction in brainstein infarction. Acta. Neurolo. Scand. 1996; 94(5): $337-2$.

87. Aubert AE, Seps B, Beckers F. Heart rate variability in athletes. Sports Med. 2003; 33: 889-919.

88. Balthazar RB, De Sousa PHF, Barbosa PHFA, De Menezes LT, Costa AS, Carneiro DVA, Marães, VRFS, Martins EF. Could heart rate variability be associated with weightbearing asymmetrically distributed in cerebrovascular diseases? International Journal of Case Reports and Images. 2012; 3(1): 1-5.

89. Lindqvist A. Noninvasive methods to study autonomic nervous of circulation. Acta Phys Scand. 1990; 138: 21-22.

90. Gleber DA, Pfeifer M, Dawson B, Schumer M. Cardiovascular autonomic nervous system tests: determination of normative values and effect of confouding variables. J Auton Nerv Syst. 1997; 62: 40-44.

91. Silva CS, Marques LS, Moraes FR, Catai AM, Oliveira L, Silva E. Investigação da variabilidade da freqüência cardíaca de mulheres nos períodos manhã e noite. Rev Bras Fisioter. 2001; 5(2): 65-71.

92. Davini R, Ribeiro LFP, Prado JMS, Martins LEB, Golfetti R, Gallo Jr L. Freqüência cardíaca de repouso e modulação parassimpática cardíaca em atletas idosos e idosos fisicamente ativos. Rev Ciên Méd. 2004; 13(4): 307-315.

93. Silva VDR, Santana JE, Vanderlei LCM, Carvalho AC. Análise do comportamento de parâmetros cardiovasculares durante a realização de exercícios físicos em hemiplégicos crônicos. Arq Ciên Saúde. 2006; 13(4): 181-185.

94. Barbosa LF, Medeiros MHG, Ohara A. Danos oxidativos e neurodegeneração: o quê aprendemos com animais transgênicos e nocautes? Quím Nova. 2006; 29(6). 
95. Zimmet JM, Hare JM. Nitroso-Redox interactions in the cardiovascular system. Circulation. 2006; 114: 1531-1544.

96. Fleissner F, Thum T. Critical role of the nitric oxide/reactive oxygen species balance in endothelial progenitor dysfunction. Antiox\& Redox. 2011; 15(4):933-49.

97. Novais LD, Sakabe DI, Takahashi ACM, Gongora H, Taciro C, Martins LEB, et al. Avaliação da variabilidade da frequência cardíaca em repouso de homens saudáveis sedentários e de hipertensos e coronariopatas em treinamento físico. Rev Bras Fisioter. 2004;8(3):207-13.

98. Sakabe DL, Catai AM, Neves VFC, Oliveira L, Silva de Sá MF, Azevedo GD, et al. Análise da modulação autonômica do coração durante condições de repouso em homens de meia idade e mulheres pós-menopausa. Rev Bras Fisioter. 2004;8(1):89-95.

99. Ciancarelli et al., Oxidative Stress in Post-Acute Ischemic Stroke Patients: Relevance of Early Intensive Neurorehabilitation Oxidative Stress in Post-Acute Ischemic Stroke Patients: Relevance of Early Intensive Neurorehabilitation. J Neurol Neurophysiol. 2013, 4:3. 
Anexo A

Parecer do Comitê de Ética em Pesquisa da Universidade de Brasília

FACULDADE DE CIÊNCIAS DA
SAÚDE DA UNIVERSIDADE DE
BnB

\section{PARECER CONSUBSTANCIADO DO CEP}

\section{DADOS DO PROJETO DE PESQUISA}

TItulo da Pesquisa: AVALIAÇÅ DO CONTROLE POSTURAL, AUTONOMICO E METABOLICO EM SOBREVIVENTES DE ACIDENTE VASCULAR ENCEFALICO

Pesqulsador: GABRIELLY CRAVEIRO RAMOS

Area Tematica:

Versao: 2

CAAE: 10217013.2 .0000 .0030

Institulça:a Proponente:PROGRAMA DE POG-GRADUAÇAిO EM CIENCIAS E TECNOLOGIAS EM

Patrocinador Principal: Financiamento Proprio

\section{DADOS DO PARECER}

NÜmero do Parecer: 271.353

Data da Relatoria: 25/04/2013

Apresentaçao do Projeto:

Trata-se do projeto de pesqulsa ¿AVALIAÇAOO DO CONTROLE POSTURAL, AUTONOMICO E METABOLICO EM SOBREVIVENTES DE $i$, na area de Saude Coletiva, de autoria de GABRiELLY CRAVEIRO RAMOS, estudante de doutorado da Faculdade da Cellanda (FCE-UnB).

O tema de carater interdsciplinar sera desenvolvido no escopo de duas Inhas de pesquisa do Programa de Pos-Graduaçăo en Clenclas e Tecnologlas em Saude. Assim, assocla a linha de pesquisa da orlentadora princlpal, Profa. Dra. Claure Nain Lunard Gomes, com a do co-orlentador, Prof. Dr. Emerson Fachin Martins. Ao assoclar duas linhas de pesquisa que se encontram alocadas em duas distintas areas de concentraç50, envolvendo ainda IInha de pesqulsa de outro programa, a proposta possibilita uma anallse baseada em evidenclas observadas em varios nivels, desde celulas ate 06 nivels sistemicos, que multo contribulr para a pratica assistenclal em saude. De acordo com a literatura clentinca, a problematica e originada na necessidade de esclarecer se 06 mecanismos de regulaçăo da funçăo neuromotora, neurovegetativa e metabolica possuem relaçăo entre sl na populaçăo especifica de sobreviventes de acidente vascular encefallico. Neste sentido, fol perguntado: Seriam as varlavels de controles postural, autonomico e metabollco observadas por medidas de simetria postural, varlabllidade da frequencla cardlaca e de Indlcadores do estresse oxidatlvo capazes de serem relaclonadas em sooreviventes de acidente vascular

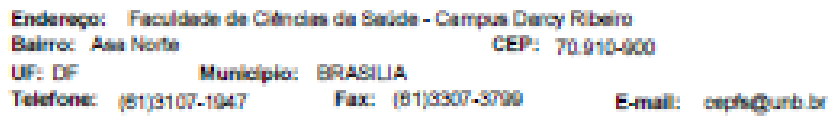




FACULDADE DE CIÊNCIAS DA
UnB
SAÚDE DA UNIVERSIDADE DE
BRASILIA - CEP/FS-UNB

Corthask do Pancer: 271300

encefall $\infty$ ? A partir das respostas a esta outros esclarecimentos contrtburdo para a resoluçăo do problema, tals como: 1. Cuals as caracteristicas da populaçăo estudada quanto a simetrla na distribulçăo do suporte de peso entre 05 pes quando os sujeltos encontram-se na postura ortostatica? 2 . Cuals as caracteristicas da populaçato estudada quanto ao cortrole autonomico coservado pela variablldade da frequencla cardlaca? 3. Cuals sto as caracteristicas da populaçăo estudada quanto ao perfl energetico e metabollco observado pelos nivels serccos de indcadores de estresse oxidativo? 4. Existe assoclaç̧̆o entre essas variavels nesta populaç̧5: 5. Quanto difere 06 perfls e comportamentos relacionados as varlavels para a populaçăo quando comparada com seus controles higidos e pareados por sexo, Idade e composlçăo corporal?

Objettvo da Pesquisa:

GERAIS

Avalar $\propto$ indlcadores do controle postural e autonomico, bem como do metabollsmo energetico de sujeitos com hemipareslas cronicas.

\section{ESPECIFICOS}

¿ Caracterizar a populaçato de Indviduos com Acldente Vascular Encefalco (AVE) cronico.

¿Caracterizar o pertl de controle postural por melo da dlstrioulçăo no suporte de peso entre 06 pes, para estabelecer indicadores de simetria postural.

¿Caracterizar o perfll de controle autonomico pelo comportamento da variabilldade da trequencla cardlaca. ¿Caracterizar o perfil de controle metabolico por melo do comportamento dos nivels de oxddo nitrico, para avalar o estresse oxidativo, peroxidaçăo Ipidlca e oxidaç5̆ protelca no plasma sanguineo.

¿ Identificar associaçdes entre as variavels mensurad3s para a populaçăo alvo dessa pesquisa.

\section{Avallaç:o dos Riscos $\theta$ Beneficlos:}

Riscos: Fol felto argumentaçăo de que năo ha riscos neta pesquisa, contudo qualquer pesquisa pode oferecer risco. Neste caso sería convenlente mencionar os riscos envolvidos na coleta de sangue. Beneficlos: Contribulçăo para o planejamento de processos de reabilitaçăo de hemlpareticos.

\section{Comentarios e Consilderaçoes sobre a Pesqulsa:}

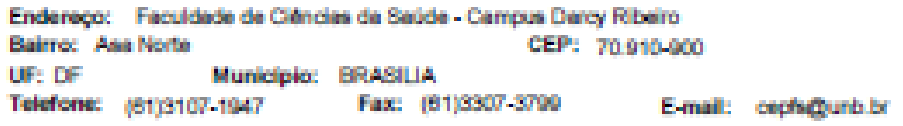




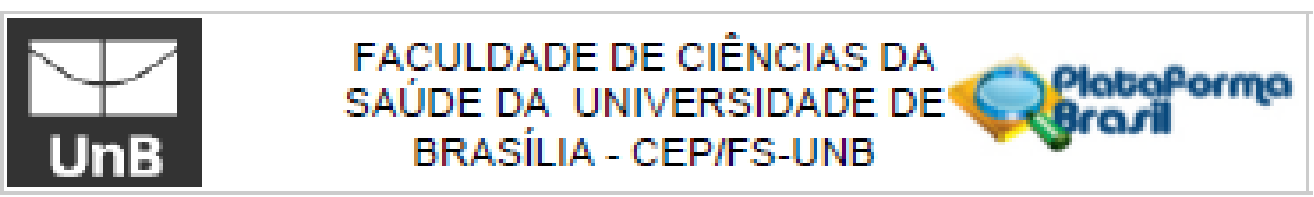

Corthuspe do Pancer 271300

A amostra por convenlencla estimada de sujeltos de pesquisa e de 40 sujeltos de pesquisa, pessoss com hemiparesia.

Criterio de Inclusto:

Os criterios salo relativos a0s 4 (quatro) grupos escoinidos para a pesquisa, determinados pela lesta (sobreviventes de AVE ou controles sem comprometimento neuroioglco pareados por sexo, idade e indice de massa corporal), assim dlviddos:

(1) grupo de sujeltos sem hemparesla (controle)

(2) grupo de sujeltos com hemipareslas assimetricos com descarga de peso no lado da lesf̆o

(3) grupo de sujeltos com hemipareslas assimetricos com descarga de peso contralateral a les50, e

(4) grupo de sujeltos com hemipareslas simetricos.

Estes tambem devern:

(a) possuir mals de sels meses pos lesta cerebral do tipo isquemica e em terntorio de irmigaçăo da arterla cereoral meda, confirmado por ressonancla magnetica, laudo medico ou caracteristicas dínicas comuns desta sindrome vascular,

(b) ser capaz de manter-se em equiliorio na posiçăo ortostatica, bipodal, por um periodo minimo de 20 (Vinte segundos) para o registro da distribulç5o do suporte de peso nessa postura; e

(c) ser capaz de realizar marcha, sem aubllo e supervisto, por pelo menos vinte e cinco minutos, em estelra ergometrica, local lzada no ambiente de coleta da pesquisa.

Criterios de Exclusalo:

Serấ excluidos todos 05 individuos que tverem qualsquer outras ateçbes neuroiogicas para alem daquela que determinou o quadro de hemiparesia e aqueles que possuam algum tipo de afeç5̆o cardlovascular ou pulmonar. Avem de existencla de doenças renal e hepatica, neoplasias, gravidez, dlsturtios psiqulatricos, tabagismo, consumo de alcool (superior a 10 doses/semana), em uso de antlinflamatorios, contraceptivos orals, drogas no tratamento de dislipidemlas, ansloliticos, slldenanll, viagra, clalls e simllares, drogas a base de nitrato (angina e outros), exercicio nas 24 hs anteriores, medcamentos betabloqueadores.

Consideraç0es acbre 08 Termos de apresentaçäo obrigatorla:

A folha de rosto esta devidamente preenchida e assinada pela pesquisadora proponente Gabrielly Craveiro Ramos, e pela Voe-dretor da Faculdade UnB Cellandla Prot. Araken dos S.W. Rodrinues.

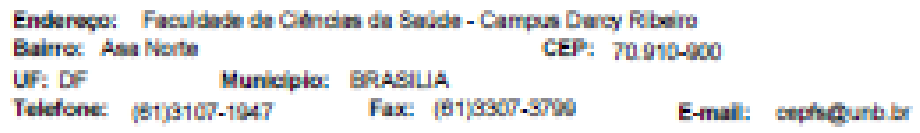




FACULDADE DE CIÊNCIAS DA
SAÚDE DA UNIVERSIDADE DE
BnB Blatilia - CEPIFS-UNB

Conthusk da Paverer 271300

O termo de responsablidade esta de acordo, assinado pela pesquisadora e pela orlentadora Prota. Claure Naln Lunardl Gomes. O termo de concordanda do Laboratorio de Movimento de Cellandla esta de acordo e assinado por Joto Paulo Crleregato Matheus. O TCLE esta devidamente Instruldo, contudo sugiro que no penultimo paragrafo a palavra ¿sobre $i$ seja substitulda pela $i s 00 i$. pols parece fazer mals sentido. Tambem sugiro introduzir espaço para o nome ao sujelto de pesqulsa e da pesqulsadora adidonal a suas assinaturas. No processo consta apenas o curriculo vitae da orlentadora da pesquisadora.

\section{Recomendaçer:}

Foram sugendas modincaçles: Substitulr a palavra ¿sobre $i$ por $i s 0 b i$, no penultimo paragrato, TCLE; Acrescentar espaço para nome de pesquisador e sujelto de pesqu'sa no TCLE. Acrescentar ao TCLE Informaçbes sobre retirada de sangue de sujeltos de pesquisa; Acrescentar o curriculo vitae de todos 05 participantes da pesquisa; as quals foram atendidas.

Conclusoes ou Pendenclas $\theta$ Llata de Inadequaç0es:

As recomendaçbes foram atendidas.

Situaģa do Parecer:

Aprovado

Necessitta Apreclaçao da CONEP:

Nă

Consideraç0es Finals a criterio do CEP:

BRASILIA, 14 de Malo de 2013

Asainador por:

Natan Monsores de Sa

(Coordenador)

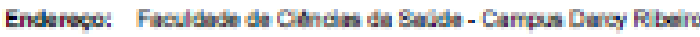

Bairrec Asa Norte CEP: 70.910-900

UF: DF Municipia: BRASILA

Telefone: (61)a107-1947 Fax: [81,8307-3700 E-mall: enphgurb b 


\section{Anexo B}

Normas da Revista

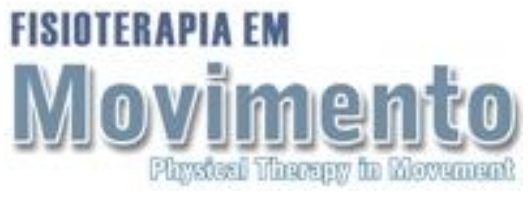

ISSN 0103-5150 versão

impressa

\section{INSTRUÇÕES AOS AUTORES}

- Escopo e política

- Forma e preparação de manuscritos

- Envio de manuscritos

\section{Escopo e política}

A Revista Fisioterapia em Movimento publica trimestralmente artigos científicos na área da Fisioterapia e saúde humanaOs artigos recebidos são encaminhados a dois revisores (pareceristas) das áreas de conhecimento às quais pertence o estudo para avaliação pelos pares (peerreview). Os editores coordenam as informações entre os autores e revisores, cabendo-Ihes a decisão final sobre quais artigos serão publicados com base nas recomendações feitas pelos revisores. Quando recusados, os artigos serão devolvidos com a justificativa do editor. Todos os artigos devem ser inéditos e não podem ter sido submetidos para avaliação simultânea em outros periódicos. É obrigatório anexar uma declaração assinada por todos os autores quanto à exclusividade do artigo, na qual constará endereço completo, telefone, fax e email. Na carta de pedido de publicação, é obrigatório transferir os direitos autorais para a Revista Fisioterapia em Movimento. Afirmações, opiniões e conceitos expressados nos artigos são de responsabilidade exclusiva dos autores. A Revista Fisioterapia em Movimento está alinhada com as normas de qualificação de manuscritos estabelecidas pela OMS e InternationalCommitteeof Medical JournalEditors (ICMJE), disponíveis em <http://www.who.int/ictrp/en/> e $<$ http://www.icmje.org/faq.pdf $>$. Somente serão aceitos os artigos de ensaios clínicos cadastrados em um dos Registros de Ensaios Clínicos recomendados pela OMS e ICMJE.

Trabalhos contendo resultados de estudos humanos e/ou animais somente serão aceitos para publicação se estiver claro que todos os princípios de ética foram utilizados na investigação (enviar cópia do parecer do comitê de ética). Esses trabalhos devem obrigatoriamente incluir a afirmação de ter sido o protocolo de pesquisa aprovado por um comitê de ética institucional (reporte-se à Resolução 196/96, do 
Conselho Nacional de Saúde, que trata do Código de Ética da Pesquisa envolvendo Seres Humanos). Para experimentos com animais, considere as diretrizes internacionais Pain, publicada em: PAIN, 16: 109-110, 1983.

Os pacientes têm direito à privacidade, o qual não pode ser infringido sem consentimento esclarecido. Na utilização de imagens, as pessoas/pacientes não podem ser identificáveis ou as fotografias devem estar acompanhadas de permissão específica por escrito, permitindo seu uso e divulgação. O uso de máscaras oculares não é considerado proteção adequada para o anonimato.

É imprescindível o envio da declaração de responsabilidade de conflitos de interesse, manifestando a não existência de eventuais conflitos de interesse que possam interferir no resultado da pesquisa.

\section{Forma e preparação de manuscritos}

A Revista Fisioterapia em Movimento recebe artigos das seguintes categorias:

Artigos Originais: oriundos de resultado de pesquisa de natureza empírica, experimental ou conceitual, sua estrutura deve conter: Introdução, Materiais e Métodos, Resultados, Discussão, Conclusão, Referências. O texto deve ser elaborado com, no máximo, 6.000 palavras e conter até 5 ilustrações.

Artigos de Revisão: oriundos de estudos com delineamento definido e baseado em pesquisa bibliográfica consistente com análise crítica e considerações que possam contribuir com o estado da arte (máximo de 8.000 palavras e 5 ilustrações).

Os trabalhos devem ser digitados em Word for Windows, fonte Times New Roman, tamanho 12, com espaçamento entre linhas de 1,5 . O número máximo permitido de autores por artigo é seis (6).

- As ilustrações (figuras, gráficos, quadros e tabelas) devem ser limitadas ao número máximo de cinco (5), inseridas no corpo do texto, identificadas e numeradas consecutivamente em algarismos arábicos. A arte final, figuras e gráficos devem estar em formato .tiff. Envio de ilustrações com baixa resolução (menos de 300 DPIs) pode acarretar atraso na aceitação e publicação do artigo.

- Os trabalhos podem ser encaminhados em português ou inglês.

- Abreviações oficiais poderão ser empregadas somente após uma primeira menção completa. Deve ser priorizada a 
linguagem científica para os manuscritos científicos.

- Deverão constar, no final dos trabalhos, o endereço completo de todos os autores, afiliação, telefone, fax e e-mail (atualizar sempre que necessário) para encaminhamento de correspondência pela comissão editorial.

\section{Outras considerações:}

- sugere-se acessar um artigo já publicado para verificar a formatação dos artigos publicados pela revista;

- todos os artigos devem ser inéditos e não podem ter sido submetidos para avaliação simultânea em outros periódicos (anexar carta assinada por todos os autores, na qual será declarado tratar-se de artigo inédito, transferindo os direitos autorais e assumindo a responsabilidade sobre aprovação em comitê de ética, quando for o caso);

- afirmações, opiniões e conceitos expressados nos artigos são de responsabilidade exclusiva dos autores;

- todos os artigos serão submetidos ao Conselho Científico da revista e, caso pertinente, à área da Fisioterapia para avaliação dos pares;

- não serão publicadas fotos coloridas, a não ser em caso de absoluta necessidade e a critério do Conselho Científico.

\section{No preparo do original, deverá ser observada a seguinte estrutura:}

\section{Cabeçalho}

Título do artigo em português (inicial maiúsculo, restante minúsculas - exceto nomes próprios), negrito, fonte Times New Roman, tamanho 14, parágrafo centralizado, subtítulo em letras minúsculas (exceto nomes próprios).

Título do artigo em inglês, logo abaixo do título em português, (inicial maiúsculo, restante minúsculas - exceto nomes próprios), em itálico, fonte Times New Roman, tamanho 12, parágrafo centralizado. O título deve conter no máximo 12 palavras, sendo suficientemente específico e descritivo.

\section{Apresentação dos autores do trabalho}

Nome completo, afiliação institucional (nome da instituição para a qual trabalha), vínculo (se é docente, professor ou está vinculado a alguma linha de pesquisa), cidade, estado, país e e-mail. 


\section{Resumo estruturado / Structured Abstract}

O resumo estruturado deve contemplar os tópicos apresentados na publicação. Exemplo: Introdução, Desenvolvimento, Materiais e Métodos, Discussão, Resultados, Considerações Finais. Deve conter no mínimo 100 e no máximo 250 palavras, em português/inglês, fonte Times New Roman, tamanho 11, espaçamento simples e parágrafo justificado. Na última linha deverão ser indicados os descritores (palavras-chave/keywords). Para padronizar os descritores, solicitamos utilizar os Thesaurus da área de Saúde (DeCS) (<http://decs.bvs.br $>$ ). O número de descritores desejado é de no mínimo 3 e no máximo 5, os quais devem ser representativos do conteúdo do trabalho.

\section{Corpo do Texto}

- Introdução: Deve apontar o propósito do estudo, de maneira concisa, e descrever quais os avanços alcançados com a pesquisa. A introdução não deve incluir dados ou conclusões do trabalho em questão.

- Materiais e Métodos: Deve ofertar, de forma resumida e objetiva, informações que permitam ser o estudo replicado por outros pesquisadores. Referenciar as técnicas padronizadas.

- Resultados: Devem oferecer uma descrição sintética das novas descobertas, com pouco parecer pessoal.

- Discussão: Interpretar os resultados e relacioná-los aos conhecimentos existentes, principalmente os indicados anteriormente na introdução. Esta parte deve ser apresentada separadamente dos resultados.

- Conclusão ou Considerações Finais: Devem limitar-se ao propósito das novas descobertas, relacionando-as ao conhecimento já existente. Utilizar apenas citações indispensáveis para embasar o estudo.

- Agradecimentos: Sintéticos e concisos, quando houver.

- Referências: Numeradas consecutivamente na ordem em que são primeiramente mencionadas no texto.

- Citações: Devem ser apresentadas no texto por números arábicos entre parênteses. Exemplos:

"o caso apresentado é exceção quando comparado a relatos da prevalência das lesões hemangiomatosas no sexo feminino $(6,7)$ " ou "Segundo Levy (3), há mitos a respeito da recuperação dos idosos".

\section{Referências}


Todas as instruções estão de acordo com o Comitê Internacional de Editores de Revistas Médicas (Vancouver), incluindo as referências. As informações encontram-se disponíveis em: (<http://www.icmje.org >). Recomenda-se fortemente o número mínimo de 30 referências para artigos originais e 40 para artigos de revisão. As referências deverão originar-se de periódicos com classificação Qualis equivalente ou acima da desta revista.

\section{Artigos em Revistas}

\section{- Até seis autores}

Naylor CD, Williams JI, Guyatt G. Structured abstracts of proposal for clinical and epidemiological studies. J

ClinEpidemiol. 1991;44:731-737.

- Mais de seis autores

Listar os seis primeiros autores seguidos de et al.

Parkin DM, Clayton D, Black RJ, Masuyer E, Friedl HP, Ivanov $\mathrm{E}$, et al Childhood leukaemia in Europe after Chernobyl: 5 year follow-up. Br J Cancer. 1996;73:1006-12.

\section{- Suplemento de volume}

\section{- Suplemento de número}

Payne DK, Sullivan MD, Massie MJ. Women's psychological reactions to breast cancer. SeminOncol. 1996;23(1 Suppl 2):89-97.

\section{- Artigo sem formato eletrônico}

Al-Balkhi K. Orthodontic treatment planning: do orthodontists treat to cephalometric norms. J Contemp Dent Pract. [serial on the internet] 2003 [cited 2003 Nov. 4]. Available from: URL: www.thejcdp.com.

\section{Livros e monografias}

\section{- Livro}

Berkovitz BKB, Holland GR, Moxham BJ. Color atlas \& textbook of oral anatomy. Chicago:Year Book Medical Publishers; 1978.

\section{- Capítulo de livro}

Israel HA. Synovial fluid analysis. In: Merril RG, editor. Disorders of the temporomandibular joint I: diagnosis and arthroscopy. Philadelphia: Saunders; 1989. p. 85-92. 


\section{- Editor, Compilador como Autor}

Norman IJ, Redfern SJ, editors. Mental health care for elderly people. New York: Churchill Livingstone; 1996.

\section{- Livros/Monografia sem CD-ROM}

CDI, clinical dermatology illustrated [monograph on CDROM], Reeves JRT, Maibach H. CMEA Multimedia Group, producers. 2nd ed. Version 2.0. San Diego: CMEA; 1995.

\section{- Anais de congressos, conferências congêneres}

Damante JH, Lara VS, Ferreira Jr O, Giglio FPM. Valor das informações clínicas e radiográficas no diagnóstico final. Anais $X$ Congresso Brasileiro de Estomatologia; 1-5 de julho 2002; Curitiba, Brasil. Curitiba, SOBE; 2002.

Bengtsson S, Solheim BG. Enforcement of data protection, privacy and security in medical informatics. In: Lun KC, Degoulet P, Piemme TE, Rienhoff O, editors. MEDINFO 92. Proceedings of the 7th World Congress of Medical Informatics; 1992 Sept 6-10; Geneva, Switzerland. Amsterdam: NorthHolland; 1992. p. 1561-5.

\section{Trabalhos acadêmicos (Teses e Dissertações)}

Kaplan SJ. Post-hospital home health care: the elderly's access and utilization [dissertation]. St. Louis: Washington Univ.; 1995.

\section{Envio de manuscritos}

Os manuscritos deverão ser submetidos à Revista Fisioterapia em Movimento por meio do site <www.pucpr.br/revfisio > na seção "submissão de artigos". 


\title{
ANEXO C
}

Artigo Publicado

ISSN 0103-5150

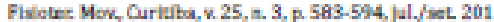
Uoendiado sob uma Licenpa Crestive Commons

\section{Baropodometric technology used to analyze types of weight-bearing during hemiparetic upright position}

Tecnologla baropodométrica utIllzada para anallsar tlpos de suporte de peso durante postura ortostática hemiparétıca

\author{
Lidiane Teles de Menezes ${ }^{[4}$, Paulo Henrique Ferreira de Araujo Barbosa ${ }^{\mathrm{N}}$, Abraão Souza Costal4, \\ Anderson Castro Mundim[4, Gabrielly Craveiro Ramosin, Clarissa Cardoso dos Santos Couto Paz'n, \\ Emerson Fachin Martinsis \\ * Physical Therapy student, scholarship in the Scientlifc Initiation Program (ProlC). Faculty of Celländla (FCE), University) \\ of Brasilla (UnB), Brasila, DF - Braxil, e-mall: bydlanne telesfymall.com \\ No Physical Therapy student, scholarship in the Scientlifc Initiation Program (ProiC). Faculty of Celländla (FCE), Universite) \\ of Brasilla (UnH), Brasilia, DF - Braxil, e-mall: phtabarbosalegmallcom \\ w Physical Therapy student, scholarshlp in the Scientiflc Initiation Program (ProlC), Faculty of Cellandia (FCE), University \\ of Brasilla (UnB), Brasilla, DF - Braxll, e-mall: abraac_costa_sehotmalloom \\ wit Physical therapist, specialization course in Neurophysical Therapy Intervention, master student in the Faculty of \\ Cellandia (FCE), Program of Post-Graduation in Health Science and Technology (PPGCTS), University of Brasilla (UnB), \\ Brasilla, DF - Brazil, e-mall: andersonmundimeyahoocom.br \\ * Physical therapist, master degree in Health Sciences, PhD student in the Faculty of Cellandla (FCE), Program of Post. \\ Graduation in Health Science and Technology (PPCCTS), University of Brasila (UnB), Brasilia, DF - Brazil, e-mall: \\ gabriellyfistoteraplaggmailcom \\ n Physical therapist, PhD in Neuroscience, associate professor in the Faculty of Cellindla (FCE), Untversity of Brasllia \\ (UnB), Brasilia, DF - Braxil, e mall: clarissacardosogunb.br \\ we Physical therapist, PhD in Psychology (Neuroscience and Behavior), assoclate professor in the Faculty of Cellandlia (FCE), \\ Program of Post-Graduation in Health Science and Technology (PPGCTS), University of Brasilia (UnB), Brasilia, DF - Brazil \\ e-mall: efmartingst unb br
}

Abstract

Introduction: Nithough baropodometric analysis has been published since the 1990 s, only now it is found a considerable number of studies showing different uses in the rehabilitation. Objective: To amplify the use of this technology, this research aimed to analyze baropodometric reconds during upright position of subjects with hemiparesis, describing a way to define weight-bearing profiles in this population. Method: 
20 healthy subjects were matched by gender and age with 12 subjects with chronic spastic bemiparesis. This control group was formed to establish the limits of symmetry during weight-bearing distribution in the hemiparesis group. Nent, hemiparesis group was submitted to procedures to measure baropodometric records used to prowide variables related to the weight-bearing distribution, the arch index and the displacements in the center of pressure ( $\mathrm{CoP}$ ). Data were used to compare differences among kinds of weight-bearing distribution (symmetric, asymmetric toward non-paretic or paretic foot) and coordination system for CoP displacements. Results. Hemiparesis group was compounded by eight symmetrics, eight asymmetrics toward non-paretic foot and four asymmetric toward paretic foot. Significant differences in the weight-bearing distributions between non-predominantly and predominantly used foot did not promote differences in the other baropodometric reconds (peak and mean of pressure, and support area). Mainly in the asymmetry toward non-paretic foot it was observed significant modifications of the baropodometric records. Conclusion: Baropodometric technology can be used to analyze weight-bearing distribution during upright position of subjects with hemiparesia, detecting different kinds of weight-bearing profiles useful to therapeutic programs and researches involving subjects with this disability.

Keywords: Barapodometry. Posture. Balance. Strolve. Hemiplegy.

\section{Resumo}

Introduçata: Embora análises baropodométricas sejam encontradas desde a deccada de 1990, somente agora É observado número considerivel de estudos mastrando usos na reabilitagho. Objettivas: Para ampliar o uso dessa tecnologia, abjetivou-se analisar nogistros baropodométricos durante a posipdo ortastaibica de sujeitos com hemiparesia, descrevendo o suporte de peso messa populaptla. Métodos: 20 sujeitos saudliveis foram pareados por getnero e idade com 12 sujeitas com hemiparesia espaistica crónica. Cantroles faram formados para estabelecer limites de simetria na distribuiço do suparte de peso no grupo hemiparesia. Em segulda. o grupo hemiparesia foi submetido a procedimentos usados para fornecer varibiveis como: distribuiga no suporte de pess, indice de aryueamento e desiocamentos no centro de pressibo (COP). Os dados diferenciaram tipas de distribuipdo do suporte de peso (simétrico, assimétrico em diregdo ao pé ndo parítico ou parético) e estabeleceram sistemas de coordenadas para desiocamentas do COP. Resultados: O grupo hemiparesia apresentou oito simétricos, oito assimétricas em diregato ao pé ndo pariético e quatro em díreçlo ao pé parética. Distribuipdo assimétrica do suporte entre os pés ndo predominantemente ou predominantemente usados ndo promoveram diferenças em registros baropodométricos (pico e médila de pressib e área de suporte). Principaimente para a assimetria em diregcdo ao pé nấ paritico, abservou-se modificapbes significativas nos registros baropodométricos. Conclusada: Tecnologia baropodométrica pode ser usada para analisar a distribuipdo no suporte de peso durante a posigfto ortastibica de sujeitos com hemiparesia, detectando diferentes thpas de suparte de pesa, útels para serem usados em programas teraptuticas e em pesquisas envohvendo sujeitos com essa incapacidade

Palavras-chave: Baropodometria. Postura. Equilibria. Acidente vascular encefailica. Hemiplingia

\section{Introduction}

Few studies have investigated the influence of hemiparetic upright position on the structural and functional characteristics of the feet and its probable implications for functioning of stroke survivals (1. 2). Although computerized baropodometric analysis represents an available technology to investigate feet. characteristics described in scientific studies since the 1990 s (3-5), just in this last decade a considerable number of studies has shown different uses of this technology $(1-2,6-19)$.

Computerized baropodometric analysis allows to record plantar imprints and ground reaction forces in the support area during quiet standing (upright position), divided by feet (right and left) and subdivided in three regions named "forefoot", "midfoot" and "backfoot" for each foot. This support area is

Flsioter Mov. 2012 jul/set;25/3):583-94 
expressed in square centimeters $\left(\mathrm{cm}^{2}\right)$ and in percentage of the total body weight $(2,7,18-19)$.

The weight-bearing distributed by feet during upright position allows to determine the percentage of total body supported by each foot and to calculate the ratio between them, giving us a symmetry ratio, important coefficient to guide therapeutic decisions during rehabilitation programs for stroke survivals with hemiparetic posture $(6,20-22)$. Moreover, for each foot it can also be calculated an arch index defined by percentage of total foot load on the midfoot imprint, informing kinds of feet ( 9 ).

Besides the mentioned records, this technology provides stabilometric parameter derived by spatial and temporal behavior of the center of pressure $(\mathrm{CoP})$, with great usefulness to assess stability and functioning in this population $(10,23)$.

In this study, computerized baropodometric analysis was performed to find the limits of symmetry to the weight-bearing distribution observed in healthy subjects, that established the criteria to classify weight-bearing symmetrically or asymmetrically distributed during 20 seconds in the hemiparetic upright position. The aim was to compare baropodometric records among different kinds of support during upright position in stroke survivals with hemiparesis, contributing to amplify the use of this technology for rehabilitation programs. Our hypothesis is that the baropodometric technology can be used to help professionals to understand the compensatory strategies used to maintain the posture and balance in hemiparetic individuals.

\section{Methods}

Subjects

Subjects with hemiparesis were recruited among the patients that composed the database of participants in previous researches occurred in the Laboratory of Therapeutic Skills in the Faculty of Cellandia, University of Brasilia, Brasilia, Federal District, Brazil. Inclusion criteria were: (1) to have a post-stroke period of over 6 months; (2) to have spastic hemiparesis defined as scores 21 on the modified Ashworth scale (24); and (3) to be able to maintain themselves in the orthostatic position during a period of time long enough to register the weight-bearing in this posture. Participants presenting other types of major orthopedic or neurologic diagnoses ( $\mathrm{e}, \mathrm{g}$, amputation, fracture of any extremity within the pastyear, Parkinson's diseases and repeated strokes) in addition to the struke that resulted in hemiparesis were excluded. Control group subjects were matched by gender and age with each bemiparetic subject and they were recruited among local community. On the basis of these criteria, 20 subjects with and 20 without hemiparesis formed the total sample ( $n=$ 40), divided in hemiparesis and control group, respectively. All subjects grve written informed consent. The protocol was approved by the local Ethics Committee of the University of Brasilia, Brazil.

\section{Study design and clinical examination}

An observational study with screening purpose in a cross-sectional prospective design was used, and the measurements were performed in a single session. Firstly, participants were assessed to record temporal and anthropometric variables (age, chronicity, height and weight), as well as personal and clinical characteristics including leg dominance (25), mental functions and spasticity

Height and total weight was used to calculate the body mass index (BMI). The mini mental state examination was included to determine a score of the mental health condition, and individuals with score $<13$ were excluded (26) and Astworth scale was used to measure the level of spasticity in the NPUH (24).

Leg dominance was identified by Waterloo Footedness Questionnaire - Revised (25) and it was used to identify the predominantly used lower limb that defines the non-predominantly-used (NPUH) and predominantly-used hemibodies (PUH). Despite hand and leg dominance do not always match in hemiparesis and control group, the correspondence of non-affected side in hemiparesis was done with dominant leg in the controls, considering to be these lower limbs the predominantly used during upright position for each group. Then, affected and non-dominant sides were considered as NPUH for hemiparesis and control group respectively.

Symmetry analysis and baropodometric measures

The measurements of the weight supported under each lower limb of the body were obtained during 
baropodometric records using a Barapodometer of the Biomech Studio - Logan Engenharia SrL, version: 1.1.3891.31030, with the Arkipelago platform Capacitive Sensory, 2010, with EPS-C system. The equipment has $400 \mathrm{~mm}$ per $400 \mathrm{~mm}$ of active surface, the dimensions of the platform are $575 \times 450 \times 25$ $\mathrm{mm}$, the thickness is of $4 \mathrm{~mm} / 5 \mathrm{~mm}$, with rubber. It is coated by polycarbonate and its weight is $3 \mathrm{~kg}$. Concerning the electronic characteristics, the platform has 2704 capacitive sensors and frequency of $150 \mathrm{~Hz}$.

The subjects were placed barefoot, with their feet free and aligned on the platform, each foot about 20 cm away from the other, without any type of additional support.All subjects were oriented to maintain an upright position as comfortable as possible, always looking to a fixed point on the wall in front of your face in a distance of around $3 \mathrm{~m}$.

The values obtained for each limb in percentage of the total body were registered as weight-bearing values for the NPUH (affected/non-dominant) and PUH (non-affected/dominant).

Symmetry ratios (SR) were calculated as described by Martins and collaborators (22), however, to calculate this coefficient, the integer values in kilograms recorded for each foot, as published by the authors, were replaced by percentage of the total body for each foot.

The $95 \%$ confidence interval $(95 \% \mathrm{CI})$ of the SR mean obtained in control group was used to establish limits of symmetry (Lie.symmetry was defined as values within $95 \% \mathrm{CI}$. Values of SR higher than maximum limit of the $95 \% \mathrm{Cl}$ would represent weightbearing asymmetries towards the NPUH and values of SR lower than minimum limit of the $95 \% \mathrm{Cl}$ would indicate asymmetries towards the PUH.

Besides percentage of the whole body, the baropometry provides information on the peak of pressure, the mean of pressure, the area of support, the Arch index, and the $\mathrm{CoP}$.

\section{Statistical analysis}

Descriptive statistics and tests for normality were carried out for all outcome variables, informing average and standard error of the mean (SEM) used to describe the variables.

All variables assessed in this study were processed by Kolmogorov-Smirnov test to verify that they showed a Gaussian distribution. The variables meet the criteria of normal distribution, so parametric tests were used in the analyses.

Student paired t-test were used to compare the means observed in hemiparesis versus control groups. Two-way ANOVA with Bonferroni post-tests was used to compare the means observed in NPUH versus PUH for each kind of weight-bearing distribution (symmetric or asymmetric toward NPUH or PUH). One-way ANOVA was used to compare the means observed among kinds of weight-bearing distribution. The significance level for all analyses was established at $\alpha=0.05$.

Cartesian coordinate systems were used to show the means of the CoP position during 20 seconds record for each subject and for the hemiparesis group.

\section{Results}

Twenty hemiparetic subjects ( 12 men and 8 female) with a mean age of $59.40=3.04$ years (ranging from 29 to 81), a mean time of chronicity of 41.45 \pm 12.45 months (ranging from 6 to 252), and twenty healthy subjects with mean age of $58.55 \pm 3.11$ (ranging from 27 to 82 ) completed all tests. Their demographic, anthropometric and clinical characteristics are given in Table 1, which demonstrates the similar characteristics between control and hemiparesis group.

The Table 2 shows that baropodometric technology provides information to define three different postural behaviors in stroke survivals, defined as symmetric ( $1.253>\mathrm{SR}>1.059)$, asymmetric with overload toward non-paretic foot $(S R<1.059)$ and asymmetric with overload toward paretic foot (SR $>1.253$ ). Possibly, the individuals with stroke adapt in different ways, generating different postural behaviors that may be related to other factors than neurologic injury.

The percentage of the total body between bilateral weight-bearing distribution (NPUH versus PUH) presented significant differences for each postural behavior (symmetric, asymmetric toward non-paretic and paretic foot), including subjects with symmetric postural behavior (Figure 1A), Although the behavior to overload paretic side has been similar between subjects with symmetric and asymmetric toward paretic foot, the magnitude of the overload

Flsioter Mov. 2012 jul/set;25/3):583-94 
toward paretic side in the symmetric subjects was not enough to provide SR value outside symmetry limits defined by $95 \% \mathrm{Cl}$ recorded for controls (Table 2).

Table 1 - Personal and clinical characteriatica by control ( $n=20)$ and hemiparesis $(n=20)$ group

\begin{tabular}{|c|c|c|}
\hline $\begin{array}{l}\text { Personal and cllnical } \\
\text { charactertstlcs }\end{array}$ & Control & Hemlparests \\
\hline Age (years] & $58.55=3.11$ & $59.4 \pm 3.04$ \\
\hline Chronicity (montha) & Not apolied & $41.45 \pm 12.45$ \\
\hline BM $\left(\mathrm{kg}^{\prime} \mathrm{m}^{2}\right)$ & $28.03=0.92$ & $27.37 \pm 1.21$ \\
\hline Mini-mental score (points) & $28.20=0.31$ & $25.10=0,95$ \\
\hline $\begin{array}{l}\text { Ashworth score in the NPUH } \\
\text { (points) }\end{array}$ & Not applied & $1.30 \pm 0.20$ \\
\hline Symmetry ratio (SR) & $1.15 \pm 0.04$ & $1.082=0.10$ \\
\hline \multicolumn{3}{|l|}{ PUH, $n(\$)$} \\
\hline Fipht & 17 (B5) & $14(70)$ \\
\hline Left & $3(15)$ & $6(30)$ \\
\hline \multicolumn{3}{|l|}{ Gender, $n\left(\%_{0}\right)$} \\
\hline Male & $12(50)$ & $12(60)$ \\
\hline Female & $B(40)$ & $8(40)$ \\
\hline
\end{tabular}

Source: Restarch dat.

Legend: Values are preserted $z$ a mean $=$ SEM (standard error of the mean) for quantiative vaiables and by absolute (n) and relative (\%) frequency for qual'tative vaiablez. Groups were matched by ape and gender. $t$ waz not found significant dif̈erences between meane. BMI - Body Mass lndex, NFUH - Non-predominarthy Used Hembodr; SR-Symmetry Rato; and PUH - Predominarty Used Hemibody.

Table 2 - Classification of the subjects with hemigaresis by weight-bearing distribution

\begin{tabular}{ll}
\hline Weight-bearing olestifioation & $\mathrm{n}(\mathrm{S})$ \\
\hline Symmetric & $8(40)$ \\
$1.253>$ SR $>1.059$ & \\
Asymmetric with overload toward nen-paretic foot & $8(40)$ \\
SR $<1.059$ & \\
Asymmetric with overload towad paretic foot & $4(20)$ \\
SR $>1.253$ & \\
\hline
\end{tabular}

Source: Research dat.

Lepend: Valuez are presented by abeduse ( $\mathrm{n}$ ) and relative $\left(\mathrm{S}_{\mathrm{j}}\right.$ ) frequency for types of weight-bearing diatbution, determined by upper and lower limits of the $95 \%$ confidence interval for Symmetry Ratio (SR) ebtained in the control group.
Differing from the other two kinds of weight-bearing distribution, asymmetrical subjects with overload toward non-paretic side overloaded predominantly used hemibody, and the percentage of total body recorded under each foot, were significantly different from subjects with symmetric postural behavior (Figure 1A)

Despite differences has been found for weightbearing distribution observed by percentage of total body, when observed by peak of pressure (Figure 1B), the difference between bilateral weight-bearing distributions was just detected for subjects with asymmetry toward non-paretic side (PUH), differing significantly from peak of pressure reconded in the subjects with asymmetry toward pareticside (NPUH). Moreover, when the same conditions were analyzed by mean of pressure (Figure 1C) and support of area (Figure 1D) records, no significant differences were detected.

The Arch Index is represented by the percentage of the weight-bearing supported by each foot (total foot) in the midfoot region. Figure 2A demonstrates Arch Index values, comparing NPUH versus PUH for each postural behavior (symmetry, asymmetry toward non-paretic and paretic foot) identified in the hemiparesis group. Significant difference was not observed between NPUH and PUH for any condition. Nevertheless, for subjects with asymmetry toward non-paretic side the Arch Index value recorded under pUH (non-paretic side) was significantly increased when compared with the same record in the subjects with symmetry.

Samples of individual records can illustrate the differences in the postural behaviors (Figures 2B, $2 \mathrm{C}$ and $2 \mathrm{D}$ ). In Figure 2B, it can be observed that although the subject had a PUH, weight-bearing for each foot was equally distributed, providing SR with values within symmetry limits defined by de $95 \%$ IC of the control. In Figure 2C, it is observed an overload toward the PUH. Differing from subjects with asymmetry toward non-paretic side, in the Figure $2 C$, it is observed a subject overloading the NPUH.

The postural behavior characterized by NPUH overloaded was observed either in subjects with symmetry or asymmetry toward paretic side. However, in the subjects with asymmetry toward paretic side this behavior was followed by enhanced decrease of the peak of pressure when compared with the peak observed in the subjects with asymmetry toward non-paretic side (Figure 1B). 
(A)

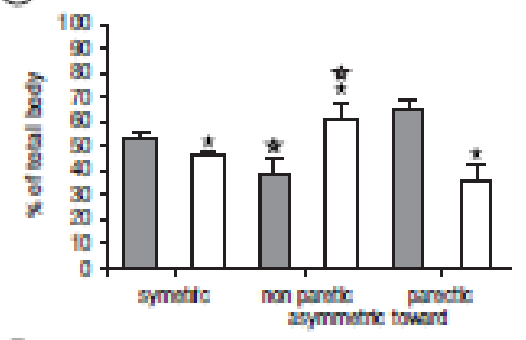

(C)

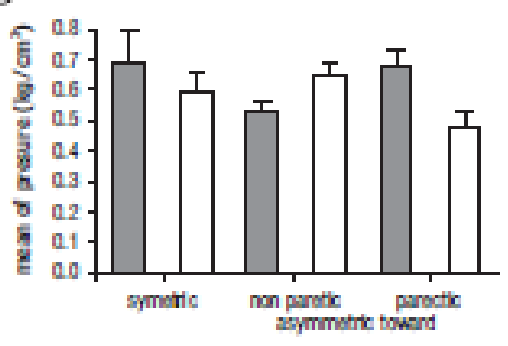

(1)

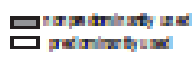

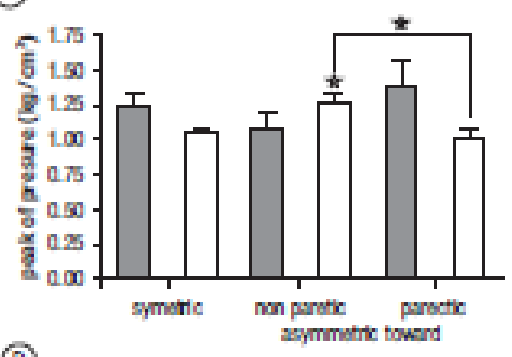

(D)

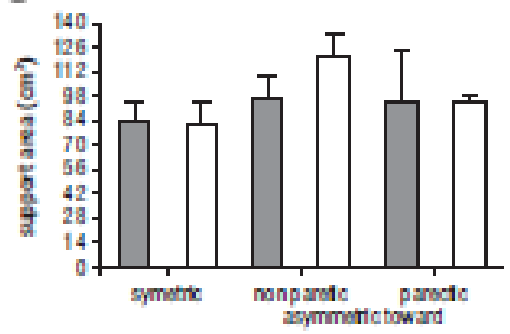

Figure 1 - Bars graphs showing baropodometric parameters (mean \pm SEM) under non-predominantly (oray bars) and predominantly (white bars) foot used for hemigaresis group classified by weight-bearing distribution type (aymmetric, asymmetric toward non-paretic side and asymmetric toward paretic side). Baropodometric parameterz are indicated by weight-bearing in percentage of the total body (A), peak of preasure in $\mathrm{kg} / \mathrm{cm}^{2}(B)$, mean of pressure under the foot in $\mathrm{kg} / \mathrm{cm}^{2}(\mathrm{C})$, and support area under the foot in $\mathrm{cm} 2$. Significant differences between non-predominantly and predominantly foot were indicated by black starz. Differences between types of weight-bearing distributions when compared with symmetric were indicated by white stars, and when compared with Source: Research date. asymmetric types were indicated by gray stars.

Other set of variables available by computerized baropodometric technology is that derived from Center of Pressure (CoP). Named as "stabilometric parameters", variables as displacement, distance and velocity of $\mathrm{CoP}$ can be investigated during upright position. Three Cartesian coordinate systems were indicated in the Figure 3 to illustrate individual (asterisks) and group (gray stars) behavior of the CoP recorded during 20 seconds in upright position for subjects with symmetry $(A)$, asymmetry toward non-paretic (B) and paretic (C) side.

The system represented in the Figure $3 A$ (symmetry) shows a majority of CoP position that was resulted from displacement swinging backward and toward the NPUH with the average of these individual CoP (group behavior) also placed in this area. However, the systems for asymmetries ( $3 B$ and $3 C$ ) showed a large variation of individual CoP.

In the Figure 3B, although a large variation has been observed for individual records, the group behavior of the subjects with asymmetry toward non-paretic side was represented by a CoP placed in the NPUH.

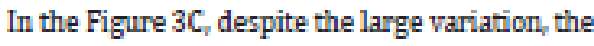
majority of the individual records of subjects with asymmetry toward paretic side swing backward and toward the PUH. The group behavior of these individual records showed a CoP placed in the backward toward PUH areas.

Ftsloter Mov. 2012 jul/set; 25/3):583-94 


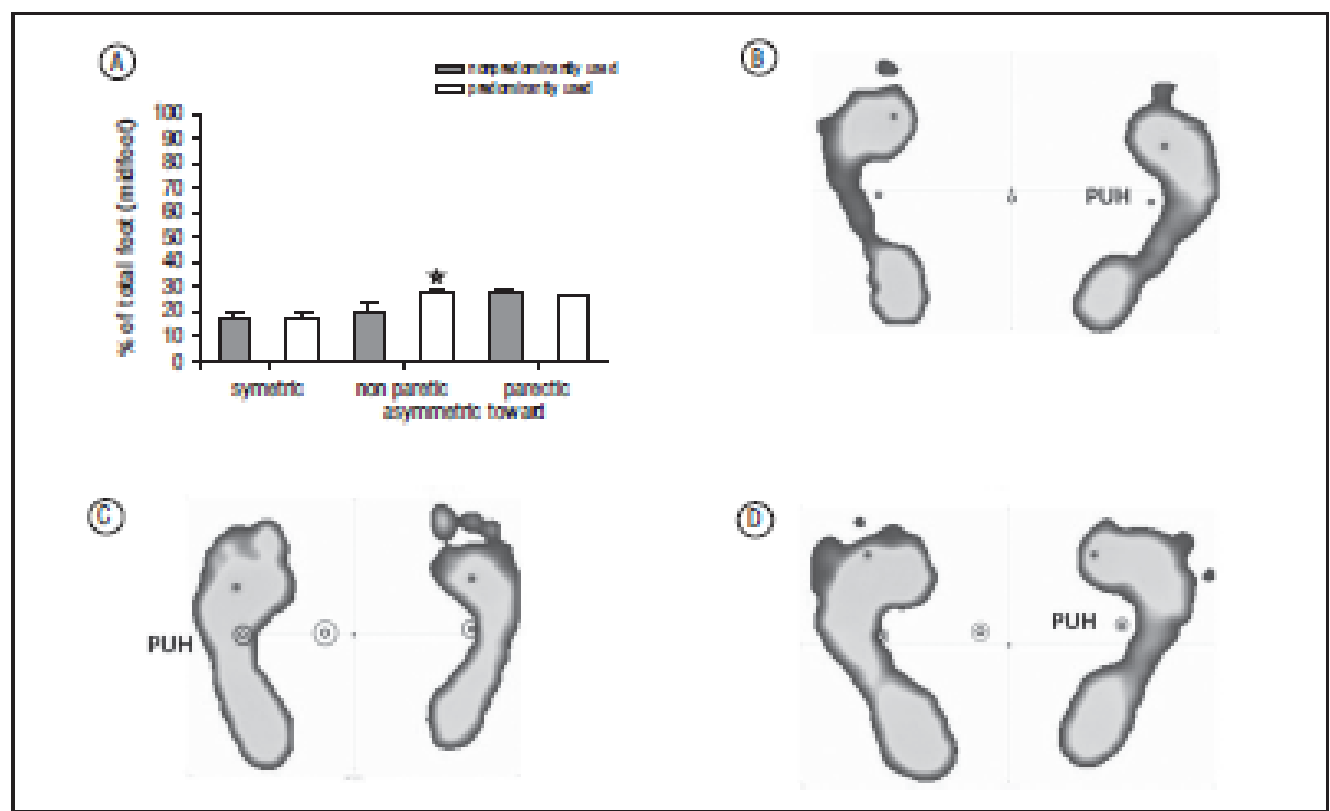

Figure 2 - Bars graph showing Arch Index (mean \pm SEM) under non-predominantly (gray bars) and predominantly (white bars) foot used for hemiparesis group classified by weight-bearing distribution type (symmetric, asymmetric toward non-paretic side and asymmetric toward paretic aide). Arch Index is indicated by weight-bearing in percentage of the total foot presented under midfoot (A). Significant difference between Arch Index when compared with symmetric type was pointed by the white star. Images $B, C$ and $D$ are baropodometric representations of the weight-bearing distribution showing, respectively, samples of subjects with symmetry (B). asymmetry toward predominantly used hemibody (PUH - non-paretic aide - C), and asymmetry toward non-predominantly used hemibody (NPUH - paretic side - D). Subjects with hemiparesis represented in the Source: Research dats. imeges $B, C$ and $D$ had, respectively, left, right and left hemiparesis.

The averages of the distance covered by CoP for each postural behavior (symmetry, asymmetry toward non-paretic or paretic sides) do not differ among them. The same was observed in the averages of the CoP's velocity.

\section{Discussion}

As it was used in previous papers published by our group (20-22), in this work SR was utilized to define types of weight-bearing during upright position. However, in this study the variable used to calculate SR was the percentage of total body supported by each foot and recorded by computerized baropodometry. It was also obtained data from a control group matched by age and gender that was used to establish a $95 \% \mathrm{CI}$ to define limits of symmetry (22).

As it was previously observed for us (20-22), in this new study using baropodometric technology, we confirm to be incorrect to always consider weightbearing asymmetrically distributed in individuals with hemiparesis, because it was found eight subjects (40\%) with hemiparesis presenting SR within symmetry limits obtained in control group. Again, now using computerized baropodometry, a majority of the subjects with hemiparesis and asymmetry during weight-bearing distribution ( $40 \%$ ) showed postural behavior classified as asymmetry toward non-paretic side (PUH) and a minority of these subjects with hemiparesis (20\%) showing

Flaloter Mov. 2012 Jul/set,25(3):583-94 
(4)

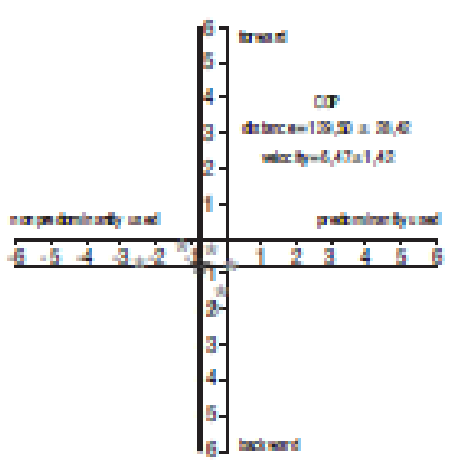

()

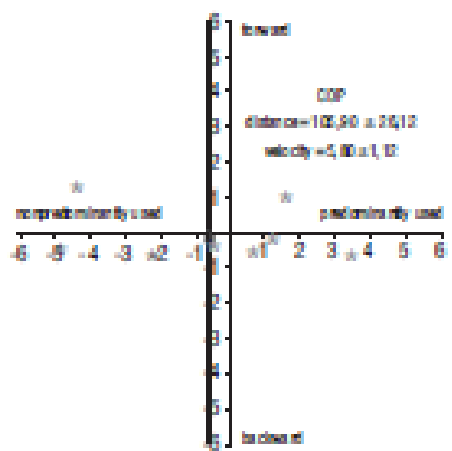

(C)

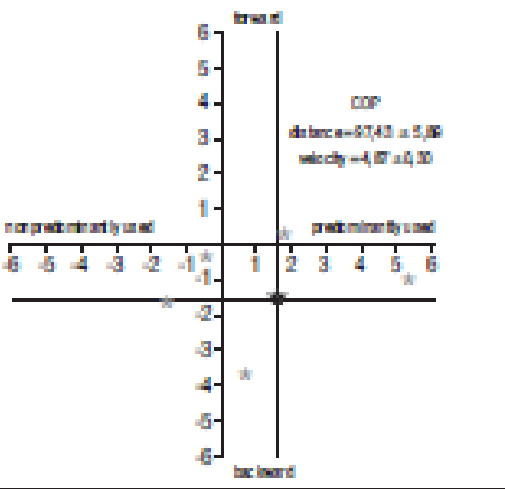

Figure 3 - Cartesian coordination systems showing individwal (asterisk) and group behavior (gray atara) of the Center of Pressure (CoP) displacements for hemiparesis group classified by weight-bearing distribution type: symmetric (A), asymmetric toward non-paretic side (B) and asymmetric toward paretic aide (C. The mean distance and velocity were described in right upper quadrant Soure: Regearch data. postural behavior classified as asymmetry toward paretic side (NPUH) was observed. These subjects with asymmetry toward paretic side probably must be individuals with Pusher Syndrome and/or some type of neglect disorder (27-28). To review this results, see Table 2 .

These results demonstrate that baropodometric technology, as well as digital scales used in the previous studies (20-22), provides variables that can be used to investigate the different wearing-bearing distribution in hemiparetic individuals.

Although baropodometry had already been used in other studies to assessment individuals with several different conditions $(9,29-30)$, the present study introduces a novelty, because it is the first research to use this technology to calculate SR in subjects with hemiparesis showing all analysis that can be applied in this population with therapeutics and research aims.

In therapeutic terms, different types of weightbearing distribution could represent different compensatory strategies to maintain posture and balance necessary to acquire motor function.

According to Genthon and collaborators (31), the weight-bearing asymmetrically distributed during upright position of the stroke survival subjects is not the primary cause of their postural imbalance, they mainly affirm that balance is the consequence of impaired control of postural stabilization involving both limbs.

Motor weakness, asymmetrical muscular tone, deficits in the somatosensory system and alterations in spatial cognition with reference to the postural body scheme may participate in this postural instability (32-33). These authors suggest that the weight-bearing asymmetrically distributed may not be the principle target during rehabilitation programs aiming to restore standing balance after stroke, and other factors could contribute to a compensatory strategy in posture control. This compensatory strategy would not be precisely symmetric (20-22)

The postural behavior analyzed by parameters provided during a computerized baropodometric records showed interesting results that must be better studied. For this twelve subjects presenting symmetry or different types of asymmetry in the weight-bearing distribution during upright position, the analysis from ground reaction forces occurring in the contact surface of the feet, the characteristics

Flsioter Mov. 2012 jul/set;25/3):583-94 
of contact in the midfoot region (Arch Index) and the variation of the CoP (stabilometric parameters) showed a lot of information.

A clear result is observed: complete symmetry during upright position and represented by SR with value equal 1 was almost not found in the hemiparesis and control group (L.e. all subjects, including controls, will always presents some level of overload toward one side). This observation is supported by evidences that showed a natural postural sway (3437). However, as observed in by $95 \% \mathrm{Cl}$ of the SR record from control group, this overload varied in a range of 0.194 with upper limit of 1.253 and lower limit of 1.059 , characterizing that subjects with SR closer than the complete symmetry (Table 2). Then, to be classified as asymmetry, the SR must overpass upper or lower limits.

Separated by types of weight-bearing distribution, subjects with hemiparesis presented differences in the postural behavior analyzed by this technology-By observing the percentage of weightbearing bilaterally distributed, it was confirmed an overload toward one side (Figure 1). Subjects with symmetric behavior significantly overloaded NPUH, however inside limits of symmetry (Figure 1A). This postural behavior is quite similar the postural behavior observed in subjects without hemiparesis $(21-22)$. As expected, significant overloads toward one side and now outside the symmetry limits were also observed in subjects with asymmetry behavior presenting two different types (Figure 1A) toward PUH in the subjects that overloaded non-paretic side and toward NPUH in the subjects that overloaded paretic side.

The overloads detected by percentage of total body (Figure 1A) were not followed by change: in the peak of pressure (Figure 1B), mean of the pressure (Figure 1C) and support area (Figure 1D). The non-matching of the differences detected from percentage of total body with the other variables recorded can suggest an effect of the normalization. Variables normalized by support area can be better used than percentage of total body to show difference between weight-bearing distributions in each hemibody, awoiding small differences related with natural postural sway (38-39).

Only in the subjects with hemiparesis and asymmetry toward non-paretic side it was observed an increase in the Arch Index (Figure 2A), reflecting consequences of the foot overloaded and with a higher peak of pressure. The increase in the Arch Index could suggest changes in the medial longitudinal arch of the foot, which could impair the absorption of the reaction shock forces during gait (40-41).

The three types of weight-bearing distribution identified in the hemiparesis showed particular postural behavior that must be better studied. In the Cartesian coordination systems for each condition (Figure 3), an interesting feature was observed: in the symmetry, the mean of $\mathrm{CoP}$ displacement during 20 second in upright position was placed in the overloaded side, differing from asymmetries where it was observed that the mean of $\mathrm{CoP}$ displacement was placed in the opposite from the overloaded side. Despite this feature could represent something important, the few subjects for demonstrate aspects of each type of weight-bearing condition represented a limitation of this study, hindering a good discussion about associations of CoP displacement and postural behavior.

The results here presented allowed to explore the potentialities of this technology for rehabilitation and future researches aiming to acquire benefits to the subjects with hemiparesis condition.

\section{Conclusion}

Baropodometric technology can be used to analyze weight-bearing distribution during upright position of subjects with hemiparesis detecting different types of postural behavior, considering the different profiles of weight-bearing distribution, and this knowledge is useful to be applied in therapeutic programs and researches involving subjects with hemiparesis.

\section{Acknowledgements}

We would like to thank for the Grant for Research from Universidade de Brasilia (UnB) and from the Conselho Nacional de Desenvolvimento Cientifico e Tecnológico (CNPq, 58/2009, process \#557752/2009-4). 


\section{References}

1. Duarte E, Morales A, Pou M, Agulrrezabal A, Agullar II. Escalada F. Trunk control test early predictor of gait balance and capacity at 6 months of the stroke. Neurologia. 2009;24[5]:297-303. PMid:19642031.

2. Valential FA, Granger B, Hennebelle DS, Eythrib $\mathrm{N}$, Robain C. Repeatability and variablitity of baropodo metric and spatio-temporal gait parameters-results in healthy subjects and in stroke patients. Neu. rophysial Clin. 2011;41(4):181-9. doi:10.1016/1). neudi2011.08.004.

3. Carugno C, lacobellis C, Pedini G. Arthrodesis of the knee: a baropodometric evaluation of the long-term results. Ital | Orthop Traumatol. 1990;16(2):229-33. PMid:2289884.

4. Carugno C, lacobellis C, Pedini C. Baropodometric studies in patients submitted to Grice-Green opera tion for primary val gus pronated flat foot. Ital / Orthop Traumatol. 1990;16(3):379-85. PMid:2099921.

5. de Oliveira GS, Greve JM, Imamura M, Bolliger Netn R. Interpretation of the quantitative data of the com. puterized baropodometry in normal subjects. Rev Hosp Clin Fac Med Såo Paula 1998,53(1):16-20. PMid:9659738.

6. Ridola C, Palma A, Cappello F, Gravante G, Russo G, Truglio G, et al. Symmetry of healthy adult feet: role of orthostatic footprint at computerized haropodom. etry and of digital formula. Ital I Anat Embryol. 2001;106(2):99-112. PMid:11504251.

7. Gravante G, Russo G, Pomara F, Ridola C. Comparison of ground reaction forces between obese and control young adults during quiet standing on a baropodo. metric platform. Cin Btomech. 2003,18(8);780-2. dol. org/10.1016/50268-0033(03)00123-2.

8. Bergami E, Glidone A, Zanoli G, Massari L, Traina GC Static and dynamic baropodometry to evaluate pa. tients treated by total knee replacement with a mo bile meniscus. Chir Organt Mov, 2005,90(4):387-96. PMid:16878774.

9. Fabris SM, Valezi AC, de Souza SA, Faintuch I, Cecco nello 1, funior MP. Computerized baropodometry in obese patients. Obes Surg, 2006;16(12):1574-8. dot. $10.1381 / 096089206779319293$.
10. Lopez-Rodriguez S, Fernandez de-Las-Peflas C, Albur: querque-Sendin F, Rodriguez-Blanco C., Palomequedel-Cerro L. Immediate effects of manipulation of the talocrural jolnt on stabllometry and baropodometry in patients with ankle sprain. I Manipulative Physiol Ther. 2007;30(3):186-92. dol:10.1016/J. Impt2007.01.011.

11. Femery V, Poudevin F, Thevenon A, Moretto P. Development and test of a new plantar pressure control device for foot unloading. Ann Readapt Med Phys. 2008,51(4):231-7.dol:10.1016/].annrmp.2008.01.007.

12. Alfieri FM, de lesus Guirro RR, Teodori RM. Postural stablitity of elderly submmitted to multisensorlal physical therapy intervention. Electromyogr Clin Neurophysiol. 2010,50(2):113-9. PMid:20405787.

13. Bellizzi M, Rizzo G, Bellizzi G, Ranieri M, Fanelli M, Megna G, et al. Electronic baropodometry in patients affected by ocular torticollis. Strabismus. 2011:19(1):21-5. dol:10.3109/09273972.2010.545 469.

14. Cuccia AM. Interrelationships between dental occlusion and plantar arch. I Bodyw Mov Ther. 2011:15(2):242-50. dol:10.1016//.Jbunt.2010.10.007.

15. Grasst DO, de Souza MZ, Ferrareto SB, Montebelo MI, GuIrro EC. Immedlate and lasting Improvements in welght distribution seen in baropodometry following a high-velocity, low-amplitude thrust manlpulation of the sacrolliac foint. Man Ther. 2011;16(5):495-500. dol: $10.1016 /$ imath 2011.04 .003$.

16. Kaercher CW, Genro VK, Souza CA Alfonsin M, Berton G, Filho IS. Baropodometry on women suffering from chronle pelvic paln-wa cross-sectional study. BMC. Womens Health 2011;11:51. dot:10.1186/1472-6874-11-51.

17. Mantini S, Bruner E, Colalacomo B, Ciccarelli A, Redaelli A, Ripani M. Preliminary baropodometric analysis of young soccer players whlle walling. geometric morphometrics and comparative evaluation. I Sports Med Phys Fitness. 2012;52(2):144-50. PMid:22525649.

18. Sawacha Z, Guameri G, Cristoferi G, Gulotto A, Avogaro A, Cobelil C. Integrated iclnematics-klnetics-plantar pressure data analysis: a useful tool for characterizing diabetic foot blomechanics. Gait Posture. 2012;36(1):20-6. doi:10.1016//.galtpost.2011.12.007.

Flsioter Mov. 2012 jul/set;25(3):583-94 
19. Syed N, Karvannan H, Malya AG, Binulcumar B, Prem V, Chakravarty RD. Plantar pressure distri. bution among asymptomatic individuals: a cross. sectional study. Foot Anile Spec. 2012;5[2]:102-6. dot:10.1177/1938640011434503.

20. Pereira LC, Botelho AC, Martins EF. Relationships between body symmetry during weight bearing and functional reach among chronic hemiparetlc patients. Rev Bras Fistoter. 2010;14[3]-229.66.

21. Martins EF, Barbosa PHFA, Menezes LT, Sousa PHC, Costa AS. Comparaçăo entre medidas de descarga, simetrla e transferécla de peso em individuos com e sem hemlparesla. Fistoter Pesqut. 2011;18(3):228-34.

22. Martins EF, de Araujo Barbosa PH,de Menezes LT, de Sousa PH, Costa AS. Is it correct to always consider weight-bearing asymmetrically distributed in individuals with hemiparesis? Physiother Theory Pract. $2011 ; 27(8): 566-71$ dol:10.3109/09593985.2011.5 52312.

23. Cultrera P, Pratelli E, Petral $V$, Postiglione $M$, Zambelan G, Pasquettl P. Evaluation with stabilometric platform of balance disonders in osteoporosis patients. A proposal for a diagnostic protocol. Clin Cases Miner Bone Metab. 2010;7(2):123-5. PMCid:3004458.

24. Bohannon RW, Smith MB. Inter-rater reliability of a modified Ashworth scale of muscle spasticity. Phys Ther. 1987;67:206-7. PMid:3809245.

25. Elias Li, Bryden MP, Bulman-Fleming MB. Footed ness is a better predictor than is handedness. Neuropsychologia. 1998;36(1):37-43. dol:10.1016/ \$0028-3932(97)00107-3.

26. Bertolucl PHF, Brucld SMD, Campacel SR, fuliano Y. O Minl-Exame do Estado Mental em uma populaça geral: impacto da escolaridade. Arq Neuro-Psiquiatr. 1994,52(1):1-7. PMid:8002795.

27. Babyar SR, Peterson MC, Bohannon R, Perennou D, Reding M. Cilnical examination tools for lateropulston or pusher syndrome following stroke: a systematic review of the literature. Clin Rehabil. 2009,23(7)-639. So. doi:10.1177/0269215509104172.

28. Johannsen L4 Broetr D, Karnath HO. Legorlentation as a clinkal sign for pusher syndrome. BMC Neurol. 2006;6:30. dol:10.1186/1471-2377-6-30.
29. Kaercher CW, Genro VK, Souza CA, Alfonsin M, Berton G, Fulho JS. Baropodometry on women suffering from chronic pelvic paln-wa cross-sectional study. BMC Womens Health. 2011;17:11-51.

30. Cappellino F, Paolucd T, Zangrando F, losa M, Adrlant E, Mancinl P, et al. Neurocognitive rehabllitative approach effectiveness after anterior cruclate liga. ment reconstruction with patellar tendon. A ran. domized controlled trial. Eur I Phys Rehabll Med. 2012;48(1):17-30. PMid:22543555.

31. Genthon N, Rougier P, Gissot AS, Froger I, Pelissier I. Pérenon D. Contribution of each lower limb to upright standing In strolke patients. Stroke. 2008,39(6):1793. 9. dot:10.1161/STROKEAHA.107.497701.

32. Geurts $A C$, de Haart M, van Nes L, Duysens I. A review of standing balance recowery from stroke. Gait Posture. 2005;22(3):267-81. dol:10.1016/J.galtpost 2004.10.002.

33. Dickstein R, Nissan M, PIllar T, Scheer D. Foot-ground pressure pattern of standing hemilplegic patients ma. jor characteristics and patterns of Improvement. Phys Ther. 1984,64(1):19-23. PMid.6691049.

34. Anker L.C, Weerdesteyn V, van Nes IJW, Nienhuls B, Stratman H, Ceurts AC. The relation between pos: tural stablitty and weight distribution in healthy sub. jects. Galt Posture. 2008;27(3):471-7.dot:10.1016// galtpost.2007.06.002.

35. Aruin AS. The effect of asymmetry of posture on anticipotory postural adjustments. Neurosel Lett. 2006;401(1. 2):150-3. dol:10.1016//-neulet.2006.03.007.

36. Centhon N, Rougier P. Influence of an asymmetrical body weight distribution on the control of undis. turbed upright stance. | Blomech. 2005,38(10):2037* 49. dol:10.1016/J.jbiomech.2004.09.024.

37. 37. Horlings CGC, Carpenter MG, Kung UM, Honeg. ger F, Wiederhold B, Allum JH. Influence of virtual reality on postural stability during movements of quiet stance. Neuroscl Lett. 2009;451(3):227-31. doi:10.1016/J.neulet.2008.12.057.

38. Singh NB, Taylor WR, Madigan ML, Nussbaum MA. The spectral content of postural sway during qulet stance: influences of age, vision and somatosensory Inputs. J Electromyogr Kinestol. 2012;22(1):131-6. doi:10.1016/J.jelekin 2011.10.007. 
39. Strang A), Haworth I. Hieronymus M, Walsh $M$, Smart LJ Ie. Structural changes in postural sway lend Insight into effects of balance training, viston, and support surface on postural control in a healthy population. Eur I Appl Physiol. 2011:111(7):1485. 95. dot: $10.1007 / 500421-010-1770-6$.

40. Cavanagh PR, Rodgers MM. The arch index: a useful measure from footprints. | Blomech. 1987;20(5):547.51 dot:10.1016/0021-9290(87)90255-7.
41. Chen CH, Huang MH, Chen TW, Weng MC, Lee Cl., Wang G). The correlation between selected measurements from footprint and radiograph of Alatfoot. Arch Phys Med Rehabll. 2006;87(2):235-40. dol:10.1016/1). apmr.2005.10.014.

Received: 07/14/2012

Recebido: $14 / 07 / 2012$

Approwed: 08/10/2012

Aprovado: 10/08/2012

Flsioter Mov. 2012 jul/set; 25/3):583-94 


\section{Apêndice A \\ TERMO DE CONSENTIMENTO LIVRE E ESCLARECIDO}

\section{TERMO DE CONSENTIMENTO LIVRE E ESCLARECIDO}

O Sr. ou Sra. está sendo convidado(a) para participar, como voluntário, em um projeto de pesquisa de doutorado da Faculdade de Ceilândia - UNB (Universidade de Brasília) intitulado "Avaliação do controle postural, autonômico e metabólico em sobreviventes de acidente vascular encefálico".

O Sr. ou Sra. receberá os esclarecimentos necessários antes e no decorrer da pesquisa e the asseguramos que seu nome não aparecerá sendo mantido o mais rigoroso sigilo através da omissão total de quaisquer informações que permitam identificá-lo(a).

A sua participação será através de testes específicos para análise de variáveis relacionadas ao controle postural, autonômico e metabólico. Existe um tempo mínimo para a realização dos mesmos, mas não um tempo máximo, sendo respeitado o tempu de cada um para realizá-los.

Os testes a serem realizados serão: análise do controle postural através de plataforma de força, com a utilização de um equipamento chamado baropodometro, no qual o Sr.ou Sra. deverá permanecer na postura ortostática por pelo menos 20 segundos. Análise da variabilidade da freqüência cardíaca através da utilização de um frequencímetro que será colocado ao redor do tórax do Sr. ou Sra., devendo permanecer por 5 (cinco) minutos, na postura deitado, sentado e em pé respectivamente. Análise do estresse oxidativo, através da coleta de amostra de 5 (cinco) $\mathrm{ml}$ de sangue, para a dosagem de nitrito, nitrato e Tbars.A quantidade da amostra que não for utilizada será descartada no laboratório da UNB após análise, em recipiente próprio para o mesmo.

Informamos que não será realizado nenhum procedimento que lhe traga desconforto ou risco à sua vida. O Sr. ou Sra. poderá ter algum desconforto quando receber uma picada para a coleta sanguínea em seu braço.

Informamos que o Sr. ou Sra. poderá se recusar a realizar qualquer teste que lhe traga constrangimento, podendo desistir de participar da pesquisa em qualquer momento sem nenhum prejuízo ao senhor (a). 
Apêndice B

AVALIAÇÃo INSTRUMENTAL PARA COLETA DE DADOS DA PESQUISA.

FICHA DE AVALIAÇÃo

EXAMINADOR:

DATA : 1

HORA:

IDENTIFICAÇÃO

Nome:

Telefone:

Data de nascimento:

Acompanhante(s) Responsável(is) Celular:

Endereço Completo:

Profissão: Naturalidade:

Ocupação atual: Religião:

Dominância: () destro ( ) sinestro. Hábitos: ( ) Fumante, ( ) Elitista, () Sedentário o, () Ativo Altura:

Peso:

IMC:

CRITÉRIOS DE INCLUSÃO:

( ) Possui hemiparesia espástica determinada por acidente vascular encefálico em território de vascularização da artéria cerebral média

( ) Não ter sido vitima de outros eventos isquêmicos encefálicos além do evento que gerou

a hemiparesia

( ) Possui adequada compreensão das instruções

( ) Possuir mais de seis meses pós-lesão

( ) Ser capaz de permanecer em pé sem dispositivo de apoio por pelo menos um minuto

CRITÉRIOS DE EXCLUSÃO:

() Afecções cardiovasculares e/ou pulmonares

( ) Afecções renais e/ou hepáticas

( ) Uso de antiinflamatórios

() Outros agravos neurológicos além dos determinados pelo acidente vascular encefálico

( ) Presença de distúrbos psiquiátricos

( ) Drogas no tratamento de dislipidemias

() Drogas ansiolíticas

( ) Drogas a base de nitrato

() Drogas betabloqueadoras

() Drogas Sildenafil, Viagra, Cialil e similares

Tempo pós-lesão (em meses):

DADOS CLí́NICOS:

1. Diagnóstico Clínico:

2. Doenças associadas: 
3. Antecedentes familiares:

4. Antecedentes Cirúrgicos:

5. Medicamentos em uso:

6. Exames Complementares:

7. Fez/faz Fisioterapia:

\begin{tabular}{|l|l|}
\hline Posição Supino \\
\hline Início & \\
\hline Pa: & \\
\hline Hora: & \\
\hline FC: & \\
\hline
\end{tabular}

\begin{tabular}{|l|l|}
\hline Posição Supino \\
\hline Final & \\
\hline & \\
\hline Hora: & \\
\hline FC: & \\
\hline
\end{tabular}

Posição Sentado

Início

Pa:

Hora:

FC:

\begin{tabular}{|l|l|}
\hline Posição Sentado \\
\hline Início & \\
\hline Pa: & \\
\hline Hora: & \\
\hline FC: & \\
\hline
\end{tabular}

\begin{tabular}{|l|l|}
\hline Posição em Pé \\
\hline Inicio & \\
\hline Pa: & \\
\hline Hora: & \\
\hline FC: & \\
\hline
\end{tabular}

\begin{tabular}{|l|l|}
\hline \multicolumn{2}{|l|}{ Posição em Pé } \\
\hline Início & \\
\hline Pa: & \\
\hline Hora: & \\
\hline FC: & \\
\hline
\end{tabular}



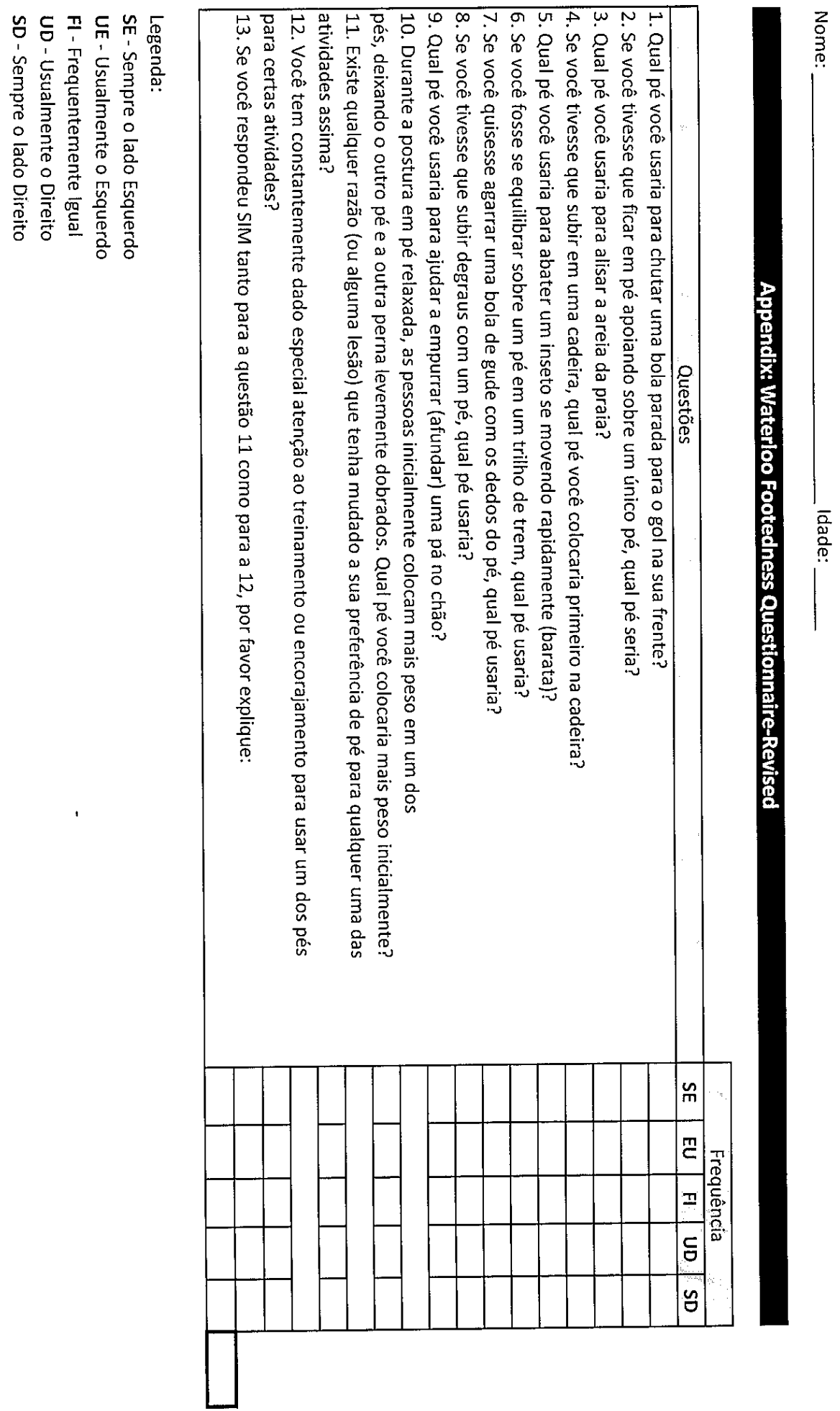


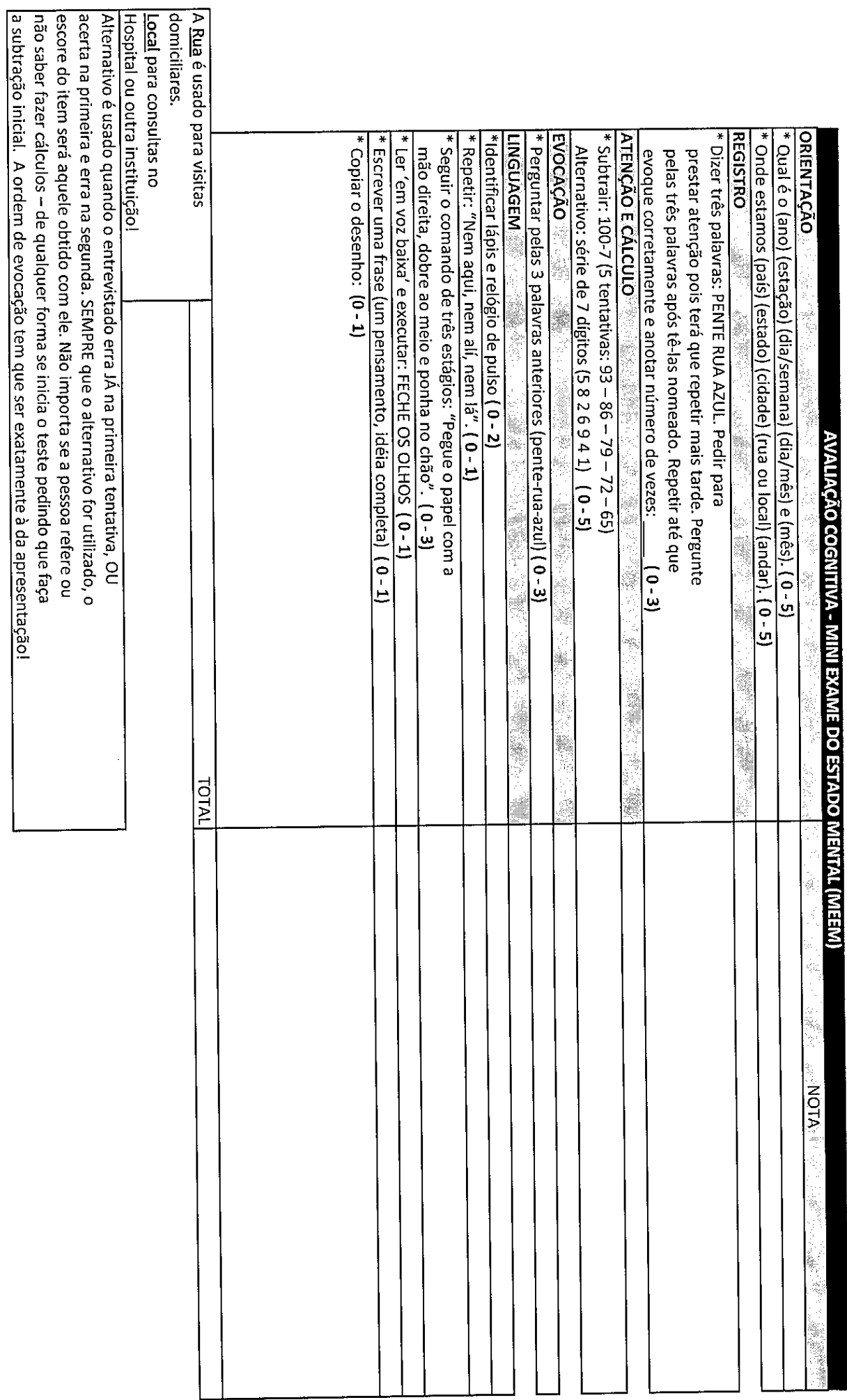




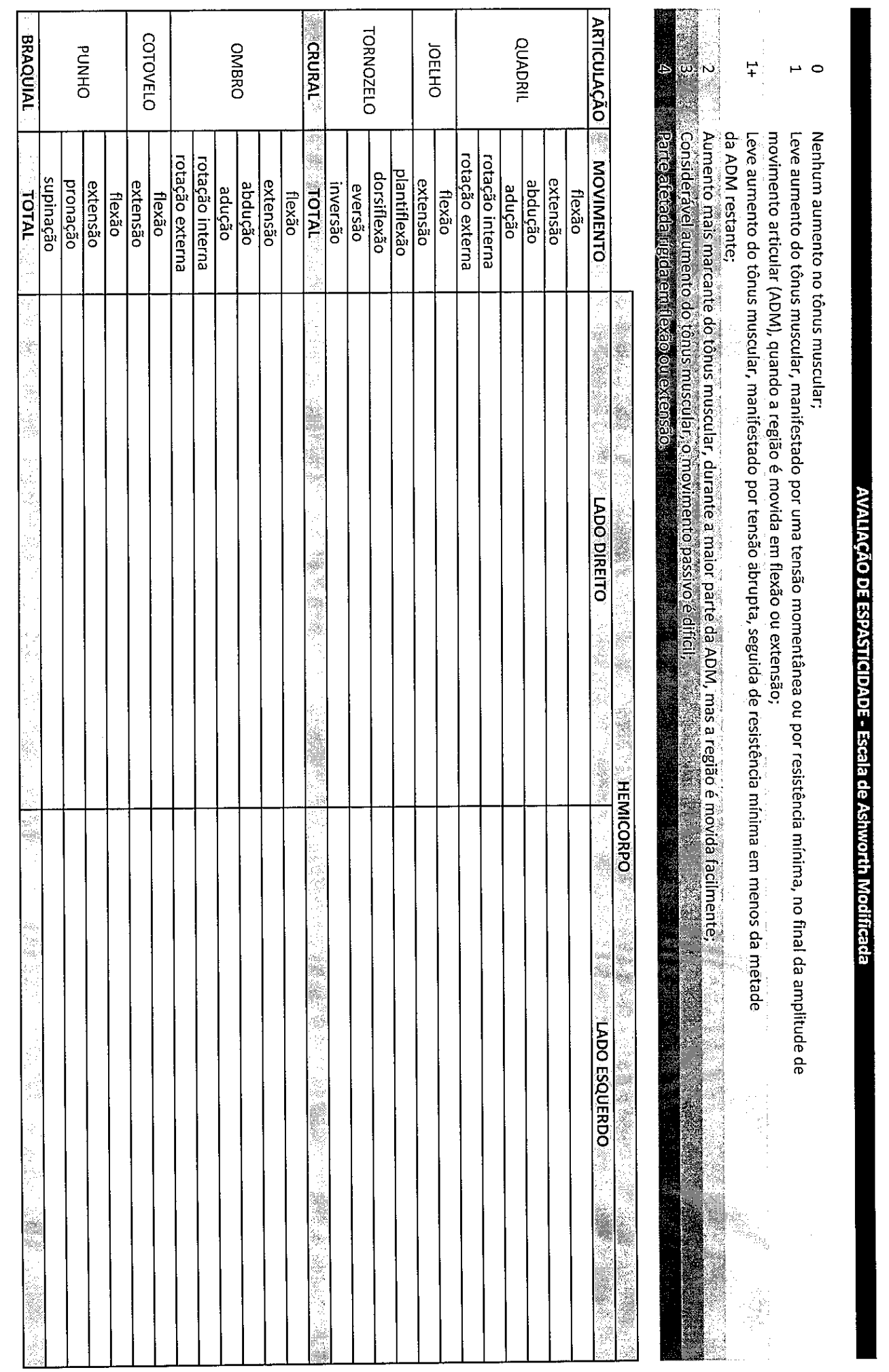

